\title{
ADAPTATION AND ACCEPTANCE IN ONLINE COURSE DESIGN FROM FOUR- YEAR COLLEGE AND UNIVERSITY INSTRUCTORS: AN ANALYSIS USING GROUNDED THEORY
}

\author{
by
}

Sally J. Baldwin

\author{
A dissertation \\ submitted in partial fulfillment \\ of the requirements for the degree of \\ Doctor of Education in Educational Technology \\ Boise State University
}

May 2017 
(C) 2017

Sally J. Baldwin

ALL RIGHTS RESERVED 


\section{BOISE STATE UNIVERSITY GRADUATE COLLEGE}

\section{DEFENSE COMMITTEE AND FINAL READING APPROVALS}

of the dissertation submitted by

Sally J. Baldwin

$\begin{array}{ll}\text { Dissertation Title: } & \text { Adaptation And Acceptance In Online Course Design From Four- } \\ & \text { Year College And University Instructors: An Analysis Using } \\ & \text { Grounded Theory }\end{array}$

Date of Final Oral Examination: 10 February 2017

The following individuals read and discussed the dissertation submitted by student Sally J. Baldwin, and they evaluated her presentation and response to questions during the final oral examination. They found that the student passed the final oral examination.

Yu-Hui Ching, Ph.D. Chair, Supervisory Committee

Norm Friesen, Ph.D. Member, Supervisory Committee

Yu-Chang Hsu, Ph.D. Member, Supervisory Committee

The final reading approval of the dissertation was granted by Yu-Hui Ching, Ph.D., Chair of the Supervisory Committee. The dissertation was approved by the Graduate College. 


\section{ACKNOWLEDGEMENTS}

Thank you to Dr. Ching, Dr. Hsu, and Dr. Friesen for serving on my committee. Each of you challenged me in a different way. I am grateful for the opportunities you created for me; they allowed me to improve and refine this work.

The participants of this study graciously shared their time and perspectives with me. Without them, this work would not have been possible. The same can be said of Dr. Uribe-Florez, who connected me with many of the participants by generously sharing her network with me.

I also appreciate Dr. Hung for his willingness to persevere in helping me, Dr. Yang for being an excellent example of a professor, and Dr. Trespalacios for his expert guidance and kindness. Finally, a special and additional thank you to Dr. Ching who has provided counsel, patience, and grace throughout this experience. 


\begin{abstract}
This study investigated the perspective of tenured and tenure-track instructors at public four-year colleges and universities involved in online course design. Using a classic grounded theory approach, 21 tenured and tenure-track instructors who had designed online courses for public four-year colleges and universities were interviewed about their experience. A pilot study was performed on this subject earlier that tentatively suggested instructors rarely use formal instructional design principles, yet their design tasks show a striking similarity to those formalized in the ADDIE model. In this study, the findings of the pilot study were expanded. Additional data helped develop a theory of adaptation and acceptance in online course design. This theory posits that instructors adapt to the online environment by incorporating what they are familiar with from faceto-face instruction. This process of incorporation is referred to here as adaptation. In addition, there is a desire for what is here designated as acceptance of their online courses: from their students, colleagues, and administrators. In response to these basic social processes, instructors develop strategies to compensate online for elements that they are accustomed to in traditional face-to-face courses (e.g., eye contact). This study provided an opportunity to understand the reason for the process of online course design from the online instructor's viewpoint, rather than simply focusing on the process of course design itself, and serves as a basis for generating hypotheses for further research.
\end{abstract}


Keywords: acceptance, assimilation, adaptation, course design, educational technology, online education, higher education, instructional design, instructional strategy, online learning. 
TABLE OF CONTENTS

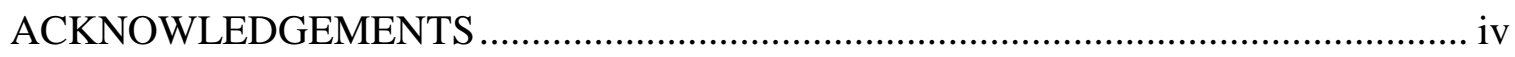

ABSTRACT

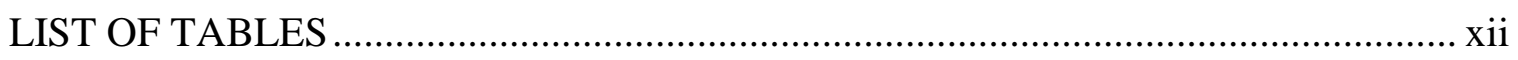

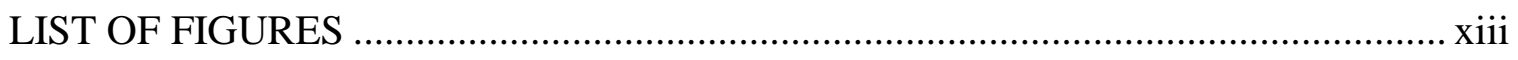

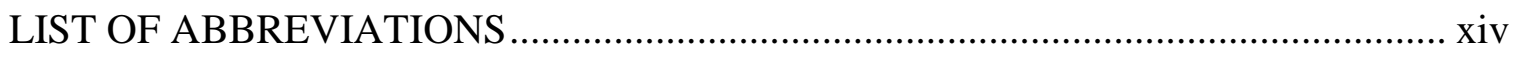

CHAPTER ONE: INTRODUCTION TO THE STUDY ……..........................................

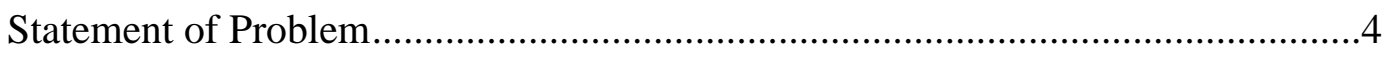

Research Question .................................................................................

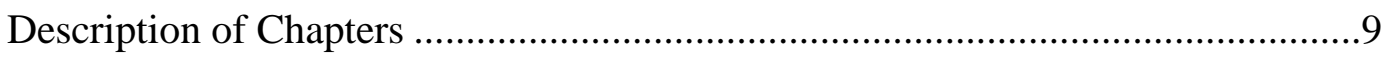

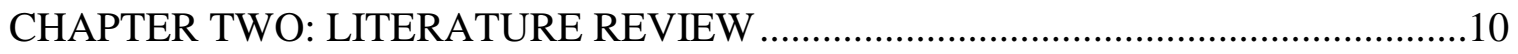

History and Models of Instructional Design ........................................................10

Instructional Design Models .................................................................12

Instructional Designers and Course Design .........................................................

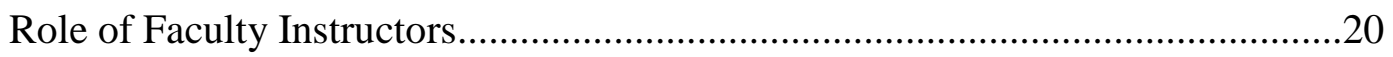

Instructors, Time, and Online Courses .....................................................21

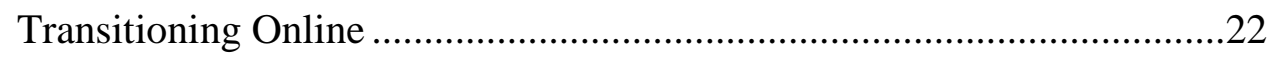

Effective Online Design and Teaching Practices.................................................26

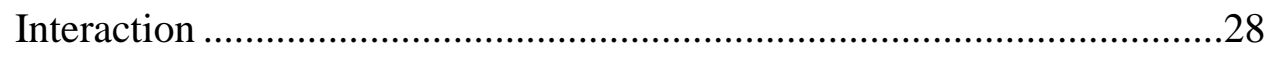

Online Course Design and Student Satisfaction ..................................................31 
Quality Guidelines

Summary .34

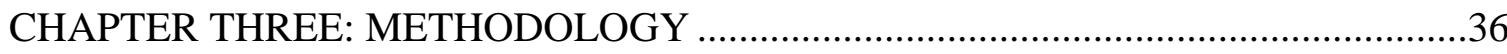

A Brief Introduction to Grounded Theory Method..............................................36

The Data Analysis Process of Classic Grounded Theory …..............................40

The Use of Memos and Constant Comparison ......................................40

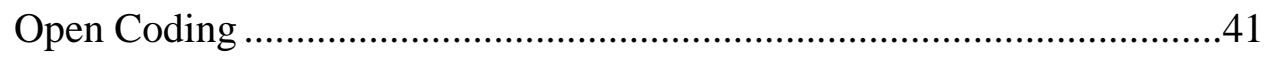

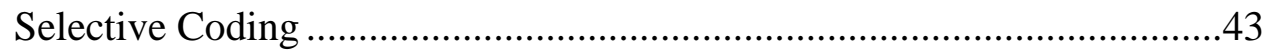

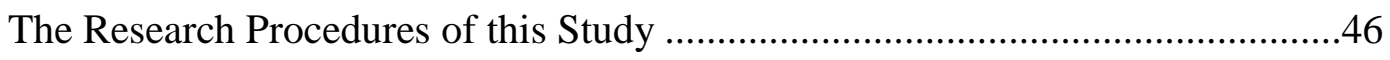

Researcher as an Instrument ....................................................... 46

Research Question ................................................................4 47

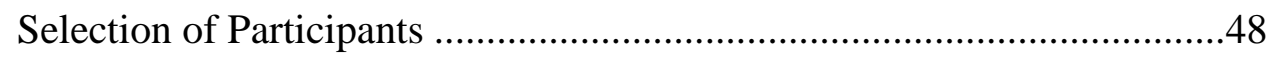

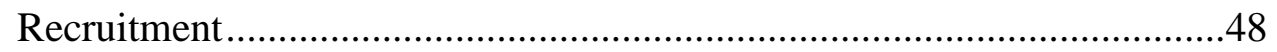

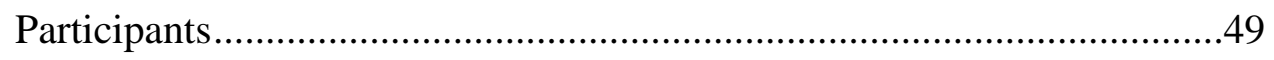

Data Collection and Analysis......................................................52

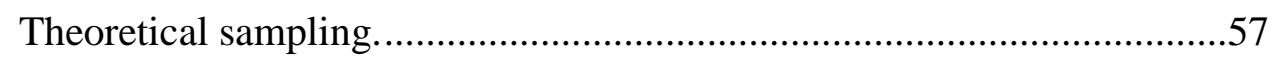

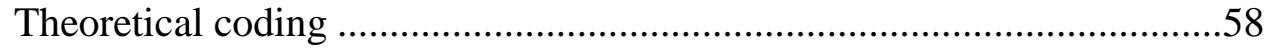

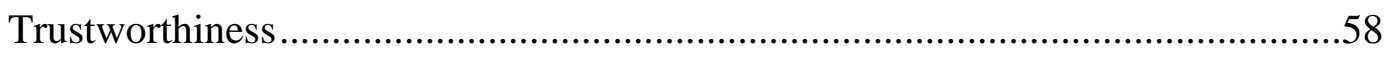

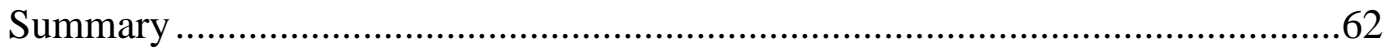

CHAPTER FOUR: RESEARCH FINDINGS ......................................................63

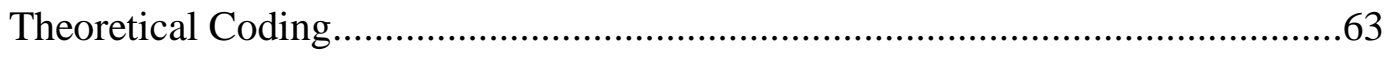

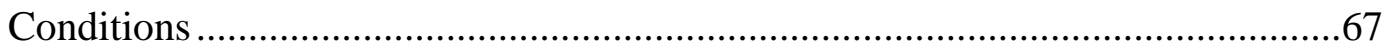

Background in Traditional Education ...............................................68 


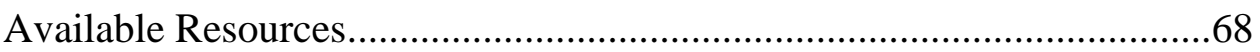

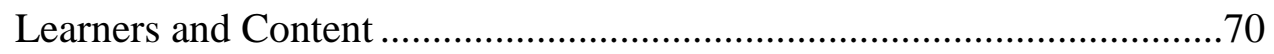

Technological Challenges ....................................................................

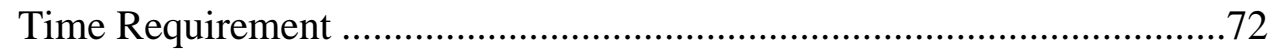

Course Design Quality ............................................................................

Adaptation and its Strategies ..........................................................................79

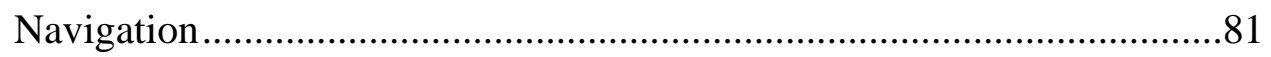

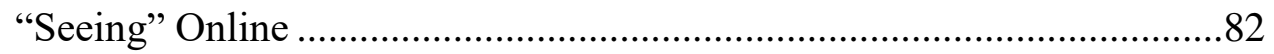

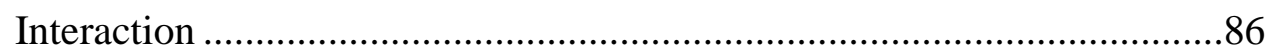

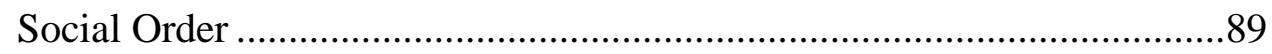

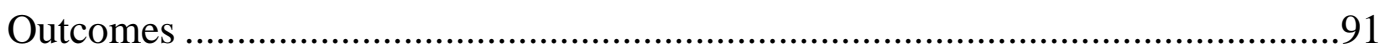

Benefits of Online Courses ........................................................................

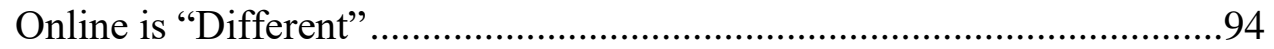

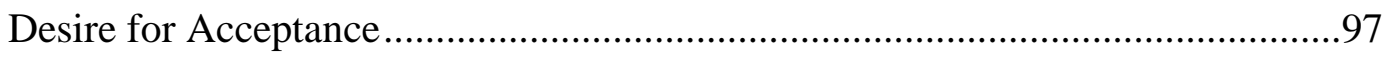

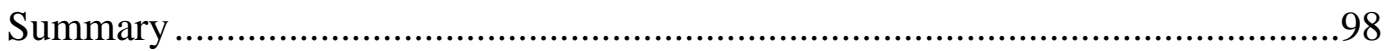

CHAPTER FIVE: DISCUSSION OF RESULTS AND CONCLUSIONS .......................99

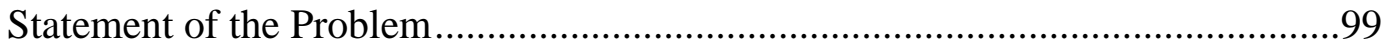

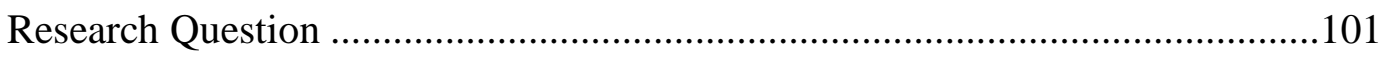

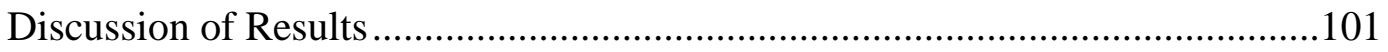

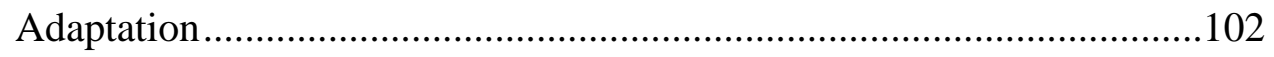

Background in Traditional Education .......................................................103

Learners and Content ......................................................................104

Technological Challenges ........................................................................104 


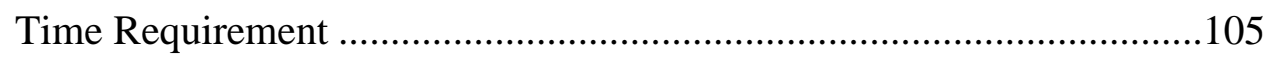

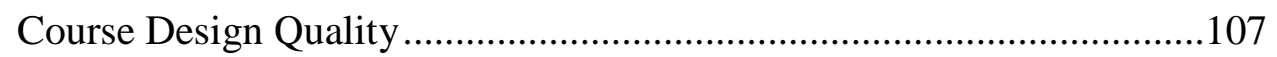

Online Course Design Strategies .....................................................108

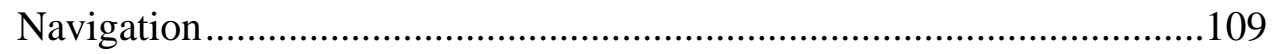

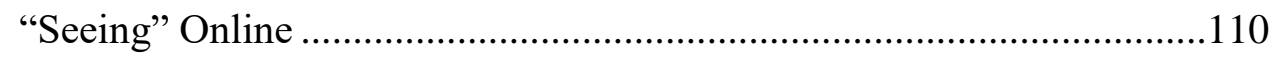

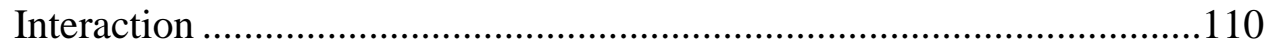

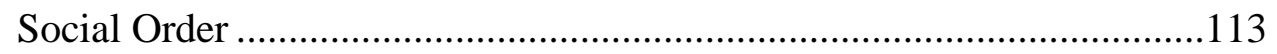

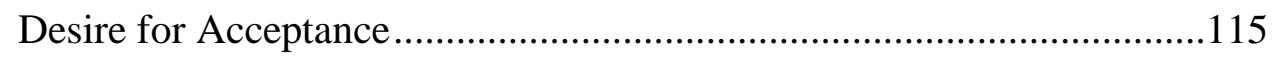

Benefits of Online Courses ...........................................................115

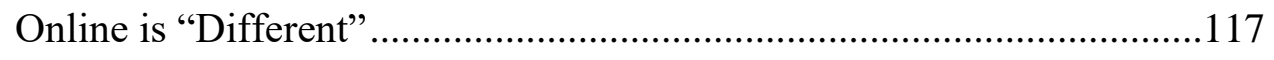

The Theory of Adaptation and Acceptance in Online Course Design................118

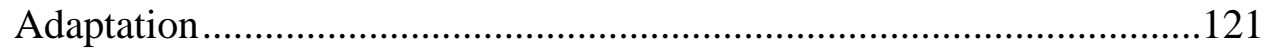

Desire for Acceptance.....................................................................124

Transferability and Limitations of the Theory of Adaptation and Acceptance in

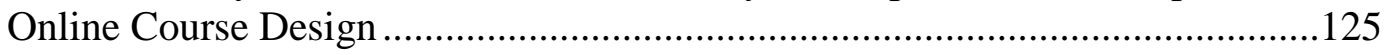

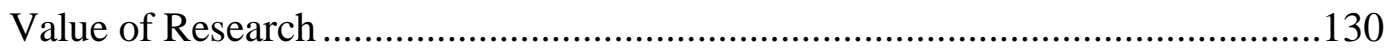

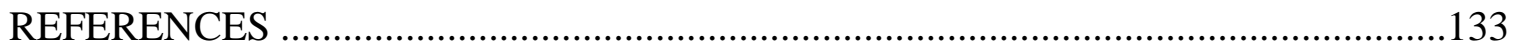

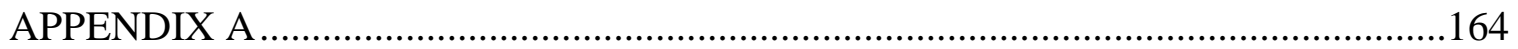

Snowball Letter ............................................................................. 164

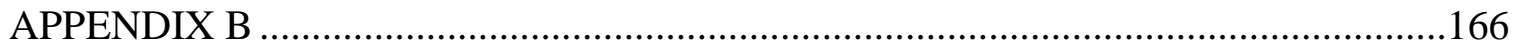

Online Course Design Study Recruitment Script .........................................166

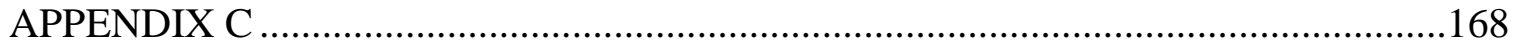

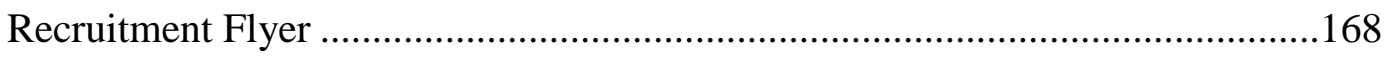

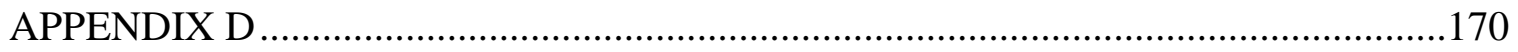


Interview Script and Questions .......................................................... 170

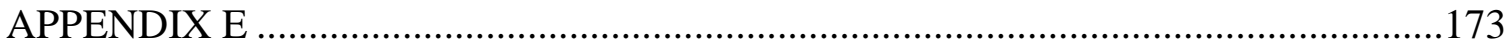

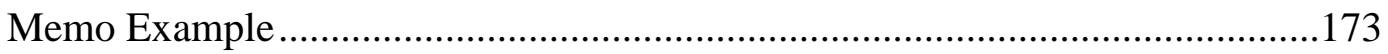

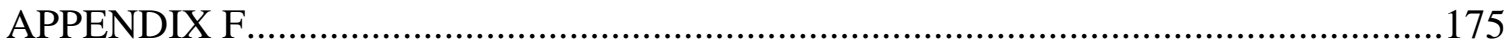




\section{LIST OF TABLES}

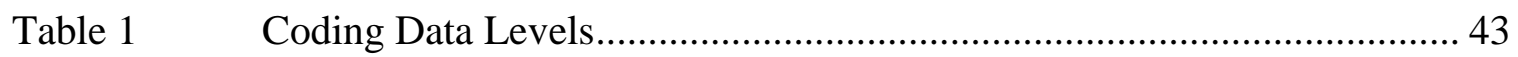

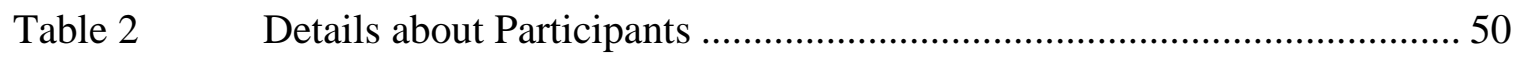

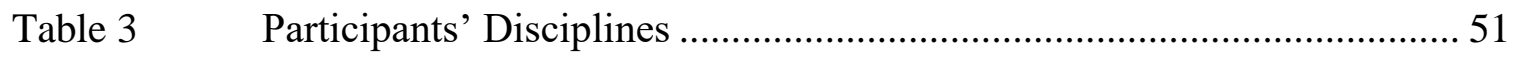

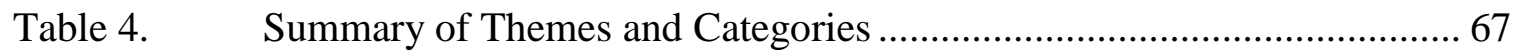




\section{LIST OF FIGURES}

Figure 1. The ADDIE instructional design model. ............................................ 13

Figure 2. Technological pedagogical and content knowledge model. Copyright 2012 by tpack.org. Reprinted with permission............................................. 24

Figure 3. The 6 C's theoretical coding family (Glaser, 1992). ............................. 45

Figure 4. Visual representation of grounded theory process............................... 53

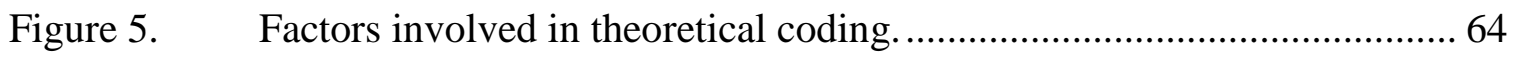

Figure 6. Visual representation of the theory of adaptation and acceptance in online

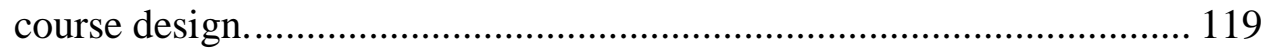

Figure $7 . \quad$ Typical traditional classroom format............................................. 123 


\section{LIST OF ABBREVIATIONS}

$\begin{array}{ll}\text { BSU } & \text { Boise State University } \\ \text { GC } & \text { Graduate College } \\ \text { LMS } & \text { Learning Management System } \\ \text { TDC } & \text { Thesis and Dissertation Coordinator }\end{array}$




\section{CHAPTER ONE: INTRODUCTION TO THE STUDY}

As to methods, there may be a million and then some, but principles are few. The man who grasps principles can successfully select his own methods. The man who tries methods, ignoring principles, is sure to have trouble. (Emerson, 1912)

We still misunderstand online course design. Yet, its importance in education continues to expand as online education grows. The explosive growth of online education has been well documented: The number of online courses nearly tripled between 1995 and 2003 (Beck, 2010). An online course, for the purpose of this manuscript, is defined as a "series of lessons delivered to a web browser or mobile device, to be conveniently accessed anytime, anyplace” (Institute for Dynamic Educational Advancement, 2016). Online course design is defined as putting content into an online context (Gormley, 2014), and developing activities and assessments through learning strategies. However, techniques vary widely. The purpose of this study is to provide insight into the perceptions tenured and tenure-track public four-year college and university instructors, who have designed online courses, have of this process.

The number of students taking at least one course online has grown from 1.6 million students in 2002, when the Sloan Consortium first started tracking online education, to 5.8 million students in 2014 (Allen \& Seaman, 2016). During Fall 2014, $26.5 \%$ of all public university students reported taking at least one course online (Allen \& 
Seaman, 2016). Research indicates online courses are offered at $90 \%$ of public two-year institutions and $89 \%$ of public four-year institutions (Schrum, Burbank, Engle, Chambers, \& Glassett, 2005). Public four-year colleges and universities are post-secondary degreegranting institutions that are predominantly funded by public means, and offer programs at the bachelor's or higher degree level (Contreras, 2009; National Center for Education Statistics, 2016). Online course offerings represent the fastest growing sector of higher education, accounting for three-quarters of all enrollment increases (Haynie, 2015; Means, Toyama, Murphy, Bakia, \& Jones, 2010). And, online education is likely to continue to grow: Online education offers convenience and flexibility, which is appealing to students and instructors (Parsad \& Lewis, 2008). Institutions view online education as a way to reach more students in a cost effective manner (Garbett, 2011; Taft, Perkowski, \& Martin, 2011).

In order to fuel this increasing demand for online courses, more instructors have been recruited to design courses (Baran, Correia, \& Thompson, 2011; Brigance, 2011; Cochran, 2015; Kidder, 2015). Instructors have unique skills that provide value to institutions and students for creating online courses. They are content experts, attuned to learners, and already a part of the institution. Academic freedom is preserved when instructors design their own courses (McGahan, Jackson, \& Premer, 2015), and instructors are accustomed to having autonomy in their courses. As a result, institutions often recruit instructors to design online courses. A national survey of 10,700 college and university faculty instructors found that "over 80 percent of faculty involved in online 
teaching and/or development are involved in both the development and the teaching aspects" (Seaman, 2009, p. 21).

Online education represents a transformative change in teaching, since instruction is packaged in advance of delivery. The instructional design of a course impacts the conditions for learning, and students' learning experiences (Merrill, Drake, Lacy, \& Pratt, 1966). Traditionally, the process of instructional design uses abstract tools (e.g., ADDIE, Dick \& Carey model, Gagné's Nine Events of Instruction) and software tools (e.g., a learning management system [LMS ${ }^{1}$ ], web tools) (Gardner, 2011). In addition, instructional design is influenced by organizational goals, policies, and the culture of the organization, particularly the organization's communication and cultural norms (Gardner, 2011). Division of labor also plays a part; a single person may do the work, or instructional design may be divided among a group of specialists within the organization. College and universities may employ instructional designers, course development teams, outside companies, or instructors to handle these functions. The goal is to transform material into clear and meaningful content to help the learners make sense of the information: Instructors must understand learners' needs, and then determine content delivery (Miller, 2007). Instructors often structure courses to promote dialogue, thus reducing the perceived distance between students, content, and the instructor (Moore,

${ }^{1}$ In writing this manuscript I use the acronym LMS to refer to learning management systems in both the singular and plural. 
1993). Online instructors also face the challenge of mastering the LMS and keeping up with emerging technologies (Yang \& Cornelious, 2005).

Research confirms the importance of the instructional designer role for online instructors. Baran et al. (2011) performed an extensive literature review, and then used a constant comparison approach to determine online instructors' key responsibilities. They found that planning, organizing and structuring the course, all aspects of instructional design, were often considered the most important tasks for online instructors. In a study conducted to help inform new online teaching programs, the most important skills identified were the ability to design instructional strategies and develop appropriate learning resources, to implement instructional strategies and to facilitate participation and sustain motivation among students (Bawane \& Spector, 2009). The "ability to design courses well is usually the most limiting factor" (Fink, 2003, p. 34) in teaching effectively online. In a poorly designed course, students become disengaged and learning suffers (Koszalka \& Ganesan, 2004). Clarity of design is linked to student satisfaction and perceived learning in online education (Swan, 2001). Course design is connected to learning outcomes in online instruction.

\section{Statement of Problem}

Researchers have surveyed instructors on their attitudes toward online instruction (Allen \& Seaman, 2016; Seaman, 2009; Worthen, 2013), but the results fail to provide 
insight into instructors' experiences of online course design. Faculty instructors ${ }^{2}$ from public and private institutions were surveyed by Gallup in a study for Inside Higher Ed about their perception of online learning (Straumsheim, Jaschik, \& Lederman, 2015), but not about online course design. In another study, faculty instructors from 107 institutions were surveyed by the Coalition of Contingent Academic Labor to understand online instructors' professional concerns (Worthen, 2013), but these concerns were focused on control of work, job security, and ownership of copyrights, not the process of course design.

Other research highlights student perceptions and learning outcomes of online pedagogies. Instructors and students were surveyed on their perception of the usefulness of various components in online nutrition courses (Kihato \& Bednar, 2004). Research has also looked at design and implementation of online learning activities, such as discussion forums (Clark, 2015; McDonald, 2009), wikis (West \& West, 2009), and student assessment (Anderson, 2004).

Good course design has an impact on the experience of students and instructors, thus impacting learning outcomes. Barberà, Layne, and Gunawardena (2014) found prior experience and institutional systems played a part in online course design in three academic disciplines, but the study did not provide detailed information to understand the role of instructors involved in course design. Alvarez, Guasch, and Espasa (2009)

${ }^{2}$ The terms faculty instructor(s) and instructor(s) are used interchangeably in this manuscript to denote tenured and tenure-track employees at colleges and universities. 
identified the course design process consists of "defining the procedures of instructional design; considering the resources and the assessment in a virtual context; presenting content/questions; translation of traditional content in online contents with interactive activities for students; [and] creation of online interactive content" (p. 332) but the instructors' perception of these tasks was not included. Kang (2000) performed a case study to investigate the process of moving traditional courses to an online format at Northern Illinois University. Kang identified instructional strategies based on interviews with faculty instructors, instructional designers, and administrators. However, this study was limited to one university and instructional designers assisted with the process. Interested in this subject, I performed a review of literature investigating instructors and online course design for a pilot study with Yu-Hui Ching and Norm Friesen, in Spring 2016, but I did not find any information that discussed instructors' perspectives of designing online courses. Without this information, it is difficult to understand the challenges and opportunities instructors believe they face when designing online courses.

For the pilot study, a grounded theory approach was used to investigate the process college and university instructors use to design online courses. I interviewed 14 college and university instructors who had designed online courses about their experience developing and designing online courses. The findings revealed that instructors begin the process with objectives and/or existing course information, often utilizing information from face-to-face courses. Next, the instructors structure the course and chunk content. The instructors interviewed rarely use formal instructional design principles, but their design tasks show a striking similarity to those formalized in the ADDIE model. The 
participants reported that the learning management system often reduces instructor freedom in online course design and that feedback from students is a major motivator for online course design after initial course delivery. Based on these results, an informal design for online courses model was created (Baldwin, Ching, \& Friesen, 2017). The present study provided an opportunity to refine the pilot study, as a result of my increased sensitivity to data gathering, analysis and the interpretive process. In addition, the present study provided more information regarding the perspectives of instructors, specifically tenured and tenure-track instructors at public four-year colleges and universities involved in online course design. The pilot study studied instructors involved in online course design without these specifications. The focus of the research changed from the process of online course design and delivery as understood by faculty designers and instructors to the reasons and rationale for this design and delivery.

\section{Research Question}

The following research question was used to guide the study: What do tenured and tenure-track instructors at public four-year colleges and universities say about the design process of online courses, and how can it be theorized? Online course design is an important task that impacts learning and perceptions of course quality by students (Moore \& Kearsley, 2011). Course design is a complex process that, in some cases, is tasked to professionals (e.g., faculty instructors) trained to perform other duties (e.g., instruct students in a face-to-face classroom). This study investigated the perspective of tenured and tenure-track instructors at public four-year colleges and universities involved in online course design. 
Grounded theory was used to generate a general explanation (i.e., a theory) based on interview data from participants (Strauss \& Corbin, 1998) who have experienced the process of online course design development and delivery. Grounded theory looks for concepts that arise from patterns in the interview data generated from participants involved in the process or area of interest. Grounded theory involves systematic procedures of collecting data through interviews, identifying categories, and connecting these categories to create a theory that explains the process (Creswell, 2007).

The findings were shaped by the views of 21 tenured and tenure-track instructors from public four-year colleges and universities through the use of interviews. The sample size was determined by the richness of data collected from each interview, based on the concept of theoretical saturation (Brown, Stevenson, Troiano, \& Schneider, 2002). Theoretical saturation was determined when the same themes and categories occurred repeatedly in the interviews, and new interviews did not result in further elaboration of the principal themes and categories. Tenured and tenure-track instructors were chosen because they have steady employment with institutions and are more likely to be involved in course design: Seaman's (2009) national survey of higher education faculty found "institutions place greater reliance on their core faculty (tenured/tenure-track) for online development efforts" (p. 17). Also, tenured and tenure-track instructors are likely to share similar commitments and opportunities (Seaman, 2009). Public institutions have determined that online courses and programs are critical to their long-term strategy (Allen \& Seaman, 2016). This research offers a basis for generating hypotheses for investigation 
in further research and provides information that helps to understand the design of online courses.

\section{Description of Chapters}

The present chapter of the dissertation has introduced the study and contextualizes its central question. In Chapter Two, literature regarding instructional design, the role of faculty instructors, effective online practices, online student satisfaction, and quality guidelines for online courses is reviewed. A brief introduction to grounded theory methodology and the data collection and analysis procedure is presented in Chapter Three. Chapter Four presents a synopsis of the information provided by participants to highlight the findings of the study. A discussion of the results and the presentation of a theory of adaptation and acceptance in online course design, derived from the findings, are found in Chapter Five. 


\section{CHAPTER TWO: LITERATURE REVIEW}

A literature review within grounded theory research serves to increase sensitivity to previous research and provide insight into the area of interest. In this study, a literature review was performed to inform readers of pertinent information and gaps in knowledge. In an effort to understand the perspectives tenured and tenure-track instructors at public four-year colleges and universities have of online course design, literature on the following subjects will be discussed in the following order:

1. History and models of instructional design.

2. Information on instructional designers and course design.

3. The role of faculty instructors.

4. Effective online practices in online course design and teaching.

5. Student satisfaction in online courses.

6. Quality guidelines for online courses.

\section{History and Models of Instructional Design}

Instructional design, the system of procedures for developing instructional programs in a consistent and effective fashion (Dick, Carey, \& Carey, 2004; Gustafson \& Branch, 2002), is based on learning theories, systematic analysis, and management methods (Smith \& Ragan, 2005; Reiser, 2001a). Instructional design is often considered a scientific discipline focused on improving the process of instruction, by "prescribing optimal methods of instruction to bring about desired changes in student knowledge and 
skills" (Reigeluth, 2013, p. 4). Instructional design originated when psychologists and educators developed training materials based on "research and theory on instruction, learning, and human behavior" (Reiser, 2001b, p. 58) for the military. Gagné, Briggs, and others researched and developed instructional materials and models for military projects. The concepts of programmed instruction, behavioral objectives, domains of learning, events of instruction, hierarchical analysis, and formative assessment led to instructional design models (Reiser \& Dempsey, 2012).

The field of instructional design became more complex as additional research about effective teaching and learning was undertaken (Moskal, 2012). Bloom's (1965) Taxonomy of Educational Objectives provided a framework to classify learning objectives. Gagné's (1965) The Conditions of Learning described five learning outcomes (verbal information, intellectual skills, psychomotor skills, attitudes, and cognitive strategies). Gagné suggested that different internal and external conditions are necessary for each category of learning. The field of instructional design expanded (Moskal, 2012); by 1980 , Andrews and Goodson had identified more than 40 instructional design models. Instructional design practices were found to have "minimal impact in higher education" (Reiser, 2001b, p. 62) until the mid-1990's when a tipping point was reached through greater availability of computers and faster communication (Reiser, 2001b). Advances in technology led to increased interest in online education. The availability of more computers, operating at a faster pace, linked to the Internet plus the world wide web appears to have led to more instructional media. Studies on cognitive load and learning led to greater interest in instructional design principles because they represent guidelines 
that assist in presenting information in a manner that encourages optimal learning (Sweller, van Merriënboer, \& Paas, 1998).

$\underline{\text { Instructional Design Models }}$

This section describes six instructional models that illustrate different aspects of instructional design:

- ADDIE model (foundational model)

- Gagné's nine events of instruction (systemic process model)

- Dick and Carey model (systems approach model)

- Johnson and Aragon framework (online course design model)

- Backwards course design (contemporary design model)

- Rapid prototyping (contemporary design model)

These examples represent a small sample of instructional design models.

ADDIE. ADDIE is at the core of instructional design (van Merriënboer, 1997).

ADDIE (Figure 1) is an acronym for the five key phases of course design: analysis, design, development, implementation, and evaluation (Huguet, 2008). During the analysis phase, goals and objectives are established, the learning environment is reviewed, and learners' existing knowledge and skills are identified. The course designer develops an understanding of the gaps between the learner's existing knowledge and skills and the desired outcomes, identifies learner characteristics, instructional needs and creates the goals and objectives for the course. In the design phase, systematic and specific actions are taken to design content, plan lessons, assessment instruments, and media selection based on the results of the earlier analyses (Gillespie, 1998). The 
instruction is conducted during the implementation phase, and in the final phase, evaluation, the course (or lesson) is evaluated and revised by the course designer (Clark, 2015). According to instructional design principles, instructors must understand learners' needs, then determine how to design content to meet these needs, and provide formative and summative evaluation to confirm needs are met (Miller, 2007). Most instructors intuitively consider these factors when creating learning (Chen, 2015), and the ADDIE phases are found in some manner in most instructional design models and frameworks.

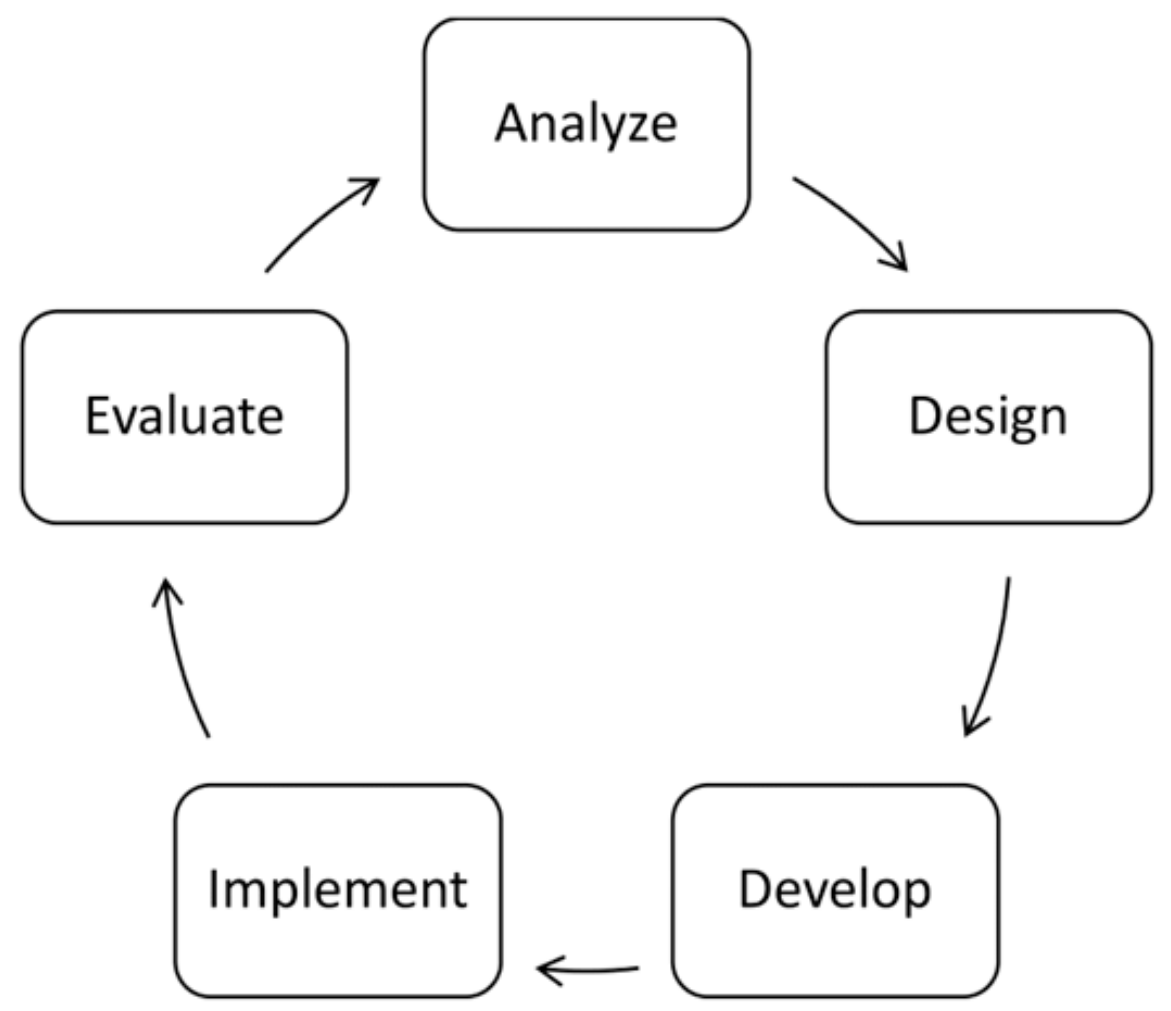

Figure 1. The ADDIE instructional design model.

Gagné's nine events of instruction. Gagné (1965), an educational psychologist, identified a series of teaching activities that he considered necessary for promoting 
learning. Gagné's nine events of instruction "remain cornerstones of instructional design practice" (Reiser, 2001b, p. 60) and are used to structure training and learning sessions. Gagné's nine events provide a systematic process to use in course design.

Gagné's nine events of instruction are:

- Gain attention

- Inform learners of objectives

- Stimulate recall of prior learning

- Present the content

- Provide learning guidance

- Elicit performance (practice)

- Provide feedback

- Assess performance

- Enhance retention and transfer to the job

These steps can be used as an outline or guideline when designing individual lessons in courses.

Dick and Carey systems approach model for designing instruction. The Dick and Carey model was developed for "training novices who required a methodology for producing instruction" (Dick, 1996, p. 58). The Dick and Carey model is a process-based, systematic method of instructional design influenced by Gagné's (1965) nine events of instruction (Dick, 1996). The Dick and Carey model focuses on the interaction of the instructor, learners, materials, instructional activities, delivery system, and learning environment to create desired learning outcomes (Dick \& Carey, 1996). 
The components that were identified in the Dick and Carey systems approach model for designing instruction (1996) are:

- Assess needs to identify goals;

- Analyze the learners and contexts;

- Conduct instructional analysis;

- Write performance objectives;

- Develop criterion-referenced test items;

- Develop instructional strategy;

- Develop and select instructional materials;

- Design and conduct formative evaluation of instruction;

- Design and conduct summative evaluation; and

- Revise instructions (this is done throughout the process).

Dick (1996) admits the model does not include procedures for implementing and maintaining instruction, a possible limitation to its use. Also, some critics suggest the Dick and Carey model is rigid and cumbersome and too focused on the instructor, with the learner positioned as a consumer of product, not an active producer (Willis, 1995). Johnson and Aragon's instructional strategy framework for online learning. It appears online learning has affected online design with more fluid approaches appearing with more traditional approaches. While not as widely referenced as the other models discussed, Johnson and Aragon's (2003) framework has been included in this review because it was specifically created to support online course design. Johnson and Aragon (2003) argue that online learning demands a combination of learning theories, not a 
single preferred perspective. The following guidelines have been paraphrased based on Johnson and Aragon's (2003) suggestions for designing powerful learning environments:

- Address individual differences by providing content in multiple media formats, allowing students control over navigation, and encouraging individual and group based activities.

- Motivate the student by using multimedia and games when appropriate.

- Avoid information overload by chunking content, limiting the number of activities, and providing a graphic organizer for the course.

- Create a real-life context through interactions in authentic settings and using case studies.

- Encourage social interaction through ongoing review and feedback and required quality interaction.

- Provide hands-on activities through project-based learning.

- Encourage student reflections using strategies like reflective journals and "muddiest point" activities.

The objective of this framework is to design online education that supports educational gains through the effective use of technology.

$\underline{\text { Backwards course design. Backwards course design refers to the instructional }}$ design process of designing a course that begins with identifying the desired results (learning goals or standards) before choosing instructional methods or materials (Wiggins \& McTighe, 2005). Wiggins and McTighe (2005) identified the phases of the backwards design process as follows: 
1. Identify desired results;

2. Determine acceptable evidence;

3. Plan learning experiences and instruction.

Backwards course design involves setting measureable learning goals and then determining the activities learners must perform to achieve the goals. An assessment is designed to provide evidence. Learning outcomes are developed to identify what the students must think and do to succeed in the assessment. Using backwards course design helps to ensure outcome goals are threaded throughout the course. It also helps avoid adding content to courses that may be unneeded or extraneous.

Rapid prototyping. Another relatively new trend in instructional design is rapid prototyping. This process involves quickly developing a prototype course or training material, and then rapidly testing and revising the material until an acceptable version is achieved (Gustafson \& Branch, 1997).

Instructional design as formalized in the models discussed above is defined as "a system of procedures for developing education and training curricula in a consistent and reliable fashion" (Branch \& Merrill, 2012, p. 8). It involves a "systematic and reflective process of translating principles.... into plans for instructional materials, activities, information resources, and evaluation" (Smith \& Ragan, 2005, p. 4). Given the fact that there are many models that can be used, Dick (1996; of the Dick and Carey model referenced here), identifies the main problem in course design is not in choosing the correct model to follow, but rather failing to use any systematic design framework, in the rush to "get something up and running on the computer" (p. 59). 


\section{Instructional Designers and Course Design}

Several studies have investigated how instructional designers solve instructional design problems. In one study, seven instructional design experts were given illstructured instructional design problems and asked to use a think-aloud procedure to articulate their problem-solving processes (Ertmer et al., 2008). The instructional designers used their previous knowledge and personal experience to interpret the problem, and then used a mental model of the instructional design process to solve the problem. The researchers discovered that it was important for the instructional designers to be able to draw on past designing experiences. In another study, 16 experienced instructional designers (with an average of 23 years of instructional design experience) were interviewed during an Association of Educational Communication and Technology (AECT) conference to determine the best way to teach instructional design (Ertmer, York, \& Gedik, 2009). The participants expressed the importance of "helping our students understand how the ID process is modified and adapted to fit changing needs" (Ertmer et al., 2009, p. 23). Most of the participants $(n=12)$ indicated the importance of determining end goals or learning outcomes as critical to successful design. In a later study, York and Ertmer (2011) found that instructional designers often use general guidelines and modified models to design courses, based on results of a series of surveys sent to 50 experienced instructional designers. Knowing the learner and determining what learners should be able to perform after instruction was found to be especially important to instructional designers (York \& Ertmer, 2011). 
Other research confirms that instructional designers adapt instructional design models based on needs (Christensen \& Osguthorpe, 2004; Kirschner, Carr, van Merriënboer, \& Sloep, 2002; Silber, 2007; Tessmer \& Wedman, 1990). Kirschner et al. (2002) noted that "while instructional models often inspire designers, their activities typically don't reflect the systematic, step-by-step approach as prescribed in traditional instructional design models" (p. 91). Zierer and Seel (2012) pointed out that while the theoretical approach to instructional design is popular in academia, this popularity does not extend to practice. Pieters (1995) surveyed 35 educational science and technology graduates who were working in education on their use of instructional design models. The respondents noted that due to time constraints, the models were not strictly used; the respondents often blurred phases and activities within their design activity. Wedman and Tessmer's (1993) survey of instructional design activities practiced by 73 instructional designers indicated that practitioners often alter activities and the sequence of activities included in instructional design models. The practitioners cited lack of time, decisions already made, and activity considered unnecessary as reasons given for omitting design activities (Wedman \& Tessmer, 1993). Silber (2007) added that instructional designers follow a set of heuristic principles, rather than procedural instructional design models. Deviations from the models may be due to resource constraints or the unique problems that need to be solved through design (Jonassen, 1997).

In a review of literature, Kenny, Zhang, Schwier, and Campbell (2005) determined that instructional designers are aware of process-based instructional design models but do not follow these models in a rigid fashion or spend a great deal of time 
using them. In summary, research indicates that instructional design models are used more broadly as general guidelines, rather than as process models by instructional designers.

\section{Role of Faculty Instructors}

Research indicates the role of faculty instructors is to teach, research, and perform service to enhance scholarship in their discipline (Dempsey, Albion, Litchfield, Havard, \& McDonald, 2007; Moskal, 2012). The norm still remains in the face-to-face classroom, but as the education landscape changes the responsibilities of faculty instructors have changed. Sasse, Schwering, and Dochterman (2008) performed a value chain analysis to investigate the relationship and relative importance between faculty teaching and research. They determined that before the growth of technology most faculty instructors were focused on research, and teaching was a byproduct of their research work. Sasse et al. (2008) identified this as a "discipline based faculty focus" (p. 40). There has been a shift, according to Sasse et al. (2008), that involves a reordering of faculty instructors' focus to one that is centered on student learning. This is a result in part from pressures for universities to efficiently use their resources (e.g., instructors), and in response to the "challenge to produce and verify student learning" (Sasse et al., 2008, p. 41). As a result, faculty instructor activity involves more time on course design, delivery, and teaching (Sasse et al., 2008). Research indicates that many institutions of higher education rely solely on faculty instructors for online course design (Cole \& Kritzer, 2009; Sasse et al., 2008; Shambaugh \& Magliaro, 1997; Smith \& Ragan, 2005). Seaman (2009) estimated that $80 \%$ of faculty instructors who are teaching online courses at the college and 
university level have developed online courses. This added role requires faculty instructors to be more than experts in their discipline. In response to this trend, universities have established "teaching and learning centers" to help instructors with technology and course design (Sasse et al., 2008).

$\underline{\text { Instructors, Time, and Online Courses }}$

Research indicates online courses require more development and design time than traditional courses (Betts, 2014; Cavanaugh, 2005; Mandernach, Hudson, \& Wise, 2013; Shea, 2007; Tomei, 2006; Visser, 2000; Windes \& Lesht, 2014). Tomei (2006) reported that the contact time for an instructor teaching the same course face-to-face and online was $14 \%$ greater for the online course, despite the instructor being familiar with the online environment. Cavanaugh (2005) suggested teaching online is one-and-a-half to two times as much work as teaching face-to-face; an important concept to consider when designing an online course (Ciabocchi, Ginsberg, \& Picciano, 2016). Every aspect of an online course must be carefully organized with explicit directions (Esani, 2010), then packaged, transmitted and presented in an electronic format (Miner, 2003). Beyond the initial course design, instructors must also spend time revising online courses, updating course dates and the syllabus every time an online course is deployed (Cavanaugh, 2005). Greater time is also involved in providing feedback to students. Carr-Chellman and Duchastel (2000) noted that online instruction is "more time intensive and requires more continuous attention in order to provide timely responses to student needs" (p. 235) than traditional instruction. 
Compensation for the time required to develop and deliver an online course has been highlighted in several studies (Ciabocchi et al., 2016; Green, Alejandro, \& Brown, 2009). In a survey of 135 online instructors from 23 different universities tenured and tenure-track faculty were dispirited by the workload involved with online education (Green et al., 2009). Tenured faculty expressed lack of sufficient financial compensation in comparison to workload, concerns about time commitment, and lack of personal connection with the university as a discouraging factor. Tenured and tenure-track faculty agreed that continuous training provided by the university, increased institutional support, and fair financial compensation in comparison to workload would encourage them to continue teaching online (Green et al., 2009). In addition, the instructors also indicated a need for institutional support for students facing technical issues. This study suggests a need to address compensation for design of online courses, and to determine how online courses should "fit into the retention and promotion process for full-time tenure track faculty" (Green et al., 2009, p. 11).

\section{Transitioning Online}

Learning to design online courses can be challenging (Swan, 2001). Face-to-face courses that are simply transferred online may be less effective because the instructional framework (structure that connects components) is not suited to online collaborative environments" (Fabry, 2009, p. 253). With little training, faculty instructors may produce courses that do not align well with learning objectives (Fabry, 2009). Instructors use their content knowledge and package it for online delivery (Fabry, 2009). This creates challenges for the instructor as he navigates the LMS and online pedagogy. Whitaker 
(2015) surveyed 84 faculty members who had transitioned from a traditional classroom to online teaching at a major research university in the Southeast. Whitaker's survey focused on the differences in teaching methods between the two modes and the adjustments that must be made. Whitaker found that faculty who were asked "to understand, design, and teach in a modality in which many had never participated as a professor or student” (Whitaker, 2015, p. 14) were at a particular disadvantage.

Teaching online challenges instructors to consider their teaching philosophy, as well as to change their content presentation to adapt to electronic delivery and access (Whitaker, 2015). In his study examining the transition of faculty to online teaching, Whitaker (2015) suggested online courses are more student-focused, meaning learners have greater control over their learning. Online learners are able to decide when they will interact, how often they will interact, and are encouraged to take part in reflective learning, according to an analysis of empirical studies on online learning (Means et al., 2010). This pedagogical change transforms the instructor's role, and it also requires new teaching methods for faculty instructors accustomed to using visual cues to confirm students' understanding and involvement (Esani, 2010).

For online course design and instruction, identifying what instructors need to know about technology and how to train them has been an ongoing issue (Koehler \& Mishra, 2005; Lackey, 2011). Instructors need to understand technology well enough to apply it, and be able to discern how to prevent technology from impeding student progress, while at the same time use it to encourage better results and greater understanding (Koehler \& Mishra, 2009). Web tools can be used to support learning 
outcomes and increase interaction (Snyder, 2009), but only if instructors have the knowledge to use them.

Mishra and Koehler (2006) developed the Technological Pedagogical Content Knowledge (originally TPCK, now known as TPACK) framework to explain the relationship between technology knowledge, pedagogical knowledge, and content knowledge (Figure 2). TPACK is important to consider when discussing online instruction because the combination of technology, pedagogy, and content knowledge impact the strategies faculty instructors use in designing and teaching online courses.

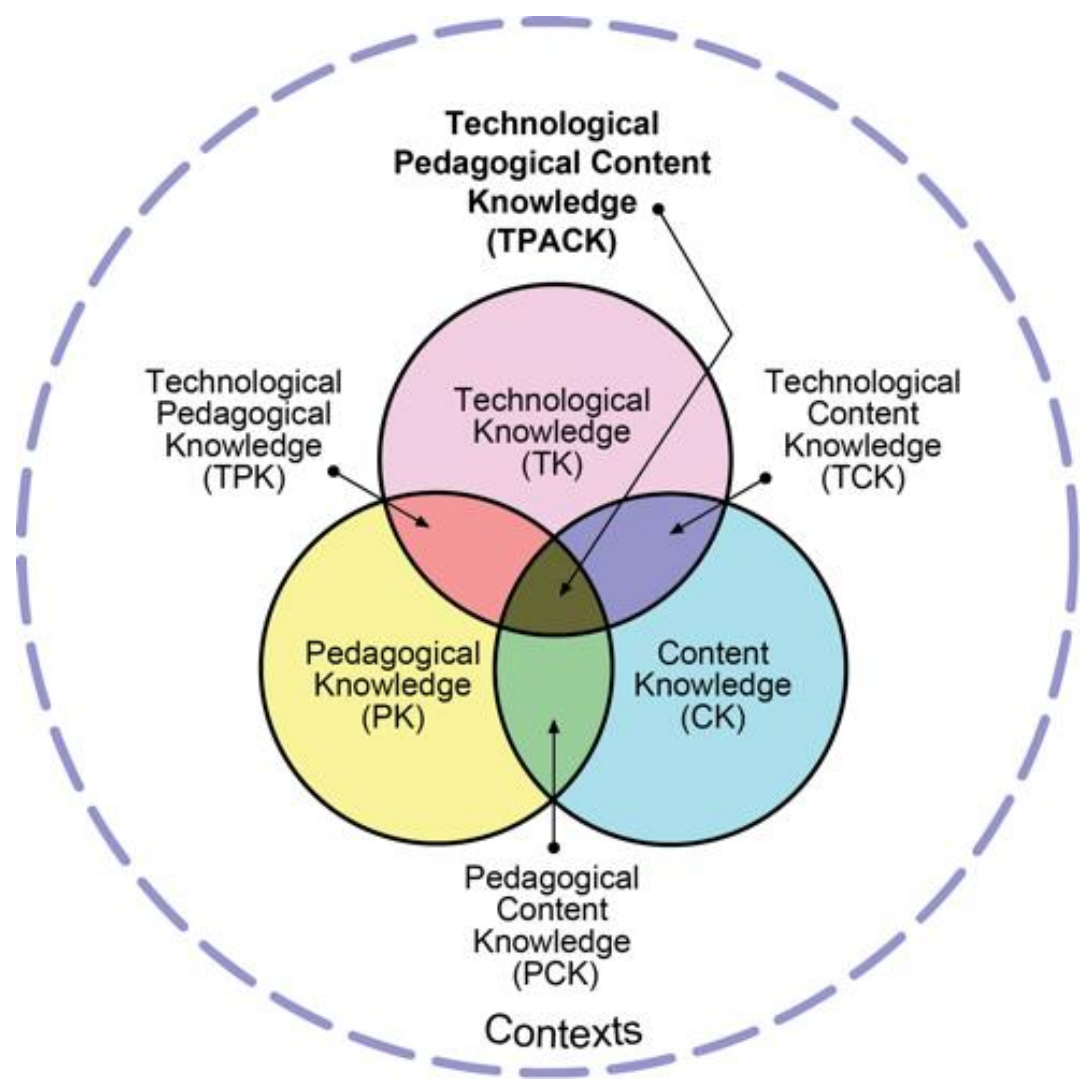

Figure 2. Technological pedagogical and content knowledge model. Copyright 2012 by tpack.org. Reprinted with permission. 
Jeffries (2005) found nursing instructors who developed and designed online courses gained a better understanding of technology involved in designing content. As a result of the course design process, instructors had less apprehension in teaching online. Online instructors also need to master the LMS and keep up with emerging technologies (Yang \& Cornelious, 2005). The LMS facilitates course design, with easy to use tools and features, but these functions do not equate to good course design (Fabry, 2009). Worse, Reeves and Reeves (2008) pointed out that the LMS helps instructors quickly design courses, but "largely fails to encourage innovative approaches to instructional design" (p. 47).

Online education requires different ways of communicating, new teaching strategies, and different instructional design tactics (Hu, 2009). These changes can be seen as tantamount to a change in social order in online courses. In these courses, the focus shifts from the instructor to the learner (Fabry, 2009; Moore \& Kearsley, 2011). In face-to-face courses content is often delivered via lectures to learners (Fabry, 2009) but the online environment offers an opportunity to design and delivery courses with the addition of technology. Fabry (2009) researched the concurrent design and development of a face-to-face course and online course. He recommended using technology tools to create an online course that optimizes interactivity. Interactivity encourages active student involvement (Fabry, 2009). Active student involvement has been found to help students master concepts faster and produce higher quality projects (Miller, 2007). Bonk and Cunningham (1998) pointed out that active involvement of students in a course can 
change the social order in learning to emphasize "guiding and supporting students as they learn to construct their understanding" (p. 27).

Hollerbach (2004), a communications professor at Southeast Missouri State University, transitioned a course online. She outlined four key elements: the curriculum, the technology, the instructor, and the students. Curriculum must be adapted to meet the needs of online students, technology must be simple enough for all participants to use (including the instructor), and students must be able to do coursework without becoming frustrated with the process. Hollerbach reported the process of transferring a course online encouraged her to consider what was being taught in the course, why it was being taught, and the best way to teach the content.

\section{Effective Online Design and Teaching Practices}

The way a course is designed communicates to the learners what is important and how they will "focus, select, organize, integrate, and apply content as they learn" (Larson \& Lockee, 2014, p. 167). Instructors must plan, organize, and structure course components (Anderson, Rourke, Garrison, \& Archer, 2001), design learning tasks (Goodyear, Salmon, Spector, Steeples, \& Tickner, 2001) and communicative strategies (Swan, 2001), and incorporate interactive technologies and teaching strategies (Williams, 2003).

Online instructors, in adjusting their role to include instructional design, need to contemplate effective practices to engage students in this media-rich environment. By effectively designing learning tasks, instructors can promote enthusiasm in their students and foster increased interest in the course (Canney, 2015). In a study examining master of 
business administration (MBA) students' perceptions of learning, satisfaction, and quality, Sebastianelli, Swift, and Tamimi (2015) found course design was the strongest predictor of all three outcomes, and the only significant factor affecting perceived learning.

Online instructors designing courses need to understand the learning process and the people involved in it. Miller's (2007) study found public administration instructors had the subject knowledge necessary for course delivery, but "very few had the understanding of the learning process necessary for high quality course design and delivery" (p. 487). As a result, little attention is paid to formulating clear learning goals and developing professional skills that will provide an effective framework for students.

The aesthetics of an online course impact the user's judgment about the site's credibility (i.e., the value of the informational content) (Selejan et al., 2016). Research indicates users prefer less complex sites (Michailidou, Harper, \& Bechhofer, 2008); however, how a course is perceived is also a function of gender and age (Selejan et al., 2016). Members of Generation Y (born in the 1980s and 1990s) "like cool graphics, have a short attention span, and do not like to read long boring texts" (Selejan et al., 2016, p. 118).

While data from LMS can provide detail on student online activity, a student's ability to understand the content and interact with it (Garrison, Anderson, \& Archer, 2004) are more difficult to quantify and report. Grounding, the process of coordinating the process and content in communication (Clark \& Brennan, 1991), depends upon shared information and mutual ground. Establishing a common ground enables 
participants (i.e., the students and the instructor) to communicate. Face-to-face teaching facilitates this process by adding eye-contact, gestures, facial expressions, and physical proximity to enrich communication. It is estimated that "approximately seven percent of the message is received by word meaning; thirty-eight percent is attributed to how it is said, and fifty-five percent of the communication message is in the form of visual cues" (Danesh, Bailey, \& Whisenand, 2015, p. 42). Online, fewer channels of communication result in the need for more explicit communication (Smith, Ferguson, \& Caris, 2001). Furthermore, online courses also have an interface that intervenes in all communication between instructors and students (Hillman, Willis, \& Gunawardena, 1994).

Shea, Fredericksen, Pickett, and Pelz (2004) performed a series of studies to determine best practices in online education for the State University of New York (SUNY). The researchers indicated providing a template for online instructors to build their course provides students and instructors a common look and feel. In addition, SUNY provides instructors with course resources that have previously been developed, designed, and delivered as a way to review examples of successful learning activities. $\underline{\text { Interaction }}$

Course structure influences interaction (York \& Richardson, 2012). Interaction is defined as dialogue between the learner-teacher, learner-content, and learner-learner (Moore, 1989). Research has supported the importance of interaction in online courses (Bernard et al., 2009; Lewis \& Abdul-Hamid, 2006; Nwankwo, 2015). Purposefully developing activities that connect students and systematically encouraging interaction 
seems to create excitement within the course and stimulates learning (Bernard et al., 2009).

Anand (2016), faculty chair of the HBX digital learning initiative at Harvard Business School, describes the four layers of learning as passive, active, adaptive and social. Instructors may design activities for students to watch and listen to incorporate passive learning. Adding polls, reflections, cold calls, and other interactive features encourages active learning. Allowing learners to move through the content at their own pace is an example of adaptive learning, but incorporating customization features (the path a student takes through a course is dependent upon whether or not he answers a question correctly) is a more difficult design feature. Social learning is viewed by Anand as a way to differentiate online courses by encouraging learners to interact with the content and other students without consuming the time of the instructors. To do this, Anand and his team suggest integrating techniques within online courses to encourage student participation (e.g., rewarding students for helping other students and prompting discussions by incorporating discussion boards directly into content pages). These techniques focus on providing the 'right' incentives to participate, with the 'right' tools to engage students (Anand, 2016).

Anderson and Garrison (1998) added teacher-teacher interaction, teacher-content interaction, and content-content interaction. These additions suggest the importance of professional development and communication between instructors. Teacher-content interaction is applicable to online course design as instructors use different technologies to present content, and also as a way to interact with the learning content provided by 
other instructors on the Internet. Content-content interaction refers to the databases, search engines, tutorials, virtual labs, and electronic books that support independent learning within the subject. For example, a geology course may include data from the U.S. Geological Survey ShakeMap. While these additional types of interaction are important to acknowledge, Rhode (2009) interviewed 10 adult online learners who reported engaging most frequently in interactions involving the online course content or the course instructor. The learners also reported valuing these types of interaction the most. This finding has been supported in earlier research (Gallien \& Early, 2008; Perry \& Edwards, 2005; Stein, Wanstreet, Calvin, Overtoom, \& Wheaton, 2005). Engagement, the act of "initiating and pursuing the interaction" (Carr-Chellman \& Duchastel, 2000, p. 238), is a critical aspect of online course design (Gunawardena \& Zittle, 1997). Developing engagement within a course results in a successful and satisfying learning experience (Conrad, 2002). Engagement is a function of a student's interest in the subject and the social setting involved (Carr-Chellman \& Duchastel, 2000). Interest in the subject matter can be facilitated "through the choice and sequencing of the information to be provided" (Carr-Chellman \& Duchastel, 2000, p. 238). The social context "either creates pressure to persevere (doing well on assignments, for instance) or adds vivacity to the interaction (dialoguing with others online, for instance)“ (CarrChellman \& Duchastel, 2000, p. 238). Engagement, however, occurs through a process of building rapport over time. In face-to-face courses, engagement can be encouraged through the physical arrangement of the classroom (Renner, 1993), yet online education demands other strategies. Conrad (2002) suggested the clarity and thoroughness with 
which course details are presented contributes to the level of engagement students feel within an online course. Incorporating interactive elements (e.g., discussion or chat room, message board, and email) in online courses increases perceived interaction with others (Cain \& Pitre, 2008; Liu, Chen, Sun, Wible, \& Kuo, 2010) and may lead to increased engagement. Embedding technology tools like blogging, instant messaging, and social media can increase the social presence of students and instructors (Young \& Bruce, 2011). Faster response to email, setting up audio/video office hour sessions to create a greater sense of connection between instructors and students may also increase engagement (Young \& Duncan, 2014). Pate, Smaldino, Mayall, and Luetkehans (2009) suggested including collaborative decision-making within online courses and requiring student posts in discussion forums can increase interaction and engagement. Furthermore, ensuring the instructor models thoughtful responsiveness with a personal tone helps to build classroom connections and build a community. Robinson and Hullinger (2008) indicated small group discussions and projects encourage deeper learning and a challenging learning environment online. The National Science Foundation Strategic Plan (2006) encouraged active learning with real life applications. Studies show instructional strategies focusing on authentic work could better engage students than the lecture format (Clase, Hein, \& Pelaez, 2008).

\section{Online Course Design and Student Satisfaction}

Course design has a direct impact on student satisfaction. Studies highlight the importance of clarity of design, interaction with instructors, and active discussion among course participants (Bradford, 2011; Paechter, Maier, \& Macher, 2010; Swan, 2001). 
Students were more satisfied with online courses when instructors provided constructive feedback, responsive communication, and relevant instructional resources and activities (Lee, Srinivasan, Trail, Lewis, \& Lopez, 2011). Feedback has been cited as a strategy for creating interaction within online courses (Hirumi, 2006; Smith \& Winking-Diaz, 2004; York \& Richardson, 2012). Mentzer, Cryan, and Teclehaimanot (2007) found student performance on tests was equal when comparing two sections of the same course (online and face-to-face). However, student grades in the online course were lower due to incomplete assignments. This study suggests that personal face-to-face contact with the instructor may positively influence students to turn in assignments.

\section{Quality Guidelines}

As the number of online courses has grown, there has been an increased focus on establishing quality guidelines (Chao, Saj, \& Hamilton, 2010; Choi \& Ahn, 2010; Mariasingam, 2005, Yang \& Cornelious, 2005). Accrediting agencies, governments, institutions, parents, and students are interested in the quality of online education (Barczyk, Buckenmeyer, \& Feldman, 2010). The Association to Advance Collegiate Schools of Business (AACSB)'s 2007 report, Quality Issues in Distance Learning, noted faculty have the primary responsibility to deliver quality distance education and they must pay careful attention to "learning design.... selection of appropriate delivery technology, and a focus on student learning outcomes" (p. 15). In Chapman and Henderson's (2010) study, business instructors and distance learning coordinators identified "rich course content, effective interaction, excellent reliability, and efficient user-friendliness" (p. 29) as important quality assurance benchmarks in online courses. 
Rich content, an element instructors designing online courses directly control, was considered to be the most important item in ensuring quality.

One goal of increasing quality in online courses is to increase retention and lower attrition rates (Gibson \& Dunning, 2012). Individual researchers have established models (e.g., the Model for Assessing and Evaluating Learning Online by O'Neil, Fisher, \& Newbold, 2004) and frameworks (e.g., Chao, Saj, \& Tessier's (2006) Online Course Quality Framework) to increase quality. Students may be used to review courses (Topper, 2007), or more commonly peer or evaluation committees (Little, 2009) may review courses.

Different types of organizations have been involved in establishing quality standards for online courses, including accrediting commissions (e.g., The American Council on Education's Principles for Distance Learning in a Learning Society) and state and regional organizations (e.g., the Open SUNY COTE Quality Rubric). Some LMS have established online course design standards (e.g., Blackboard Exemplary Course Program). Corporations have established standards as well (e.g., Quality Matters [QM]). Faculty members at different colleges and universities have also promoted course quality by establishing evaluation instruments (e.g., the California State University Quality Online Learning and Teaching Rubric [QOLT]) and participating in peer review activities (Aman, 2009; Gibson \& Dunning, 2012). However, each of these organizations has defined their standards differently (Choi \& Ahn, 2010; Mariasingam, 2005). Research was not found on the extent tenure and tenured-track instructors who design online courses at public four-year colleges and universities use quality standards. This plethora 
of standards may be overwhelming for instructors who lack time to find and use them, or may not have an instructional design background.

The Institute for Higher Education Policy, at the request of the National Education Association and Blackboard, compiled a list of quality benchmarks based on a comprehensive literature review (Phipps \& Merisotis, 2000). Next, faculty, administrators, and students at six higher educational institutions (that were identified as leaders in Internet-based education) were surveyed to determine the extent that the benchmarks were being followed, as well as the benchmarks' impact on academic quality. This study suggested an institution should establish minimum standards for course design. The learning outcomes should determine the technology used to deliver content. Also, materials should be continually reviewed to ensure they meet program standards (Phipps \& Merisotis, 2000). These guidelines have provided a base for several studies to evaluate quality in online course design (Chao et al., 2010; Twigg, 2001; Yang \& Durrington, 2010), but it is unclear if instructors at public four-year colleges and universities are aware of this information, and how it impacts online course design.

\section{Summary}

Course design is the "anchor around which the class (and learning) happens" (Koehler \& Mishra, 2005, p. 135). Research has described the importance of marrying technology, pedagogy, and content to develop better online courses. There is a large base of instructional design models and principles but research is limited in regards to the use of these tools in practice by tenured and tenure-track instructors at public four-year 
colleges and universities. Research cites that there has been pressure for instructors to develop online courses to keep up with the demand for more online courses.

Course design impacts students' perceptions of learning, satisfaction and quality. In effective online course design, emphasis is typically placed on interaction and communication. Communication differs in online courses compared to face-to-face courses and is in part a function of course design. Online courses take more development and design time, and more time responding to students. Transitioning to online courses provides instructors an opportunity to consider alternative means of instruction and assessment (Shea et al., 2004).

Online course quality is a focus of accreditation agencies, in addition to being a concern of instructors and students. Different quality standards have been established by different organizations for online course design. This study provides information regarding the perceptions of tenured and tenure-track instructors of public four-year colleges and universities on the design of online courses.

The next chapter will discuss the research methodology. 


\section{CHAPTER THREE: METHODOLOGY}

This chapter provides information about the grounded research method and describes the research procedures that were used to guide the emergence of a theoretical model for this study. In an effort to understand the perspectives tenured and tenure-track instructors at public four-year colleges and universities have of online course design, the following subjects will be discussed in the following order:

1. A brief introduction to grounded theory method.

2. The data analysis process of classic grounded theory

3. The research procedures of this study.

4. The trustworthiness of this study.

\section{A Brief Introduction to Grounded Theory Method}

Grounded theory is the "discovery of theory from data systematically obtained from social research" (Glaser \& Strauss, 1967, p. 2). The goal of grounded theory is to generate a theory "that accounts for a pattern of behavior which is relevant ... to those involved" (Glaser, 1978, p. 93). This pattern of behavior is termed a basic social process (Glaser, 1978). Wilson (1997) suggests theories should explain or help us understand; theories should connect observations and evidence, and include concepts clustered together to form a whole. Glaser and Strauss (1967) note that the theory produced is not a perfect description of the whole field. Rather, it is "a theory that accounts for much of the behavior" (Glaser \& Strauss, 1967, p. 30) of the participants by generating general 
categories and their properties, to serve as a guide for others. Grounded theory results "are not proven; they are theory" (Glaser, 1992, p. 87).

Grounded theory is based on pragmatism and symbolic interactionism (Corbin \& Strauss, 1990; Strauss \& Corbin, 1994). Pragmatism suggests that theory is not a result of a pre-existing reality but interpretations made from given perspectives, as seen or researched by others (Addelson, 1990; Dewey, 1938). Symbolic interactionism, derived from pragmatism, sees reality developed through the meaning people assign to things, which is developed from social interaction and then adjusted through interpretation (Blumer, 1969).

Glaser and Strauss published The Discovery of Grounded Theory (1967) to introduce grounded theory. Although initially working in agreement with each other, a philosophical split developed between Glaser and Strauss that resulted in two different approaches to grounded theory. The data collection, pacing, and timing of data collection, data analysis, and research product vary depending on the approach used (Glaser \& Holton, 2004). Glaser's classic approach starts by identifying an area of interest and asking participants open questions, to allow the participant's own story to unfold without the direction of preconceived questions (Elliott \& Higgins, 2012). Glaser (1992) warns against creating research questions or hypotheses at the beginning of the study. Classic grounded theory allows the researcher to proceed and modify the theory through comparisons of the concepts (words or phrases that highlight an area of importance) derived from open-ended interviews with participants. Glaser (1992) encourages researchers to explore the area of interest "with the abstract wonderment of what is going 
on that is an issue and how it is handled" (p. 22). With classic grounded theory research, data are collected and compared to develop a general theory of a process from the participants' point of view. During interviews, participants are asked a broad question to encourage them to talk about the main concerns regarding the area of interest. Glaser (1992) suggests taking field notes rather than taping and transcribing interviews to avoid being overwhelmed by descriptive detail.

The classic approach uses constant comparison of data, the "process of taking information from data collection and comparing it to emerging categories" (Creswell, 2013, p. 86). Constant comparison of data continues by comparing categories to categories, searching for themes (main ideas of the categories), and then determining a core category (the focus of the study). Glaser (1992) writes:

In [classic] grounded theory the analyst humbly allows the data to control him as much as humanly possible, by writing a theory for only what emerges through his skilled induction. The integration of his substantive theory as it emerges through coding and sorting is his verification that the hypotheses and concepts fit and work and are relevant enough to suggest. They are not proven; they are theory. (p. 87).

A classic grounded theorist's goal is not to describe a unit but to conceptualize a process within it: people, place, and time are not categorized, concepts are. (Glaser, 2002). The theory provides a generalized picture, not a specific picture of the entities. Sufficient illustration should be used to help readers understand the reference in terms of their own experience. This helps the reader grasp the theory. Glaser (1992) states that a 
grounded theory can only be validated by "its fit to the data and integration" (p. 105). Studies that create a high impact can be verified through further research.

Strauss' systematic approach begins with a research question that identifies the phenomenon to be studied. He encourages a review of literature prior to collecting data to help the researcher understand what is known about the subject (Glaser, 1992; Heath \& Cowley, 2004; Strauss \& Corbin, 1998). With the systematic approach, structured interviews are conducted using scripted questions. The interviews are recorded and transcribed for coding. Strauss' systematic approach uses “a well-defined 'coding paradigm' and always looks systematically for 'causal conditions', 'phenomena', 'context', 'intervening conditions', 'action strategies' and 'consequences' in the data' (Kelle, 2005, p. 14). The systematic approach uses predetermined coding categories and systematic design, "emphasiz[ing] the use of data analysis steps of open, axial, and selective coding, and the development of a logic paradigm or a visual picture of the theory generated" (Creswell, 2007, p. 424). Corbin and Strauss (1990) suggest that a systematic grounded theory should provide readers with information of how the original sample was selected, the major categories that emerged, the events, incidences and actions that indicated these categories, the categories that guided theoretical sampling, the hypotheses developed and tested, and the emergence of the core category. Systematic grounded theory can be validated by comparing the theoretical scheme to the data (Strauss \& Corbin, 1998).

The classic approach of grounded theory was chosen for this study. A review of literature revealed a paucity of information on the perspectives of tenured and tenure 
track instructors at public four-year colleges and universities about the process of online course design (as indicated in Chapter Two), making it difficult to develop a coding paradigm in advance (as suggested by the systematic approach). Also, the nature of the problem indicated the classic approach would be the most appropriate choice since I was interested in understanding the reasons and rationale for elements incorporated during the online course design process based on information from interviews with instructors directly involved in online course design. Classic grounded theory provides an opportunity to add and alter interview questions based on emerging categories and themes, whereas with systematic grounded theory researchers rely on set interview questions (Glaser, 1992). As a result, using classic grounded theory allowed more flexibility in researching the area of interest than systematic grounded theory (Glaser, 1992).

\section{The Data Analysis Process of Classic Grounded Theory}

The following section outlines the data analysis process of classic grounded theory. This section includes:

1. The use of memos and constant comparison.

2. The process of open coding.

3. The process of selective coding.

4. The process of theoretical coding.

\section{The Use of Memos and Constant Comparison}

The data collection and analysis process involves the use of memos and constant comparison of data. Researchers collect data in the form of information from participants 
(what has been directly said and what can be inferred from these statements). Researchers write down ideas about concepts and their relationships, and note abstract ideas to generate memos. Memos are used to raise the data above mere descriptions to a conceptual level (Glaser, 1978). Writing theoretical memos is "the core stage in the process of generating theory" (Glaser, 1978, p. 83). Researchers use the process of constant comparison (comparing collected data [e.g., information from interviews] to find commonalities and variations).

\section{Open Coding}

Researchers use open coding to "cod[e] the data in every way possible" (Glaser, 1978, p. 56). During open coding the researcher explores data, working to transcend above "his involved empirical view of his field notes" (Glaser, 1978, p. 56). Researchers code the data through the process of identifying and categorizing information to understand "what is this about?" and "what is being referenced here?" (Glaser, 1978).

Researchers first code data into concepts. Concepts are words or phrases that highlight an area of importance to the research (Ke \& Wenglensky, 2010). These concepts are sorted to form categories, based on patterns identified through the constant comparison of data. Morse (2008) describes categories as a collection of similar data brought together into the same place. Categories are groups of concepts that share characteristics or fit together. For example, in this study the concepts "eye contact", "the ability to see students", and "physical presence" were sifted into a category called "seeing" and renamed as "seeing online" later. By continuing with the process of constant comparison of data, these categories expand and contract as more data is collected. 
As data is collected and analyzed, the researcher attempts to determine gaps in the research where more information is needed. Theoretical sampling is the process of data collection "whereby the analyst jointly collects, codes, and analyzes his data and decides what data to collect next and where to find them" (Glaser, 1978, p. 36). With theoretical sampling, the researcher decides who to interview and what questions to ask while constantly comparing data to fill gaps in the research.

As interviews progress, categories are reduced and themes begin to emerge. Themes are a higher level of categorization that distill a group of categories further. Themes are described as "the meaningful 'essence' that runs through the data" (Morse, 2008, p. 727). Themes suggest to the researcher what the data is about (in this study, adaptation was a theme that was considered). From themes, a core category is selected, based on constantly comparing, sorting, and analyzing the data collected. This core category becomes the focus of further data collection. The core category is the phenomenon around which the themes relate to or revolve around; the core category represents the main concern of participants (Holton, 2008). The criteria for selecting the core category is that it is "central, relating to as many other categories and their properties as possible, and accounts for a large portion of the variation in a pattern of behavior" (Holton, 2008, p. 90). The coding data levels are identified in Table 1. 
Table 1 Coding Data Levels

\begin{tabular}{ll}
\hline Data Level & Definition \\
\hline \multicolumn{1}{c}{ Concepts } & $\begin{array}{l}\text { Words or phrases that highlight an area of } \\
\text { importance }\end{array}$ \\
Categories & $\begin{array}{l}\text { Groups of concepts that share characteristics or fit } \\
\text { together }\end{array}$ \\
Themes & $\begin{array}{l}\text { Broad areas that represent the underlying meaning } \\
\text { of data }\end{array}$ \\
Core category & $\begin{array}{l}\text { The focus of the study } \\
\text { Theoretical codes }\end{array}$ \\
\hline
\end{tabular}

\section{$\underline{\text { Selective Coding }}$}

Once a core category has been selected, the next step is selective coding. Selective coding is the process of limiting coding to categories that relate to the core category. The researcher continues to conduct interviews, compare and sort data to further understand the core category. Themes are continually evaluated as a way to explain the core category. The process of selective coding continues until the point at which no new information can be collected that adds to the emerging theory and relationships between categories have been delineated properly (Brown et al., 2002). This phase is called theoretical saturation. Once theoretical saturation has been reached interviews stop and theoretical coding begins.

\section{Theoretical Coding}

Theoretical coding is used to "give integrative scope, broad pictures and a new perspective" (Glaser, 1978, p. 72) to the data. A theoretical coding family is an abstract framework that helps the researcher conceptualize how the themes (and thus categories 
and concepts) "relate to each other as hypothesis to be integrated into a theory" (Holton, 2008, p. 91). Theoretical coding fosters the fit and work of classic grounded theory. Glaser (1978) provides a number of theoretical coding families for the researcher to consider. By considering different theoretical coding families, in conjunction with one's research, a researcher is able to organize the participants' fractured stories (turned into themes, categories, and concepts) into an organized whole theory (Glaser, 1999). Theoretical coding is used to show how themes relate to one another and helps the researcher step back to consider the data through the lens of many possible theoretical coding families. Researchers use diagrams to comprehend and test the theoretical coding scheme.

For this research, the theoretical coding family of the six C's (Figure 3) was used. With the six C's, the researcher places the core category in the center and then considers the context, conditions, causes, covariances, contingencies, and consequences to explain what is happening. "Context" is a synonym for ambiance (Glaser, 1978). "Condition" is an intervening variable (Selvaraj \& Fields, 2009). "Cause" is the reason or explanation (Selvaraj \& Fields, 2009). "Covariance" is a correlation where one category changes with another (Strauss \& Corbin, 1998). "Contingency" is an "unanticipated or unplanned event that changes conditions that can call for some sort of action/interactional (problem solving) response to manage or handle them" (Strauss \& Corbin, 1998, p. 181). "Consequence" is "the result of the phenomenon and dependent on "cause"" (Selevaraj \& Fields, 2009, p. 474). The process of theoretical coding helps the researcher ground the core category in data. 


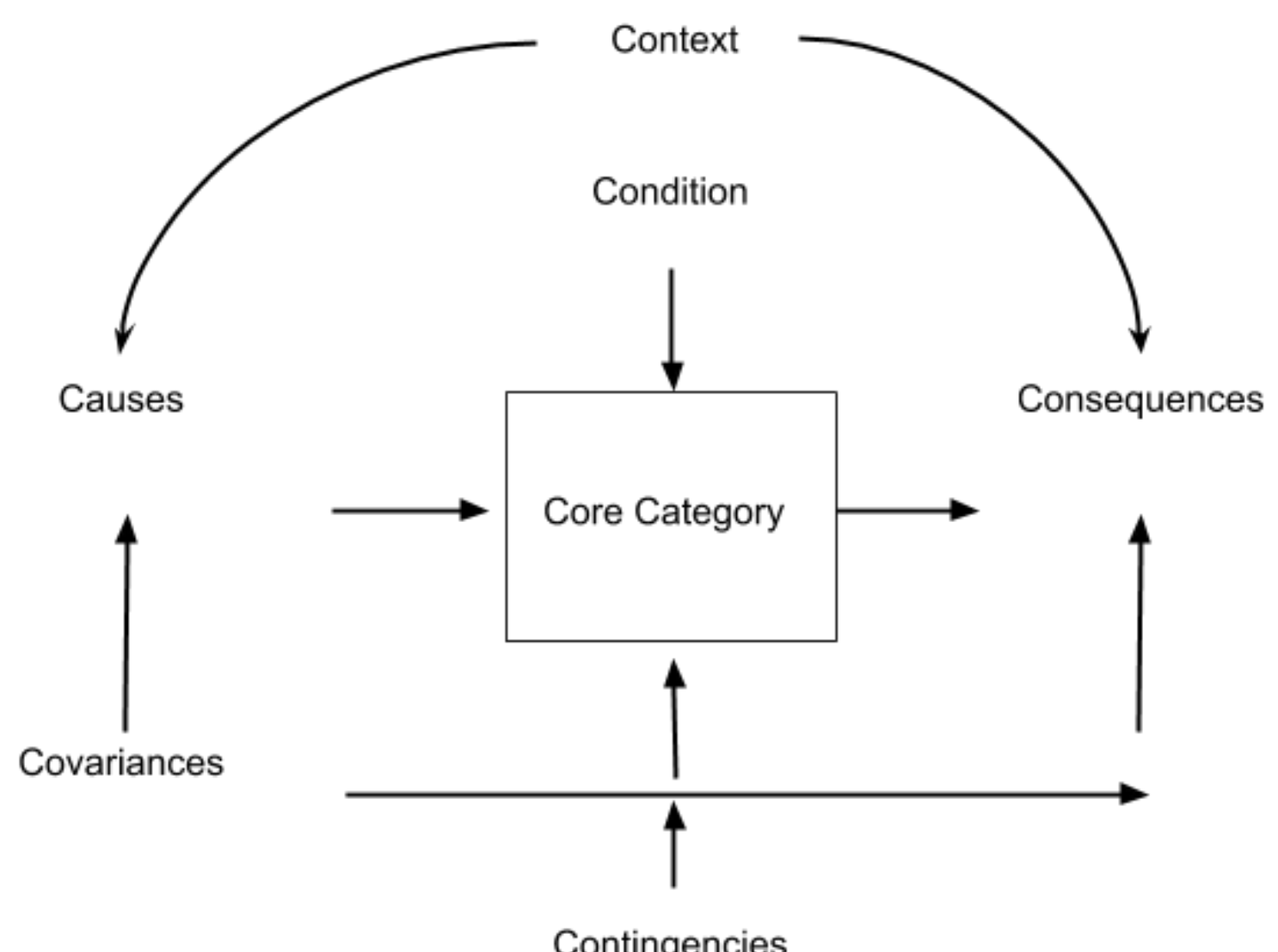

Figure 3. The 6 C's theoretical coding family (Glaser, 1992).

Theoretical coding "is not a theory in and of itself.... the meaning has to be written" (Glaser, 1998, p. 169) and explained to the reader. Theoretical coding leads to the generation of a theory. A theory is an explanation that connects observations and evidence, clustering concepts together to form a whole (Wilson, 1997). By utilizing theoretical coding, the final theory is generalized, not bound to individual participants (Glaser, 1978). 
Grounded theory results are generally presented in a manner similar to naturalscientific research reports, and include an area of interest, methods, discussion and results sections. The theory that has been generated through the research is reported at the end of the study (Creswell, 2007).

\section{The Research Procedures of this Study}

This section provides details pertaining directly to the research procedure of this study. Information on the following subjects will be discussed in the following order:

1. The researcher as an instrument.

2. The research question.

3. The selection of participants.

4. The data collection and analysis.

$\underline{\text { Researcher as an Instrument }}$

I followed the interpretive framework of postpositivism. This scientific approach to research views "inquiry as a series of logically related steps, [and] believe[s] in multiple perspectives from participants rather than a single reality" (Creswell, 2013, p. 24). This study relied upon multiple perspectives of participants, a series of logically related steps, and rigorous, systematic data collection and analysis.

In grounded theory research, the researcher is not considered naïve or objective, rather, his bias and experience become a part of the theory through rigorous application of the method (Glaser, 1999). It is important to acknowledge the relevance of my background to the study. I have been an online student and instructor. I am an experienced instructional designer. I have conducted research to understand the role of 
evaluation rubrics in course design and have worked to develop an online course design checklist to improve quality in online courses. In Spring 2016 I performed a grounded theory pilot study that investigated the process of college and university instructors designing online courses, in collaboration with Yu-Hui Ching and Norm Friesen. This experience and understanding contributed to this current research by stimulating the initial research interest and providing motivation to conduct the study. It is inevitable that these experiences shaped my interpretation of the data. In large part, classic grounded theory relies on the researcher's ability or theoretical sensitivity (Glaser, 1992). Glaser (1992) defines theoretical sensitivity as the "researcher's knowledge, understanding, and skill, which foster his generation of categories" (p. 27), eventually resulting in a theory that can be verified by relevance, fit, and work (which Glaser suggests are the criteria of grounded theory). My awareness of instructional design, instructional design models, and online course design added to my theoretical sensitivity of the subject.

\section{$\underline{\text { Research Question }}$}

The purpose of this study, which employed a grounded theory research method, was to identify the perceptions of tenured and tenure-track instructors of public four-year colleges and universities on the design of online courses. The following research question was used to guide the study: What do tenured and tenure-track instructors at public fouryear colleges and universities say about the design process of online courses, and how can it be theorized? 


\section{$\underline{\text { Selection of Participants }}$}

Criterion sampling was initially used to select the participants for this study, followed by theoretical sampling as the research progressed. Criterion sampling is choosing participants based on pre-determined criteria (Patton, 2001). The criteria for participants of this study were tenured or tenure-track instructors who have designed online courses for public four-year colleges and universities without the assistance of instructional designers. A recent survey showed that $27.2 \%$ of faculty instructors at public four-year colleges had taught a course exclusively online, compared to only $8.5 \%$ of faculty instructors at private universities (Eagan et al., 2014). It is estimated that $80 \%$ of faculty instructors who are teaching online courses at the college and university level have developed online courses (Seaman, 2009). Public institutions have determined that online courses and programs are critical to their long-term strategy (Allen \& Seaman, 2016). Tenured and tenure-track instructors were selected as a group who were likely to have similar concerns within the substantive area, as opposed to adjunct faculty. Furthermore, tenured and tenure-track instructors are viewed as core faculty and more often relied upon to develop online courses (Seaman, 2009).

\section{$\underline{\text { Recruitment }}$}

Participants were selected to provide a variety of perspectives (including gender, academic discipline, years of service, and number of courses developed) to contribute more information. After receiving approval from the Boise State University Institutional Review Board, participants were recruited by reaching out to instructors met at professional conferences and through Boise State University's educational technology 
program. To gather more participants, snowball sampling was used (Appendix A). Participants were asked to recommend other individuals to include in the study. Initially this led to several participants from the same institution. A recruitment flyer was posted on social media to enlarge the pool of participants and add diversity. Interested individuals were screened to ensure they met the study's criteria. I used a recruitment script (Appendix B) and called potential participants with an explanation of the study, requesting their participation. I also circulated a recruitment flyer (Appendix C) to instructors I know at colleges and universities to encourage participation. Theoretical sampling (the process of deciding who to interview and what questions to ask while constantly comparing data to fill gaps in the research) was used during the research to yield a variety of participants from different disciplines and with different levels of experience in online course design. A hallmark of good grounded theory, according to Creswell (2007), is that the emerging theory explains variations in the behavior of participants. While the participants had different experiences, the focus of the study remained on the themes and categories that emerged from the process or action central to course design (Creswell, 2013).

\section{Participants}

Twenty-one participants were interviewed for this study. The participants reported designing from one to one hundred courses over a period of one to twenty-three years. All but one of the participants currently teaches face-to-face courses or has taught faceto-face courses. None of the participants were formally educated online. The participants in this study reported mostly teaching themselves how to design and teach online courses. 
Five of the participants considered their technology skills to be at the intermediate level, and the remaining participants considered their skills to be advanced. Three of the participants were in the 30-to-39 age range, nine participants were between 40 and 49 years old, and nine participants were 50 years old or older. More details about the participants are illustrated in Tables 2 and 3.

\section{Table 2 Details about Participants}

\begin{tabular}{ll}
\hline Age & Percent of participants \\
\hline $30-39$ & $14.29 \%$ \\
$40-49$ & $42.86 \%$ \\
$50+$ & $42.86 \%$ \\
\hline Gender & \\
\hline Female & $66.67 \%$ \\
Male & $33.33 \%$ \\
\hline Technology skills & $19.05 \%$ \\
\hline Intermediate & $80.95 \%$ \\
\hline Advanced & \\
\hline Number of online courses designed & $23.52 \%$ \\
\hline $1-2$ & $23.81 \%$ \\
\hline - 10 & $19.05 \%$ \\
\hline $15+14$ & \\
\hline
\end{tabular}


Number of years designing online courses

\begin{tabular}{ll}
\hline $1-2$ & $14.29 \%$ \\
$3-5$ & $23.81 \%$ \\
$6-10$ & $28.57 \%$ \\
$11-14$ & $14.29 \%$ \\
$15+$ & $19.05 \%$ \\
\hline Number of years teaching & \\
\hline $1-5$ & $9.52 \%$ \\
$6-10$ & $9.52 \%$ \\
$11-15$ & $19.05 \%$ \\
$16-20$ & $19.05 \%$ \\
$20+$ & $42.86 \%$ \\
\hline Teach face-to-face & \\
\hline Yes & $80.95 \%$ \\
No & $4.76 \%$ \\
\hline Not anymore & $14.29 \%$ \\
\hline
\end{tabular}

Table $3 \quad$ Participants' Disciplines

scipline

siness

mputer Science

rriculum \& Instruction

ucation 
ucation Leadership \& Administration/Research

ucation Leadership/Research Methods

ucational Leadership \& Administration

ucational Technology

ucational Technology, Research \& Assessment

rticulture \& Horticulture Science

tructional Technology

nguage, Literacy, \& Culture

arning Design \& Technology

rary \& Information Science

search \& Statistics

spiratory Care

cial Justice

sual Communication Design

\section{$\underline{\text { Data Collection and Analysis }}$}

Participants were recruited one by one. I obtained a signed consent form prior to beginning interviews. Each interview lasted approximately 20 to 45 minutes, depending on the participant. Each participant was interviewed one time. Memoing and constant comparison of data followed the interviews. For the first nine interviews, I performed open coding on the data after each interview. For the next six interviews, I performed theoretical sampling. For the last six interviews, selective coding was used. Below is a 
visual representation of the process (Figure 4). More discussion on this data collection and analysis process follows.

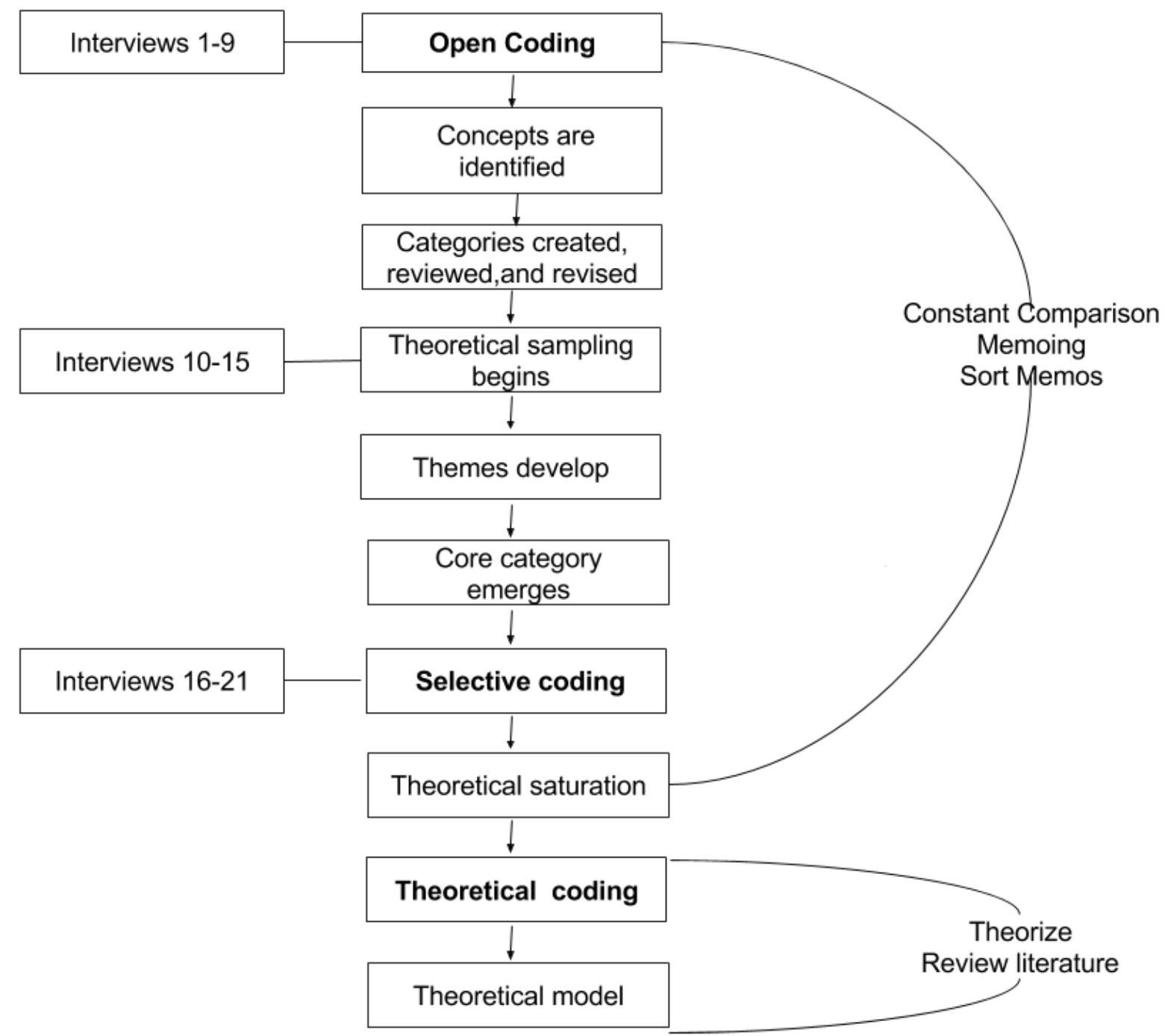

Figure 4. Visual representation of grounded theory process.

Open-ended interviews. Open-ended interviews were conducted over the telephone. Each participant was informed that the purpose of the study was to identify the perception tenured and tenure-track public four-year college and university instructors 
have of designing online courses. The interviews began with basic background questions, including asking the number of online courses the participant had designed, number of online courses taught, number of years involved with education, and if they teach face-toface classes. In addition, I asked participants their current position, age, and the type of LMS that they use. After these background questions, participants were asked the broad question, "Based on your experience, what do you think about the design of online courses?" with the intention to "instill the spill" (Glaser, 2009, p. 22) (see Appendix D for full interview script and questions). By following Glaser's (1999) guidelines of using an open question and prompting for more detail, participants were encouraged to keep talking about their main concerns (as dictated by Glaser, 1999) about the online course design. Additional questions were asked to understand the participants' perspective better including:

- Why did you start designing online courses?

- What training have you had to designing online courses?

- What course features do you consider to be important?

- What supports are provided by your institution for online course design?

- Do you take advantage of these supports? Why or why not?

- How do you perceive the effectiveness of these supports?

- Do you use a course evaluation rubric?

- What is the worst part about designing an online course?

- What is the best part about designing an online course?

Documentation. Glaser (1992) advises against recording the interviews to 
encourage participants to speak more openly and freely. That said, I recorded most of the interviews, but did not transcribe any of them. Instead, I took notes during the interviews. Immediately following each interview, I wrote more detailed notes. My intention was to understand online course design from the perspective of each participant and avoid getting lost in descriptive detail. I transferred notes onto the computer. Then, I printed out the notes and made memos throughout the process. I used the interview notes to refresh my memory, and pulled supporting statements from my notes when writing up the study.

Memoing. I memoed by jotting notes down by hand, as thoughts occurred, in an attempt to raise the data above mere descriptions to a conceptual level (Glaser, 1978). Memos were generated from interview notes, reading in the field, and through reflection. These memos were often incomplete sentences, "ticklers" or reflections. They were kept separate from notes, but reviewing notes often spurred additional memo bits. Memoing also helped capture my ideas of the emerging theory (Holton, 2007). An example of my memos can be found in Appendix E.

Open coding. During open coding I explored the data. I used a constant comparison method of analysis to uncover differences and similarities in the data, and determine why those differences and similarities were there (Strauss \& Corbin, 1998). As part of coding, memos were reviewed, and titled by concept and assigned a color. As more participants were interviewed, patterns of concepts began to develop and these patterns were divided into categories. Concepts were sorted into color-coded categories, as part of the coding and analysis. The color-coded categories were then reviewed. Some of the categories initially were "strategies," "technical ability," "LMS". These categories 
emerged from concepts. For example, "strategies" (a category) emerged from the concepts "templates" "continual refinement" and "communication". The data I used to generate the theory were the categories and themes developed from notes and memos taken during and after each interview.

I asked the following questions, during the process of open coding, to help direct the research: "What is this data a study of?" "What category does this incident indicate?" "What is actually happening in the data?" "What is the main concern being faced by the participants?"(Glaser, 1978, p. 57). The purpose of these questions was to focus on the emerging patterns (a reoccurring concept or theme), by constantly comparing incidents, and to rise above the descriptions provided by participants. Open coding was used to get a general idea of what was going on and was performed as data were collected and themes were uncovered.

My goal evolved to discover the basic social process that accounts for the behavior of the participants, as I learned more about performing grounded theory research. I kept the three questions: "What is this data a study of?" "What category does this information indicate?" "What is actually happening in the data?" active in my mind during the collecting, analyzing, and coding process. I analyzed the memos and notes line by line, after failing to grasp the answers to the three questions by reading the notes and memos as a whole. This led to more memos and different categories. Once more robust categories began to emerge, theoretical sampling and selective coding were used to collect more data. 
Theoretical sampling. Theoretical sampling is the process of data collection "whereby the analyst jointly collects, codes, and analyzes his data and decides what data to collect next and where to find them" (Glaser, 1978, p. 36). During this period (from the tenth interview on), additional interview questions were added to generate data to the developing categories:

- What is the job to be done in online course design?

- What are your thoughts on evaluation tools?

- What is main concern of instructors with course design?

Answers to these questions helped draw further attention to themes that were relevant to the participant cohort. As a part of this process I cut up all of my notes and memos and sorted them into different categories. A core category began to emerge (acceptance), as I compared, analyzed, and sorted data. This core category related to as many categories and accounted for a large portion of behavior (Glaser \& Holton, 2004). The goal of grounded theory is to generate "a set of carefully grounded concepts organized around a core category" (Glaser \& Holton, 2004, p. 41). Selective coding was used after the $15^{\text {th }}$ interview. Subsequent data collection and coding were informed by the core category and themes related to the core category.

$\underline{\text { Selective coding. During selective coding, new concepts (from new participants) }}$ were compared to other concepts to establish "underlying uniformity and varying conditions of generated concepts" (Holton, 2007, p. 271). Theoretical sampling continued until theoretical saturation was reached (Glaser \& Holton, 2004). Theoretical saturation was determined to have been reached when participants no longer added additional 
information to the core category.

Theoretical coding. Upon theoretical saturation of the data, theoretical coding occurred. Glaser (1998) offers many theoretical coding families to help the researcher conceptualize the data. I identified the six C's (causes, contexts, contingencies, consequences, covariances, and conditions) as the theoretical coding family (Glaser, 1978) that best matched the data.

\section{Trustworthiness}

The intention of this study, as that of all grounded theory studies, is to provide "a relevant theoretical abstraction about what is going on in the area studied" (Glaser \& Strauss, 1967, p. 23). A grounded theory's workability, relevance, fit, and modifiability should be enough to trust the plausibility of the theory (Glaser, 1978, 1998; Glaser \& Strauss, 1967).

- Workability means that the theory should work or function to explain participants' main concern of the participants in the area of interest. I attempted to increase the workability of the theory presented by fitting (almost) all of the evidence or concepts provided in the data into the theoretical account.

- Relevance means the theory should be important to someone. The theory should relate to the main concerns voiced by the participants and how they address these concerns (Glaser, 1992). Glaser (2012) suggests "the credibility of the theory resides in its relevance and fit for a conceptual explanation on how a main concern is continually resolved, not by illustration used as if it is proof' (p. 70). 
This study has the potential to be relevant to instructors who are involved in online course design and administrators who oversee these instructors.

- Fit and modifiability means that the theory can be changed to fit the data, and modified based on changing data (Glaser, 1992). Glaser (1992) states that a grounded theory can only be validated in terms of "its fit to the data and integration" (p. 105). I performed constant comparison of data throughout the data collection and analysis process. I coded concepts into several categories, combined categories, and revised themes as I collected more data in an attempt to achieve fit.

The theory I developed is purposefully general to address the need for the theory to allow the user some control over the "structure and process of daily situations as they change through time" (Glaser \& Strauss, 1967, p. 237). Heath and Cowley (2004) also suggest it is important to remember that "the aim is not the theory, but $a$ theory that aids understanding and action in the area under investigation" (p. 149).

Sikolia, Biros, Mason, and Weiser (2013) identified the use of credibility, transferability, dependability and confirmability as ways to increase trustworthiness of grounded theory studies.

- Credibility refers to "how much the data collected accurately reflects the multiple realities of the phenomenon" (Sikolia et al., 2013, p. 2). The credibility of this study has been enhanced by spending adequate time with each participant in an attempt to fully understand their perspectives. In 
addition, interview questions were updated based on data collected to focus more precisely on the information provided by the participants. Furthermore, participants' words are used in the findings to support the emerging theory. I ensured enough data was collected to accurately reflect multiple realities of the process, using theoretical sampling to simultaneously collect, code, and analyze data. I was able to determine gaps in the research that needed to be evaluated, for instance, by making sure both novice and more experienced instructors were included in the research. Data was collected to the point of theoretical saturation, meaning no new data emerged, and the core category and themes related to the core category were well developed. Negative case analysis was performed to understand the variances of individual responses that differed from the main group (Brown et al., 2002). For instance, some instructors felt a greater connection to students online than other instructors. This data was evaluated to determine how it impacted the theory, as well as the reasons behind the different perceptions of connection among instructors. This helped me ensure the core category was applicable to a wide variety of participants and enough data had been obtained to fully delineate the core category (Brown et al., 2002).

- Transferability refers to "the applicability of one set of findings to another setting” (Sikolia et al., 2013, p. 3). Transferability can be enhanced by including a variety of participants and providing a clear description of the research (Brown et al., 2002). To strengthen the transferability of this study I 
included participants with a wide range of experience in online course design, from a variety of disciplines and institutions.

I have attempted to provide "thick descriptions" of the methodology and findings to help future researchers. Detailed memo writing was used since it is considered an effective way to reduce bias and amplify participants' voices (Glaser, 2014). Memo writing throughout the study promoted reflection and an opportunity to evaluate the study (Shenton, 2004). Memo writing helped to develop my theoretical sensitivity, which Glaser (1992) defines as the “researcher's knowledge, understanding, and skill, which foster his generation of categories" (p. 27) and ultimately the generation of the core category. In addition, the interview notes, memos, diagrams, and additional data have been retained in the event an auditor should choose to review the research techniques (Shenton, 2004) or should other researchers be interested in research in a similar setting (Cooney, 2010).

- Dependability refers to confirmation that the data "represents the changing conditions of the phenomenon under study" (Sikolia et al., 2013, p. 3). Dependability can be verified through an independent auditor. For this study, my graduate advisor, Yu-Hui Ching, reviewed the findings and discussed the relationships between concepts, categories and themes with me.

- Confirmability refers to the ability for another researcher to confirm the results, when presented with the same data (Sikolia et al., 2013). By retaining 
all of the notes, memos, sorted categories, and drafts another researcher could evaluate and confirm this study.

Both Glaser's measures of workability, relevance, fit, and modifiability, along with Sikolia et al.’s (2013) measures of credibility, transferability, dependability and confirmability were considered in this study to help ensure trustworthiness. The methods used to collect, analyze, and present data, as well as retaining all documentation helped to achieve these measures.

Studies that create high impact and interest should be researched further (Glaser, 1992). I have attempted to create a theory that can be verified by additional research (e.g., an experiment or survey) (Glaser, 1992), and I hope that it will produce impact in the larger context of research and practice.

\section{Summary}

This study sought to identify the perception tenured and tenure-track public fouryear college and university instructors have of designing online courses. Twenty-one tenured and tenured-track instructors from public four-year colleges and universities were interviewed for the study, answering the guiding question, "Based on your experience, what do you think about the design of online courses?" Data from the interviews was analyzed, sorted, and coded using a constant comparative method. Data was collected to the point of theoretical saturation, and then theoretical coding was used to weave the story back together. 


\section{CHAPTER FOUR: RESEARCH FINDINGS}

This study was conducted to understand the perceptions of tenured and tenuretrack instructors of public four-year colleges and universities on the design of online courses. This chapter presents a synopsis of the information provided by participants to highlight the findings of the study, based on the interviews with the participants. The information in this chapter was derived through the constant comparison of data, comparing information to understand concepts, categories, and themes, and then determining the core category. Theoretical coding (as described in Chapter Three) was used to understand how the categories and themes relate to the core category and fit into a theory. In this chapter, the theoretical coding of the data is discussed. In addition, the following themes are discussed:

1. The conditions instructors experience in the online environment.

2. The strategies instructors use in the online environment.

3. The outcomes that instructors express.

\section{Theoretical Coding}

Having discussed the data collection and analysis process in Chapter Three, I will start the discussion of the findings by illustrating the theoretical coding process that helped to conceptualize the relationships between the identified themes and categories. Theoretical coding was used as a way to weave the story back together and to help conceptualize the relationships between the identified themes and categories. I used the 
six C's (causes, contexts, contingencies, consequences, covariances, and conditions) as the theoretical coding family (Glaser, 1978) that best matched the data (Figure 5). I will briefly explain the six C's in respect to the coding, and the focus of this chapter will be on the relevant items (the core category and consequences of behavior).

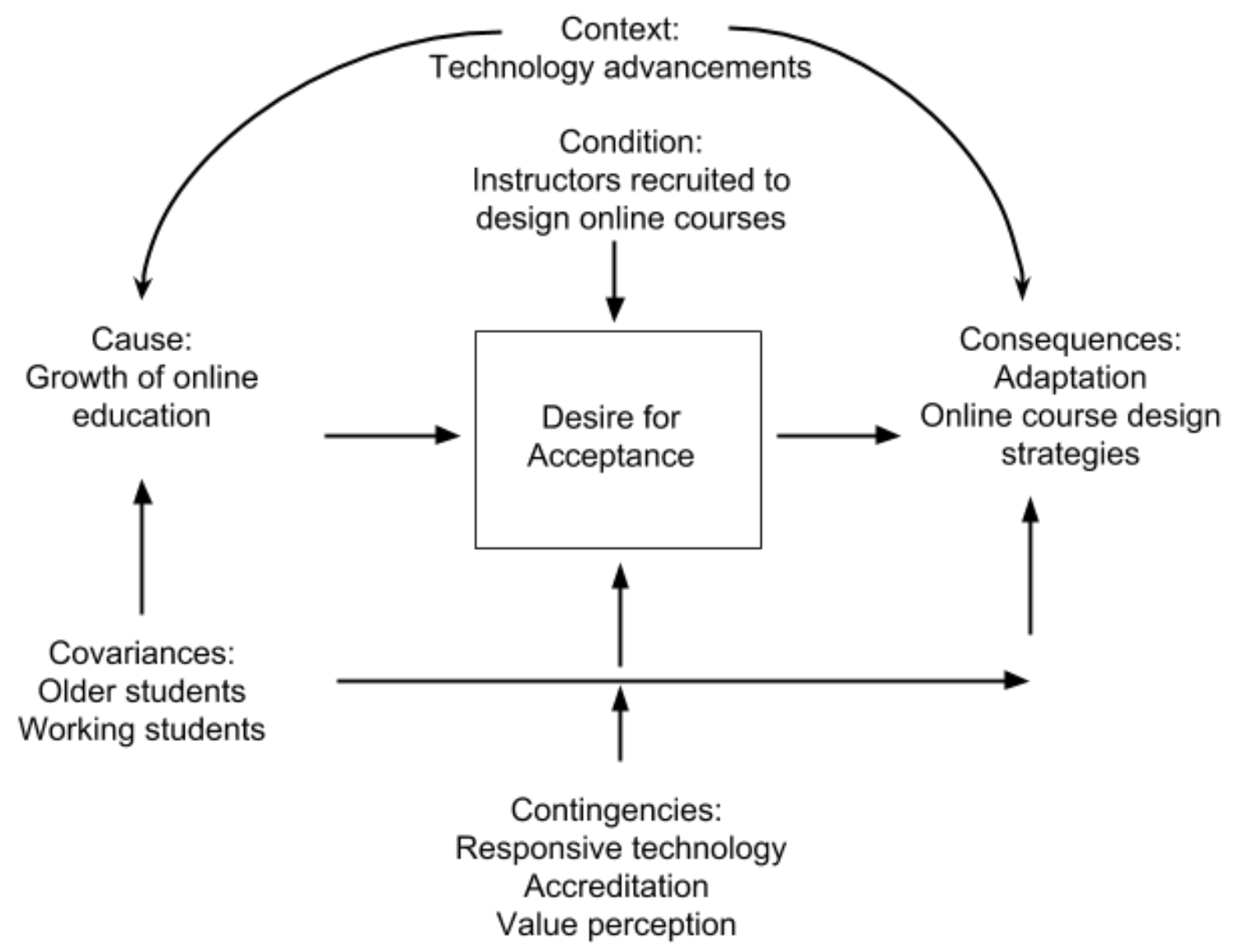

Figure 5. Factors involved in theoretical coding.

The instructors make use of what they know from face-to-face instruction to make sense of the online environment. This is adaptation, which is shown in the box on the right side of the diagram as a consequence (one of the six c's), directly or indirectly, of other 5 c's. Adaptation is "the process of change by which an organism or species becomes better suited to its environment" (Adaptation, 2017) or "the adjustment to 
environmental conditions" (Adaptation, 2017). Piaget (1952) indicated humans adapt to new information through assimilation, in which new experiences are reinterpreted to fit into existing ideas. The participants' ideas of instruction and course design are rooted in their experiences in the face-to-face environment. The participants use resources available from their face-to-face courses, colleagues, and the Internet as the basis for the strategies they use in their online courses. They also consider their knowledge about learners and content. As they adapt to the online environment, they make adjustments to overcome technological challenges also using their technological abilities and the capabilities of the LMS. They also adapt to the time requirements needed to design and instruct online courses, learning to adjust to different expectations and requirements. Finally, some of the participants also must adapt to quality oversight in the form of quality evaluation instruments (e.g., QM or QOLT). The instructors use online course design strategies to gain acceptance for online courses as they adapt to the online environment.

The core category, desire for acceptance, is featured in the center. Technological advancements create the possibilities and the commonplace reality of online education that is the context for this phenomenon. The cause (i.e., reason or explanation motivating the desire for acceptance, and modified through covariances, contingencies, and context to lead to the consequence of adaptation) is the growth of online education. Instructors have been recruited to design online courses as a condition (i.e., an intervening variable). Covariances (where one category changes with another) include older students and working students. Online education appeals to the growing ranks of "non-traditional" 
students (e.g., older, working students). These covariances positively impact the growth of online education (cause), and shape the environment and are most immediately affected by the instructors' adaptations of face-to-face conditions and strategies to this environment. There is a desire for acceptance for courses that are delivered online. The core category of desire for acceptance emerged through the constant comparison of data provided. Acceptance is the "process or fact of being received as adequate, valid, or suitable" (Acceptance, 2017). Instructors desire acceptance from students, colleagues, and administrators, and thus is directly related to the cause, context, conditions, contingencies, and covariances. It is this desire, my data strongly suggests, that drives the adaptation work of the students. These realizations helped me focus upon the consequences of the instructors' behavior; in a search for desire for acceptance of online courses, the instructors have created strategies to bridge or overcome the differences between traditional (i.e., face-to-face) education and online education. Accreditation policies applied to online education raise questions about the value of an online education compared to a traditional education (Phipps, Wellman, \& Meisotis, 2002). When students are not physically on campus, questions arise as to whether they actually obtained an education of the same rigor as traditional students (Phipps et al., 2002). This and other contingencies create a new landscape that impacts the desire for acceptance since instructors are being asked to deliver content differently than in the past. The themes and categories that emerged as a result of coding are shown in Table 4. These are discussed in more detail in the rest of this chapter. 


\section{Table 4. Summary of Themes and Categories}

Adaptation- theme

Background in traditional education- category

Available resources - category

Learners and content- category

Technological challenges- category

Time requirement- category

Online course quality-category

Online Course Design Strategies- theme

Navigation- category

"Seeing" online- category

Interaction- category

Social order- category

Desire for Acceptance- core category (main concern of participants)

Benefits of online courses- category

Online is "different"- category

The rest of the chapter will discuss the conditions instructors experience as they adapt to the online environment, the online course design strategies instructors use, and the outcomes that instructors express in their desire for acceptance.

\section{Conditions}

In this section I discuss how instructors respond to the conditions they experience in the online environment. These conditions have been categorized as:

- Background in traditional education,

- Available resources,

- Learners and content,

- Technological challenges, 
- Time requirement, and

- Course design quality.

\section{$\underline{\text { Background in Traditional Education }}$}

The participants described adapting to the online environment as part of the process of designing and teaching online. The participants often mentioned that they were never trained to teach online (or face-to-face, but they had "plenty of examples of how to do that, from years of schooling"). The participants' ideas of instruction and course design are rooted in their own experiences in the face-to-face environment. Several participants described going to school to become content experts; then they began teaching by replicating how they had been taught. All but one of the participants had experience teaching students face-to-face. The other participants either currently teach in traditional classrooms or have in the past. Although several participants reported recently taking online training classes or viewing online courses on the Internet, none of the participants were formally educated online. The participants in this study reported predominantly teaching themselves how to design and teach online courses. They picked up ideas for online strategies (as part of the adaptation process) by reading books, looking online, or, in a few cases, taking online courses at their institutions.

\section{$\underline{\text { Available Resources }}$}

The participants described being tasked with designing an online course and working to figure out what content to include in a course and how to adapt it to the online format. The participants reported using existing resources (sometimes from their face-toface experiences, from a colleague, or the Internet) when designing a new online course. 
Otherwise, as one participant pointed out, "the task of course design can be daunting." As part of the adaptation process, some participants mentioned duplicating face-to-face courses and figuring out that this tactic did not work. Often, participants noted that an instructor cannot simply "fly out the door" and teach a class: online instruction must be packaged in advance for delivery.

The participants expressed attempts to adapt to the online environment based on practices used face-to-face. A participant stated, "habits bleed over, even in a different space and format." This is the process of adapting to a new environment. One participant described figuring out how to teach students statistics by reviewing her face-to-face lesson materials and the tools used (a statistics software program), and then working through the process of introducing this information to students online. Another participant went through a process of looking at her face-to-face syllabus and considering "what works online."

A participant described holding online Google Hangouts with her students, to help them address questions about course content, much like she would help groups of students struggling in a face-to-face course. Another instructor indicated she liked to "interject herself into the discussions" between students by providing comments within the discussion forum. She reasoned that if she was in a face-to-face classroom she would add comments to a class discussion. However, when designing online courses, she mentioned, she could add images or other supporting information to further substantiate her comments. 


\section{Learners and Content}

In adapting to the online environment, the participants design courses based on their knowledge about learners and the content. This is similar to traditional education. However, since online courses are typically designed in full before the semester starts, online instructors must picture students while designing the course, not as they actually are, but as they predict they will be. This differs from typical traditional instruction where many smaller decisions may be based on face-to face interaction with students. This was particularly troublesome to one participant who described "the worst part of online course design is getting started and not knowing students and trying to guess what they need." Another participant mentioned that "in a regular classroom you can adjust the work based on the 'feel' of the room. Online this is harder." The participants described different design strategies to adapt to this difference. For example, one participant reported "starting small and building upon successful student evaluations" when a course was well received. And, although one participant indicated he used "something like backwards course design" to help him figure out what makes the most sense for his online students (based on their reactions and evaluations), none of the participants described using a formal instructional design model. They stated that they design and develop a learning experience "surrounded around key learning objectives and course goals" or "by deciding what the students need to be able to do" by the end of the course. Similar to face-to-face instruction, the participants are concerned with identifying what a student needs to know and do to succeed in the course. 
Most of the participants described the need to adapt from lecturing in front of a classroom of students, perhaps with the aid of a PowerPoint presentation, to presenting content online. One instructor noted that she videotaped a 45-minute lecture and "bored herself to tears" when she reviewed it. As a result, she learned to reduce all videos down to considerably less time and avoid packaged materials (e.g., materials developed by publishing companies).

\section{$\underline{\text { Technological Challenges }}$}

The participants stated that in a traditional classroom they were confident in their abilities but the online environment required them to make adjustments. The participants noted the importance of taking into account their own technological abilities (and the capabilities of the LMS), as well as the technological abilities of their students when adapting to the online environment. Two of the participants mentioned "biting off more than [they] could chew" when designing online courses, in an effort to balance the possibilities provided by the Internet, their technological abilities, and their willingness to commit the time to the activity. Several participants described scaling back from more extravagant course design based on what they were able to successfully implement online.

The participants also expressed concerns about losing content, systems crashing, and other travails associated with using technology. As one participant pointed out, "just one experience (e.g., hard drive crash) creates hesitation and some distrust in technology." Another participant mentioned fear when initially tasked with course design. While he felt "comfortable using a PC, learning to use [LMS] was a whole new 
area to conquer." Participants expressed the need to expand their skill set to learn how to use the LMS, and technology in general (e.g., "things just keep changing.... I try to keep current with technology but it is a constant battle").

\section{$\underline{\text { Time Requirement }}$}

The participants described adapting to the time requirements of designing and teaching online courses. In a traditional course, the time required for instructors is relatively predictable. The course has a set schedule (day/time of week) and student interaction is largely limited to class time, with a few students occasionally visiting during office hours. Traditional courses are less planned, according to the participants. In comparison, online courses often need to be designed for the entire semester or quarter, with participants reporting a need to plan the course in advance. The participants felt pressure to "get something online" in advance of online courses opening for students, while juggling other professional commitments. The participants expressed amazement at the time necessary to scout for materials, learn new technology, and overwhelmingly, the time involved interacting with students when adapting to the online environment. To adapt, the participants develop strategies to try to corral the time needed to design and teach online courses.

Designing online courses adds time. The participants reported spending more time to create online course compared to a traditional course. Several participants mentioned the ability to improvise a face-to-face course, but noted that this was not possible online. Participants stressed the link between course design and teaching as they discussed the time involved in online courses. The participants emphasized the need to prepare an 
online course, resulting in more work upfront. Several of the participants acknowledged the importance of taking time in advance of the start of the course to carefully plan the course. By planning ahead, the time commitment of teaching the course can be reduced, according to one participant.

"Learning technology takes time, too." Participants also discussed the time involved in learning and using technology. One participant noted her development time was increased each time her institution changed LMS. Another participant pointed out that he is the content expert, editor, writer, and videographer for his courses. While pleased with his ability to perform in these capacities, he suggested the time involved in online courses is much greater than face-to-face courses, as a result of these duties.

Online courses do not have a set schedule. The participants noted that time instructing online courses is spent differently than in traditional courses. In a traditional course, "an instructor can pontificate for two and a half hours a week and think that they have taught; an online instructor can't do that-it is an everyday job, always present, always on my mind. Students must be dealt with continually." This sentiment was repeated by many participants, who expressed the need to be involved with online students is much greater than with their face-to-face students.

Adapting instruction for a new delivery format. The participants explained that instruction in the online format is different. Rather than standing in front of students and answering questions for the whole class to hear, or giving quick feedback during class discussions, online instructors often respond to learners singularly and provide more feedback to ensure understanding. The participants reported finding out that activities 
online tend to involve more instructor time, so they adapt assignments accordingly. The participants remain focused on designing the course around the objectives and goals, but they are mindful that they need to develop activities that will not be overwhelming to grade and provide feedback.

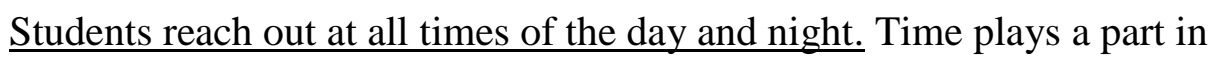
interactions with students, as a product of the connection between designing and teaching online courses. In a traditional classroom, an instructor can answer questions in class and improvise. This is not possible with online courses. While most of the instructors have set up question and answer forums within their courses, students often reach out directly to instructors. The instructors feel a commitment to respond to students. With online courses, students have the ability to 'be in class' around the clock, seven days a week. Students with questions and concerns reach out to instructors, often expecting an instant or near instant response based on their previous experiences with electronic communication. This can be difficult to endure or exhilarating for instructors. Some participants enjoy the opportunity to thoughtfully respond to students online, pointing out that answers to questions can be supported with additional information (e.g., links, attachments) and the instructor's response can be richer than in a face-to-face setting, as a result of having time to reflect on the subject. In addition, a participant mentioned the ability to respond to students without waiting for the next scheduled class meeting, a benefit over face-to-face courses. One participant noted that responding to students quickly was necessary to set an example of the behavior expected from the students. Another participant communicated to her students that she would be offline Thursday 
through Sunday. She did this, in part, to encourage students to look at the assignment well in advance of the due date (Sunday), and to stimulate students to communicate with her without the additional pressure of a deadline. This tactic also helps to balance her time working online. Almost all of the participants mentioned the volume of questions students asked online. The participants often discussed the need to consider how to provide better quality feedback in less time when designing online courses.

Participants worry that they need to monitor students more. There are time sensitive activities that can impact the course experience for students and instructors that are unique to the online environment. Participants mentioned that online courses should be monitored, since the students could conceivably be online anytime. One participant worried that students might be rude or offensive to a classmate and she would not catch the transgression quickly enough. A participant noted that in a face-to-face discussion in class, should someone make an irresponsible or indelicate comment she is present to correct the situation and re-focus the group. Online she is less likely to notice this problem without setting up text notifications to her mobile device to get notified of each comment made in the course. While this is an effective way to monitor the discussion board, this practice takes additional time and effort, especially compared to a traditional class discussion that is bounded by time and place.

Online courses create new time expectations for students, too. The participants mentioned that online learning takes more time for the students, an element of online learning that must be taken into account when designing the course. A participant suggested students must be on task more, taking more responsibility for their own 
learning than with face-to-face learning. Several participants noted the need to scale back on assignments so that they could provide sufficient feedback to students.

Online design and teaching are new, different activities, added on to other responsibilities. Faculty instructors are obligated to research, publish, and provide service to the university and profession, so the time involved in designing and teaching an online course is an element of concern. The participants noted that a lot of work involved with online course design does not leave sufficient time for research and service activities required for promotion and tenure. There was a suggestion that online course design should be a paid activity or be compensated through load adjustment.

\section{Course Design Quality}

Some instructors designing online courses must also conform to different evaluation tools than they are accustomed to in face-to-face courses. In a traditional classroom, instructors are in charge of the course content and delivery with very little oversight. Depending on an institution's policies, online courses are sometimes subject to quality oversight in the form of quality evaluation instruments. During the interviews, participants were asked if they use a quality evaluation instrument, and if they did, which instrument, and why that particular instrument. The only participants who reported using a course quality evaluation instrument worked at institutions that subscribe to Quality Matters (QM) (seven participants) or were employed by institutions requiring use of the Quality Online Learning and Teaching (QOLT) instrument (three participants). Quality evaluation instruments impact adaptation to the online environment for some of the participants in this study. 
There was lack of consensus regarding evaluation instruments and training for quality. Participants reported mixed feelings in regards to online course quality evaluation instruments and training. Some participants reported that the quality evaluation instruments and training helped them organize their courses better. In other cases, memories of the training had faded ("I did Quality Matters training during a really busy semester") or the training was viewed more as "a hurdle" than as useful professional development. QM emerged as the most noted evaluation instrument in this study due to the volume of participants who were at institutions demanding its use.

Some of the participants indicated that the benefits of a quality evaluation instrument include meeting expectations or standards. These participants like the structure provided by these instruments, and felt using an evaluation instruments adds clarity, and helps to draw attention to accessibility and student services. Another instructor equated QM to training wheels on a bicycle, suggesting that a "typical" course may benefit from the structure and support QM offers. However, this particular participant noted that just because a course meets QM standards "it may still be boring.... QM doesn't focus enough on engagement."

Who measures course quality? What is quality? These were other concerns as well. Participants indicated a desire to have an instrument that is less prescriptive than is currently available at their institution. One instructor pointed out that the QM reviewers on his campus were former students that had not progressed much beyond his course, and he would have more faith in receiving comments about his course from trusted peers. Others felt the instruments seemed redundant and overbearing. Following the evaluation 
instrument was restrictive to one participant; she reported feeling "like [she is] being manipulated with something that doesn't match [her] learning strategies." This makes her feel compromised. The term "lockstep" was used to describe using an evaluation instrument, and a participant suggested that the instrument seemed less relevant for adult learners. Several participants cited additional reasons why their learners and courses were unique and the current instrument were not a good fit. Other participants also mentioned that evaluation instruments feel too rigid and regimented, and encroach on academic freedom. The participants appreciate the ability to present content in a manner that avoids a "generic" or "cookie cutter" approach, terms that some of the participants associate with the use of an evaluation instrument.

There is a desire for course quality. The participants work to design online courses that promote an effective learning experience. They are definitely in favor of quality online courses. But, as one participant mentioned, "online course quality [at his institution] is like the wild west." He desires some sort of validation but he does not like the idea of a formal evaluation instrument [i.e., QM]. The participants, for the most part, indicated that having a system where someone in their department ("a trusted peer") reviews their online courses would be of more value to them than a national evaluation instrument. The participants indicated that their colleagues have greater knowledge of the students and content involved in the courses, and would be able to provide more valuable feedback than using a specific instrument. One participant described a standardized evaluation instrument as being "like training wheels" but stated a course peer review 
(from a colleague) offered an "opportunity to focus more on the students' experience" and would provide better feedback for him.

Quality is important for online courses and face-to-face courses. The participants readily agreed that quality is important in education. However, the participants reported the addition of quality evaluation instruments and training for online courses seems unfair. In the traditional classroom the instructor is clearly in charge with little oversight, the participants pointed out. One participant noted that institutions "work to hire great professors, and [the institution] should get out of the way and let them teach." Several participants suggested that face-to-face courses get away with less quality monitoring than online courses. Some participants indicated that quality assurance should apply equally to both formats.

\section{Adaptation and its Strategies}

The instructors reinterpret the conditions they experience in the online environment in relation to what is known. The participants adapt to the online environment using their background in traditional education as a base. The participants repeatedly referenced face-to-face instruction with statements like, "with face-to-face you can get away with more last minute things," "online course design is more specific," and "an online course must be built in advance."

As a part of the coding of the findings of the study, I identified several categories related to the strategies instructors used to design online courses. I categorized these strategies as the theme "online course design strategies." These are the online course design strategies that instructors use to adapt to the online environment. While online 
course design is often considered a separate activity from online instruction (e.g., when an instructional designers design a course for an instructor), for the participants in this study, the two tasks are intertwined. Actions are taken to design online courses that facilitate instruction. The participants endeavor to accommodate what they know from traditional instruction about pedagogy, technology, and content to the online environment. For example, the participants describe using online course design strategies to help the students navigate through online courses. They also described using technology as a way to connect with students online, as a way to "see" students. Often, the participants use discussion forums, group work, or peer review to increase interaction in online courses. The participants indicated a change in social order online, so they use online course design strategies that include replying to student emails with carefully measured responses to adapt to the online environment. The participants reported using strategies when designing online courses to help the courses run smoothly, taking into account the differences between face-to-face and online instruction.

In this section I discuss strategies instructors use in the online environment. These strategies have been categorized as:

- Navigation,

- "Seeing" online,

- Interaction, and

- Social order. 


\section{$\underline{\text { Navigation }}$}

In a traditional classroom, the path is clear. Learners know (from past experience) to walk down the hallway, open the door and sit down. Even though courses are held in different buildings the basic cues are there (e.g., room number, door, chairs) to provide the learner with information as to what to do. Online courses do not have these cues. Often online courses within the same university use different formats. Instructors try to design online courses that are easy to navigate as a way to get students through "the door" to the content.

Helping students get to class. The participants described the frustration students experience when they have trouble accessing a course for the first time or when students are able to sign in but don't understand how to get around the course. In response, the instructors use strategies to ensure that all students can navigate through the course successfully. Many participants favor templates to help provide cues for learners, so the focus can be on substantial areas of the course. A participant pointed out that he uses a course design template, "even though it is not amazing," to provide alignment, hierarchy, contrast, and consistency of content placement. He pointed out that "you can't have information wherever the professor wants — these students are going into debt—don't make them hunt to do the work!" Participants noted that learning how to create easy pathways for students to understand where to find assignments, how to complete modules, and how to turn in work is an important first step for students in online courses, which is facilitated by good design. 
Easy to navigate courses help students and instructors. Helping the students

know where to find information as quickly and simply as possible helps the course run more smoothly, according to the participants. One participant pointed out that she used to think students reaching out to ask questions about navigation was interaction, but then she realized it was just confusion. She indicated that now her goal in online courses is to have questions about content, not about navigation. Clear navigation and course structure cuts down on panicked calls and messages from students. The participants mentioned that while the LMS facilitates adding content, the LMS does not necessarily contribute to ease of navigation for the student.

Chunking content helps students navigate. Breaking content into 'chunks' or modules was frequently indicated as an important strategy to help students navigate online courses. Participants break the course content up into chunks or lessons, and they also break individual pieces up. For instance, a participant recalled a screencast she recorded to describe a specific sticky point in the lesson. The recording took too long, so she broke it into two pieces. "Too long and the students check out," she warned. Participants described another benefit of having the content "chunked" is being able to align specific learning objectives with the instruction, activities, and assessments. This strategy also helps to ensure that work is broken down for the students and the instructors. Adding dates to the chunked content (i.e., modules) also helps pace the course and makes it easier for student to understand expectations.

"Seeing" Online 
In a traditional classroom, the instructor and students share eye contact and physical presence. In an online course, the instructor and students are separated by time and distance. The instructors crave what they know from traditional instruction. Eye contact, body language and verbal responses provide feedback and connection in face-toface instruction (Bower, 2001). A frequent complaint from the participants was the inability to see "the whites of students' eyes" or, in other words, to have eye contact with students. The participants reported difficulty in teaching without "seeing" the students" reaction to content. To overcome this challenge, strategies are developed.

Eye contact is familiar to instructors. The instructors report using technology as a way to "see" students. The participants explained that in a face-to-face course, eye contact between an instructor and student acknowledges presence, confirms understanding, or indicates confusion. In an online course, according to the participants, it can be more difficult to communicate these elements. However, the participants use technology to overcome the problems created by technology, by adding video chat and tools like VoiceThread, to virtually "see the whites of students' eyes."

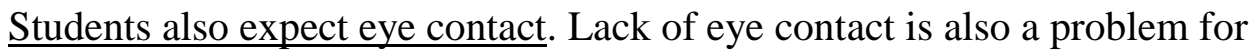
students. The participants often remarked on the large volume of questions from students. One participant explained the propensity of students to ask questions online as an attempt to be reassured from their concern of being alone online. "Are you there? I can't see you" was often the feeling expressed by the participants in regards to students, and how the participants felt students perceived others in the course, when unable to interact directly with each other. One strategy to combat this issue, mentioned by several participants, is 
using a general question and answer forum for students to ask questions. By making this forum available to the whole class, instructors are potentially able to answer questions and avoid repeating questions. Participants also frequently encourage students to jump in and respond to questions, in an effort to build a community and reduce their own workload.

Participants are curious about "seeing" what their students see. A participant described feeling unsure of the students' perception of the course. In a traditional course, the participant reported, he felt more aware of how students perceive the course, as a result of his years as a student and instructor. Participants reported wanting to "see the course from the students' view." Even though "student view" is a common feature in LMS it is not always the actual student view of the screen that the participants want to understand. The participants described a curiosity in how it feels to be a student in an online course, or, in other words, the person logging into the course, interacting with content and classmates. One participant clarified her point by describing an interest in knowing how it feels to be the student, sitting in their "space" dependent on the speed of the Internet, and looking at the course, isolated from classmates and the instructor. She and others mentioned it is hard to gauge the clarity of communications online, until the course is released for students. One participant described the difficulty in "trying to guess what students will read or look at in the course." Another participant worried that students might feel "like a cog in an assembly line" if her prose was not personal or was somehow misinterpreted. One participant wondered, "What troubles do [students] have? Is [the system] slow? Where are the stumbles?" 
Once the course is deployed, there is often a delay in response from students, since the students typically do not view the course all at once or respond immediately. The time delay in messages between students and the instructor can impact relationship building and engagement in online courses, stated another participant. This is further complicated by the inability to "see" the student. To help address time-lapse, the participant suggested using multiple forms of media (e.g., images, video, voice) to develop social presence.

Participants want to "see" successful moments. An 'aha!' moment, described by the participants as the moment when students comprehend an important lesson, is valuable feedback for the instructor that helps to increase satisfaction in the course for the instructor and students. The participants mentioned that, compared to face-to-face classes, it is hard to "see" an 'aha!' moment online. To help increase their connection with the students to "see" if and when this moment happens, participants describe incorporating activities that encourage the student to use newly developed knowledge and skills in an authentic manner. Students respond with a new type of 'aha!' moment online: Several of the participants noted student reflections on assignments about "actually being able to use" what they (the students) are learning in "real life," thus providing the instructors and students additional satisfaction. For example, one participant boasted about a note she had received from a student using skills from a lesson in his job. Another participant described the excitement she felt in hearing that a student received a job offer after visiting a professional as part of an assignment for her online course. 


\section{$\underline{\text { Interaction }}$}

Learners and the instructor interact with each other through conversation and eye contact in a traditional classroom, as a byproduct of physical presence. Learners often interact with one another in the classroom, either as a result of walking through a door together, asking questions, or as a result of being in the same classroom, at the same time, for the same course. When instructors are designing online courses they use strategies (e.g., discussion forums) to recreate the classroom environment to stimulate studentinstructor interaction, student-student interaction, and student-content interaction.

Participants use technology to connect with students online. Tactics used by the participants include videotaping the grading process so that students could understand, in detail, the grading remarks. Other participants meet with students over voice and video calls (e.g., FaceTime, Skype) to provide face-to-face communication. One participant mentioned making a video to show where she grades, including the view from her desk, to help connect with students. Another instructor mentioned that she spends more "quality time" responding to online students, since she is able to type, rather than handwrite her feedback. She also appreciates that by communicating through the open channels of an online course, she is able to ask a clarifying question when grading and get a response from a student. This interaction creates a richer learning experience for students. The ability to provide individual feedback to each and every student, while involving a great deal of time, is one of the elements that creates a stronger learning experience for the students, according to the participants. 
Online design and teaching strategies help students interact. Online education was described by participants as "more deliberate than face-to-face" courses. Instructors acknowledged an advantage in online courses, compared to face-to-face instruction, is the ability to require everyone in the course to contribute. Participants often start online conversations by asking students to post introductory videos, or other personal images. This strategy aids in involving students and helps them identify with other students within the course. Discussion forums are common. However, as the participants frequently pointed out, these discussions are different than a discussion in a traditional course, in which two to three loquacious students will frequently answer every question ("the battle of the fastest hand"), while three to four students in the class will not speak throughout the semester. The participants appreciate the ability to draw students out and bring them into the course through online discussion. Reflection journals were also mentioned as a way to "hear" students online.

One participant noted that the "students' feeling of success is based on interaction and communication, not on course content." The participants create strategies to encourage interaction, expressing a need to add variety to the course activities to avoid repetition and boredom. Discussion board fatigue is a danger in online courses according to the participants, so they add guest speakers and use tools like VoiceThread to help "humanize" the course. Additional frequent strategies used by the participants include group work and peer review. One participant frequently paired students to encourage interaction and help facilitate understanding in the course. Another participant described starting online courses with an activity that requires each student to communicate, 
followed by additional activities that incorporate pairs of students. Later in the course, she adds activities that involve larger groups of students. By having students interact with each other online, the participants bridge the distance between learners. One participant described holding several video conferences a week throughout the semester to help students understand concepts. Another participant holds mandatory online sessions once a week, starting with an online welcome meeting, as a way to encourage group interaction. The participants echoed the sentiment that, "Success comes from making connections, not content" (Anand, 2016) in describing their online course design.

The participants see value in designing authentic assignments for online courses to facilitate student-content interaction. In part, because these assignments are well received by students (e.g., "students love assignments that they can use") but also as a way to take students outside of the virtual atmosphere into a space grounded by reality. Many of the assignments described by participants incorporate reaching out to friends and experts face-to-face: observations, interviews, and group activities demand students walk outside of the virtual classroom to interact with others. One participant noted the ability for online students to use content authentically by designing activities where the students apply their new knowledge and produce an artifact. Another participant described wanting students to "get away from the computer" and stated she often "gives students assignments to go and observe meetings or professionals at work." One participant stated he likes to "prime students for what they are going to do" so he tries to be "strategic by picking authentic activities." Participants frequently described working 
to make assignments engaging and relevant to the students' lives for the purpose of improving learner-content interaction.

\section{$\underline{\text { Social Order }}$}

In a traditional classroom, the layout of the room or the instructor's position (standing up, by a desk, or behind a podium, in the center of room) signify social importance, as does his or her delivery of course content in the form of a lecture or as the director of the conversation. In face-to-face classrooms, teachers address questions about content. This is true online, but in addition, online instructors also deal with questions regarding technology or student services. While happy to answer questions about content, the participants were not always able to help students solve technological issues. This frustrated and surprised some of the participants. The online course environment (shaped by the course design and instruction) changes the social dynamics found in a traditional classroom.

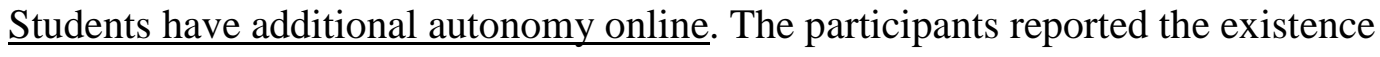
of a different type of relationship with online students. More than one participant indicated, that in person, they lecture on a subject, ask students questions, and encourage classroom discussion. In online courses, they use discussion forums and activities to encourage students to log in and engage. The participants noted that students can log into an online course whenever they want. A participant pointed out that this forces the students to initiate action. In a traditional course, the participant pointed out, he calls on students and they do not have the luxury of not replying immediately. 
Students behave differently online. The participants described sometimes having difficulty with the sequence of what students' view online. One participant stated, "students won't listen to lectures or play videos...they just jump to the assignment." This creates more issues for her, since students are then less likely to understand the assignment. To combat this tendency, some participants assign "prerequisite" labels within the LMS to ensure students must click on instructions. Another participant described making critical information bold, to draw attention to it, but even then he was not sure if this tactic was effective in making students notice the information. A participant suggested he felt "in the dark" about the students' readiness to learn (e.g., equipped with proper technology, interest in the subject matter), and preparation to be self-reliant. Participants reported displeasure when students had not set up notifications within the LMS, or failed to regularly log in and be an active member in the course.

Participants mentioned some online students feel empowered to speak freely, without the scrutiny of other students typically present in a traditional classroom. Students may feel freer to debate and even challenge the instructor, when not in a face-toface context. As a result, participants sometimes felt students were strident or more emotional online, compared to a face-to-face course. One participant mentioned seeing a different side of students-especially when technology was an issue or there were questions about an assignment with an approaching due date. When students become emotional, she must remind herself "why the students are reacting that way" and remain calm. The participants indicated emotional engagement is a potential land mine. Students, in frustration, may send quick messages via the LMS or emails, that may be interpreted 
differently than intended, a condition psychologists label 'communication disconnect' (Kruger, Epley, Parker, \& Ng, 2005). Another participant noted that online "everything seems magnified.” Acknowledging this tendency encourages the participants to carefully measure responses, particularly when responding to frustrated students, and work to design courses that are clear and organized.

\section{Outcomes}

I categorized the consequences of the participants' behavior (i.e. the outcomes) after identifying the themes of adaptation and online course strategies. The outcomes have been sorted into the following categories:

- Benefits of online courses, and

- Online is "different."

\section{Benefits of Online Courses}

Benefits of online touted. For the participants, acceptance occurred as a result of "figuring out how to do what they wanted to do" in the new environment. One participant described her initial unease because she "is very interactive" and had to figure out how to replicate the feeling of being with her students online. In general, the participants were quick to mention benefits of online courses. Most of the participants mentioned accepting online courses after realizing the multimodal possibilities available to online course designers. The participants noted that online courses provide a chance to do more for students. A participant mentioned the ability to expand students' learning beyond classroom walls and the transparency (e.g. all grades and comments posted online) of the online courses. One participant noted that online courses are still unbridled by many 
rules, with freedom to innovate and take risks, which is appealing. Another participant suggested that "online courses provide an opportunity to be expansive."

Another participant mentioned "if you designed every course with the same rigor, you'd have better face-to face courses." Many of the participants boasted of their ability to systematically design courses that incorporate rich media to support learning objectives. The range of materials available on the Internet—web recordings, videos, readings_-were cited as being appealing. Other participants mentioned the power of online learning, including the ability to be creative and develop authentic activities that drive learning. One participant noted the ability to design a course that is socially and culturally responsible online, by including racial, ethnic, and gender diversity in images and text selections. This approach encourages students to look beyond their own worldview. Other participants viewed helping students gain confidence in an online format as an added benefit of developing and teaching online. For example, one participant who instructs students in a traditionally difficult subject described providing "lots of contact and support" through a wide range of technology (e.g., web conference calls, short videos, detailed comments on assignments, screen sharing).

Other participants realized that designing and teaching online has helped them develop better habits ("I plan full semesters now for both formats"). An additional benefit to online courses, according to the participants, is having an opportunity to review the course content, as it is designed, to make it more engaging for students. This helps instructors reflect on the course and the learners. This is a more elaborate process than simply making a syllabus for a face-to-face course since participants' report designing 
online courses fully in advance of deployment. Online instructors are able to actually view the course and its content, not just a summary or the course highlights. The participants were proud of their ability to create interactive, meaningful courses that help students learn.

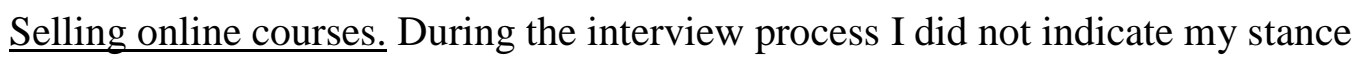
on online course design or learning, and I often felt that the participants were "selling" online courses to me as an effective form of instruction. After this happened repeatedly, a theme emerged from the data suggesting the need for instructors to demonstrate the advantages of online course design, in a quest for acceptance and validation. Some participants talked about learning pedagogical principles by participating in QM training (e.g., aligning objectives, assignments, and assessments). One participant stated that his online course was superior to his traditional courses due to the amount of planning involved in the online course. The opportunity to design online courses has helped the participants to teach better in their face-to-face classes. For example, one participant suggested face-to-face courses could be improved by using the chunked content and authentic activity process inherent in online courses instead of the typical traditional lecture format.

The participants described trying to persuade others to accept the advantages of online courses. One participant was pushing her department to add additional online learning opportunities for students, including practicums traditionally observed by instructors traveling to the student's workplace. She pointed out that it is difficult for instructors who are not familiar with online courses to understand the benefits. She 
indicated that having the students record a video of themselves, in lieu of an instructor being present to observe, would allow the instructor and student an opportunity to watch the student's performance together, rewind critical points to highlight, correct, and praise behavior. She said that "members of her department have trouble seeing beyond the socalled isolation of online learning to see the potential benefits." Using technology to recreate face-to-face contact, or creating a course without this condition, is daunting to some instructors at her institution. Others (like the participants in this study), having tried the format, see benefits to designing and teaching online courses.

Online is "Different"

Designing online courses involves different knowledge and skills than those used face-to-face. The participants must figure out new ways to present content, learn new technology, and expand their skillset beyond the skills normally used in a face-to-face classroom. For example, the participants described working to figure out different elements of a course (e.g., course technology) on their own. This contrasts with traditional teaching, according to the participants. A participant mentioned that in "online courses you can't lecture and do an activity, followed by a discussion in a neat and tidy unit.... online doesn't work that way." As a result, she learned (using online course design strategies and adapting to the online environment) to "think differently" and described "accepting what I could and could not do online." A participant described "learning 'techy stuff' to help students," which made her feel like she was "embarking into the unknown." This sense of exploration was described as "stretching" by another participant. She stated she "learns by doing" and has experienced "personal growth not 
possible in my regular classroom." Another participant described getting help "from IT (informational technology) department, not my peers like I usually do.”

The participants described feeling like "outliers" or "pioneers" in their acceptance of online courses. Many of the participants were the only ones in their department to design and instruct online courses. Other participants were part of a department that offered more online courses than other departments at their college or university. This aspect of doing something different than the majority of their colleagues (either within their department or at their college or university) was mentioned frequently in interviews. Working outside of the norm can be difficult. Another participant stated he "felt like he was helping his profession" by being an online course designer and instructor. This feeling of doing something new or different both inspired and bothered the participants. One instructor mentioned the disconnect between accepting face-to-face courses and online courses may be "because we are more familiar with face-to-face." Another participant mentioned that while an online course might seem "static, it is a process that could be improved through collaboration with others. We need to work within [our] department to build upon each other... we can do better than we do now."

Participants struggle with acceptance from stakeholders. While the participants have learned to accept online courses as valuable, they still struggle with other stakeholders' acceptance. Students often sign up for online courses assuming that it will be easier than a face-to-face course, according to the participants. Colleagues are also a problem. Several participants noted a divide between those instructors who have taught online and understand advantages of the medium, and those who have yet to develop or 
teach an online course, who are concerned that an online course may result in a lesser learning experience. Administrators were also mentioned as being less understanding about the time commitment involved in online courses. A participant mentioned that course design is not "seen as influential in tenure...it is a second class activity."

The participants yearn for others to realize the effort they describe putting into online courses, and indicated a desire for others to realize the benefits of the format. One participant described a desire for "peer feedback from people I know and respect." A participant described "feeling more personally connected online" and working to help "bring students into discussion" in hopes that the students will also feel more connected. She also described "the multimedia possibilities that [LMS] provides" and stated that she thought "students might enjoy this smorgasbord" and take more online courses.

The issue of online being "different" became especially clear as participants discussed student evaluations. Participants frequently remarked that their online courses earn lower evaluations from students and that their online evaluations are not on par with what they are accustomed to with their face-to-face courses. This causes concern among the participants because they feel part of the student evaluations are colored by the ease of use of the LMS or the students' own proficiency with technology, items beyond the participants' control. A participant yearned for "true honest feedback from students," indicating that he often felt online evaluations were shadowed by extraneous elementsincluding "the simple fact that the course was online." He stated "a need to break away from face-to-face as the gold standard" and be "realistic about the differences" between 
online and traditional formats. Both, according to this participant, deserve to viewed as "viable learning experiences."

\section{Desire for Acceptance}

The online environment offers similarities to face-to-face instruction, yet it is "different." While online education is growing, the participants still described feeling like "pioneers" in their acceptance of online education. The participants have the benefit of having experienced both online and face-to-face education. As a result of their experience with online course design and instruction, the participants were often eager to tout the benefits of online courses. They want others (e.g., students, colleagues, and administrators) to also realize that online education offers benefits. The categorization of the outcomes (i.e., benefits of online courses and online is "different") led me to identify the main concern of the participants (i.e., core category) as a desire for acceptance. Acceptance involves gaining approval. With traditional courses, there is often automatic acceptance, regardless of actual quality, that a course has value, according to the participants. The participants in this study crave a similar acceptance for online courses. The participants noted that online courses are often considered to be of less value or lower quality than face-to-face courses. This bothered them, but they understand. A participant summed up instructors' concerns by stating, "when an instructor looks at online course design he is concerned with how to replicate learning outcomes in face-toface. We often revert back to face-to-face. That is what we know. It is hard to picture the unknown." Another participant noted that before designing and teaching online he was "used to face-to-face courses, just like everyone else.... teaching online was awkward at 
the start." Many of the participants described being initially wary when asked to teach an online course, because they too were concerned about the legitimacy of the format. One participant indicated that at first she was opposed to online learning, but after teaching in the format, surprisingly, she has become a spokesperson for online courses. She, and the other participants, yearn for acceptance of online courses from students, colleagues, and administrators.

\section{Summary}

The themes of adaptation, online course design strategies, and the core category of desire for acceptance were identified as important elements to the participants of this study. The participants adapt to the online environment by reinterpreting traditional education. They utilize online course design strategies to gain acceptance for online courses as they adapt to the online environment. The participants' desire for acceptance of online courses emerged as the main concern for tenured and tenure track instructors designing online courses at public four-year colleges and universities. Chapter Five provides a discussion of the results, presentation of the theory, limitations, and the value of the research. 


\section{CHAPTER FIVE: DISCUSSION OF RESULTS AND CONCLUSIONS}

This chapter discusses the findings, beginning with a statement of the problem, followed by a review of the research question and interpretation of the data presented in Chapter Four. This chapter endeavors to connect the literature reviewed in Chapter Two with the findings presented in Chapter Four. A theory is presented based on the data collected and analyzed from interviews with tenured and tenure-track instructors at public four-year colleges and universities. As discussed in Chapter Three, the theory provides a generalized picture, not a specific picture of the entities. In this chapter the following subjects will be discussed in the following order:

1. A statement of the problem.

2. The research question.

3. A discussion of the results.

4. The theory of adaptation and acceptance in online course design.

5. The limitations and transferability of the theory of adaptation and acceptance in online course design.

6. The value of the research.

\section{Statement of the Problem}

Research indicates online courses are offered at $89 \%$ of public four-year institutions (Schrum et al., 2005), and online course offerings represent the fastest growing sector of higher education (Haynie, 2015; Means et al., 2010). With the growth 
of online education, more instructors have been asked to design online courses (Baran et al., 2011; Brigance, 2011; Cochran, 2015; Kidder, 2015). There are many benefits to using instructors to design online courses: they are subject matter experts, attuned to the learners, and already a part of the institution. A national survey of 10,700 college and university faculty instructors found that "over 80 percent of faculty involved in online teaching and/or development are involved in both the development and the teaching aspects" (Seaman, 2009, p. 21).

Designing an online course involves planning, organizing, and structuring the course (Baran et al., 2011). The "ability to design courses well is usually the most limiting factor" (Fink, 2003, p. 34) in teaching effectively online. Course design is connected to learning outcomes in online instruction. Good course design has an impact on the experience of students and instructors, thus impacting learning outcomes and student retention. Online course design is an important part of online education that impacts learning and perceived course quality by students (Moore \& Kearsley, 2011).

Research provides information on the importance of marrying technology, pedagogy, and content in online courses. Course design influences interaction (York \& Richardson, 2012). Research indicates the importance of interaction (Bernard et al., 2009; Lewis \& Abdul-Hamid, 2006; Nwankwo, 2015; Roblyer \& Wiencke, 2004), social learning (Anand, 2016), and engagement (Gunawardena \& Zittle, 1997) in online courses. Transitioning to online courses provides instructors an opportunity to consider alternative means of instruction and assessment (Shea et al., 2004), but the literature reviewed failed to provide details about instructors' perceptions of online course design. 


\section{Research Question}

The research question addressed in this study is: What do tenured and tenure-track instructors at public four-year colleges and universities say about the design process of online courses, and how can it be theorized?

\section{Discussion of Results}

I have structured the discussion of results by arranging the themes and categories in the same order as Chapter Four. The following will be discussed in connection with existing research:

- Adaptation (Theme)

○ Background in traditional education

- Available resources

- Learners and content

○ Technological challenges

○ Time requirement

○ Course design quality

- Online course design strategies (Theme)

○ Navigation

○ "Seeing" online

- Interaction

○ Social order

- Desire for Acceptance (Theme)

○ Benefits of online courses 
○ Online is "different"

$\underline{\text { Adaptation }}$

The participants, tenured and tenure-track instructors at public four-year colleges and universities, design online courses by referencing their face-to-face experiences. The participants described adapting to the online environment as a result of their background in traditional education, the availability of resources, familiarity with learners and content, technological challenges, time requirements, and a drive for online course quality. These conditions were discussed in Chapter Four as categories within the adaptation theme. As discussed in Chapter Four, adaptation is "the adjustment to environmental conditions" (Adaptation, 2017). The participants have been tasked to design online courses. Context drives behavior: when instructors consider how to teach their students they reflect back to what they know from prior practice and how they were taught. The participants adapted to the online environment through the process of instructing learners with technology, using methods and materials adapted from face-toface instruction. The participants are acclimating to the different environment through the lens of what they do know and understand: face-to-face instruction.

The acknowledgement that online teaching is different than face-to-face instruction was universal among the participants. Other instructors who have transitioned from a traditional classroom to online teaching have identified the need for new teaching methods for the online environment (Whitaker, 2015). Whitaker suggests that a new teaching philosophy is needed to adapt to an environment that is more student focused, and the presentation of content must adapt to electronic delivery and access. Researchers 
recommend that online courses should feature learner autonomy while providing content that has relevance to learners and encourages active and authentic learning (Ke \& Kwak, 2013). The participants interviewed in this study acknowledged that designing an online course is quite different than lecturing to students in a face-to-face situation.

$\underline{\text { Background in Traditional Education }}$

The participants in this study adapted to the online environment based on their experiences with teaching and learning in a traditional environment. Participants reported planning learning experiences and instruction, quickly developing a course, and then testing and revising materials until an acceptable version is achieved, aspects of backwards design and rapid prototyping (Gustafson \& Branch, 1997). These aspects of course design appear to be implicitly a part of the participant's knowledge of instruction in a traditional classroom. The participants use their previous knowledge and personal experience to design online courses, similar to the instructional designers in Ertmer et al.'s (2008) study. In Ertmer et al.'s (2008) study seven instructional designers used their previous knowledge and personal experience to interpret the problem, and then used a mental model of the instructional design process to solve the problem. Other research supports the idea that designers adapt instructional design models to needs (Ertmer et al., 2009; Kirschner et al., 2002; Silber, 2007). The instructors adapt to the online environment based on their experiences in traditional instruction. This behavior is based on a routine of behavior (i.e., habit): it is natural to revert to the most common, comfortable experience, even in a different space or format (Duhigg, 2013). 


\section{$\underline{\text { Learners and Content }}$}

The participants use what they know (e.g., knowledge about content and learners) to gather materials and deliver instruction in the process of adapting to online courses. This is supported by research. Fabry (2009) determined instructors use their content knowledge and package it for online delivery. A participant reminded me "the curricular system supports the process of comparing online to face-to-face, starting with course design: it is easier to use existing resources when designing a new online course." Smith et al.'s (2001) research indicated designing an online course helps the instructor reflect and analyze the content in a new way. Hollerbach (2004) reported the process of transferring a course online encouraged her to consider what was being taught in the course, why it was being taught, and the best way to teach the content. The participants in this study indicated a similar inclination to reflect on their course designs, as a result of participating in online course design.

\section{$\underline{\text { Technological Challenges }}$}

The participants in this study indicated that their technological abilities and that of their students (i.e., technological challenges) are additional elements to consider. The warning that "Mere content knowledge is likely to be as useless pedagogically as contentfree skill" (Shulman, 1986, p. 8) is pertinent to the participants. They described a need to marry content knowledge with technological skills in order to design effective online courses. Previous research supports this finding that students must be prepared to learn in an online learning environment (e.g., knowledgeable about the technology to be used) (Bozarth, Chapman, \& LaMonica, 2004). 


\section{$\underline{\text { Time Requirement }}$}

The amount of time needed to design online courses, teach and respond to students was frequently mentioned by the participants. The participants expressed the need to carefully organize every aspect of an online course with explicit directions, then package and present the information in an online format, findings also confirmed by research (Esani, 2010; Miner, 2003). The participants' indication that online courses require more development and design time than traditional courses is supported by research (Betts, 2014; Mandernach et al., 2013; Shea, 2007; Windes \& Lesht, 2014).

While the amount of time involved in online course design and teaching was not quantified by the participants in this study, Tomei (2006) indicated that contact time for teaching the same course face-to-face and online was $14 \%$ greater for the online course, even with instructors familiar to online teaching. Cavanaugh (2005) suggested the time difference may be even greater, estimating it is one-and-a-half to two times as much work as teaching face-to-face. The participants often expressed concern over the time involved in interacting with students online. Some of the participants mentioned incorporating social learning within the design of their online courses so that students can interact without consuming the time of the instructors. This is a time-saving strategy supported by research (Anand, 2016).

The participants in the study noted the importance of designing online courses to save time later in instruction. The participants expressed the need to minimize barriers between students and content and modify face-to-face assignments to allow sufficient time for grading and feedback. By considering potential navigational/instructional issues 
in advance, when designing courses, instructors can reduce problems and student frustration. This is a strategy that instructors use to reduce the amount of time spent responding to student problems. Olson, Mata, and Koszalka (2013) led a discussion about online course design with a focus group of online students. The students stressed the need to reduce barriers between students and content. As a result of the study, Olson et al. (2013) urged course designers to maximize "curriculum navigational freedom while minimizing curriculum complexity" (Olson et al., 2013, p. 205). Whetten (2007), in reflecting on principles of effective course design after 30 years as a university professor and director of the teaching and learning support center at Brigham Young University (BYU) suggested, "a well-designed course is like a well-written exam: It takes longer to prepare, but the additional time is more than made up later via faster grading and fewer student complaints" (p. 355).

Participants in this study suggested more time is required of students in online courses than in traditional courses. It is time consuming to navigate an online course, write out discussion comments (often based on a set of standards, such as a word count requirement), and manage assignments isolated from others in the course. The participants in this study suggest students must be on task more than when they are in a traditional course listening to a lecture. Young and Duncan's (2014) survey of 8,000 students comparing online courses to face-to-face courses rated student effort significantly higher in online courses, as a result of the increased workload and working asynchronously. Additional research supports these findings as well (Agosto, Copeland, \& Zach, 2013; Bruce, Young, \& Kennedy, 2012; Horspool \& Lange, 2012). 
The participants in this study also noted that online communication is more time consuming than in traditional education. Young and Bruce (2011) suggested specific instructional design strategies to increase social presence and facilitate communication, such as embedding technology tools like blogging, instant messaging, and social media, but these items were not discussed by the participants. The participants in this study and Green et al.'s (2009) study suggested online students need more technical support to help reduce the time commitment of instructors trying to solve non-instructional issues.

The participants in this study noted the amount of time needed to gather resources, learn technology, and add/change content in the LMS, activities that do not contribute to promotion and are rarely compensated. The participants expressed a desire to be given additional consideration, through payment for course design time or load adjustments. Similar concerns were expressed by the 135 online instructors surveyed in Green et al.’s (2009) study.

\section{Course Design Quality}

The participants of this study support online course quality; they feel personally responsible for the quality of the online courses they design and teach. Part of the participants' interest in promoting quality in online courses is a result of their desire for acceptance as online course designers and instructors. The participants expressed concern over who monitors online quality. None of the participants had experienced the use of a formal evaluation instrument of the design of their face-to-face courses, yet several of the participants work at institutions that utilize a formal online course design quality evaluation instrument. While some of the participants accepted the use of these 
instruments, having "drank the Kool-Aid" (a term used by participants less accepting of QM), others did not. The participants, for the most part, indicated that having a system where someone in their department (“a trusted peer") review their online courses would be of more value to them than undergoing review through with the use of a national evaluation instrument. They also expressed the need to monitor quality for online courses and traditional courses. However, in general, research supports the use of online course design instruments (Legon, 2015; Shattuck, 2010) (though this research may be supported through the national organizations distributing the instruments).

Research suggests instructional design quality guidelines are valued by instructors (Chao et al., 2010; Chao et al. 2006; Little, 2009; McGahan et al., 2015). However, the participants in this study did not mention using design quality guidelines. The only quality guidelines that the participants reported using were QM or QOLT evaluation instruments, when mandated by a participant's institution.

\section{$\underline{\text { Online Course Design Strategies }}$}

The participants reported using online course design strategies (e.g., simplifying navigation) to facilitate instruction. Literature supports the role course design plays in communicating what is important (Larson \& Lockee, 2014) and fostering increased interest in course content (Canney, 2015). The participants developed online course design strategies to involve students more within the courses. They described tactics such as getting each student to respond to discussion questions in online forums and looking at technology features to support student interaction. 
The participants' described considering technology features (e.g., being able to "see" and "hear" students) to design the best way to present content to learners. Shea et al.'s (2004) study of SUNY online instructors also indicated that transitioning online provides instructors with an opportunity to consider alternative methods of instruction. $\underline{\text { Navigation }}$

The participants in this study felt strongly about the importance of clear navigation. Research confirms the importance of designing an obvious path for students to follow to learning outcomes (Anderson et al., 2001; Bradford, 2011; Larson \& Lockee, 2014). By using clear elements in course design to steer students through online courses, students are better able to focus on learning.

Navigation can be facilitated through online course organization. Using a template to build courses was found to be a good way to provide students and instructors a consistent look (Shea et al., 2004). The participants in this study suggested a template helps student navigate courses more easily. The participants also reported chunking content as a way to help facilitate navigation. Participants in this study indicated having "all the information [students] needed to begin their learning effectively and in an organized manner" (Conrad, 2002, p. 216), was important. Conrad found the clarity and thoroughness of the course details impacted the level of engagement students feel. The participants in this study also indicated that organization and attention to detail in course design are important to reduce confusion, and help reduce additional work as a result of more questions from students. Research indicates students report higher satisfaction when course content is well-organized (Olson et al., 2013; Paechter et al., 2010). 


\section{"Seeing" Online}

The participants reported a need to overcome the lack of social and emotional cues that they were accustomed to in the traditional classroom. Esani (2010) suggested that new teaching methods are needed for instructors accustomed to using visual cues to confirm students' understanding and involvement. The participants in this study try to duplicate a traditional environment by adding technological tools like video conferencing. They describe having class meetings via Skype or Google Hangouts, and using tools like VoiceThread to "see" students. Research indicates that 55\% of communication is in the form of visual cues (Danesh et al., 2015). Student and instructor isolation can create distress in online courses (Hara, 2000). As a result, instructors designing online courses are challenged to create strategies to communicate better with students.

\section{$\underline{\text { Interaction }}$}

Different types of online interaction were identified in the literature review. Moore (1989) identified interaction between students, student and content, and students and instructor as important. Each of these interactions was mentioned by participants in this study. The participants described strategies of purposefully asking students to interact with one another for group work, or with content through learning activities. For example, the participants in this study used discussion forums to increase learning and interaction, a tactic supported by research (Cain \& Pitre, 2008; Liu et al., 2010). Requiring that students post responses to a discussion prompt can help increase interaction (Pate et al., 2009; Robinson \& Hullinger, 2008). 
The participants described designing online courses to promote student interaction by including authentic assignments. Research supports the inclusion of authentic assignments as a way to optimize students' involvement with content (Carr-Chellman \& Duchastel, 2000; Fabry, 2009; The National Science Foundation Strategic Plan, 2006). Purposefully developing activities within online courses that encourage interaction also stimulates learning (Bernard et al., 2009). The participants suggested active learning with a focus on authentic work increases communication and the learning experience, a strategy supported by research (Clase et al., 2008). The participants in this study use student reflection to promote student-content interaction. While the use of reflections in online courses has been supported in research (Black, Sileo, \& Prater, 2000; Herrington \& Oliver, 2002; Seale \& Cann, 2000), the participants in this study indicated that the purpose of reflection as a strategy is to help the students' knowledge grow, aid in studentinstructor interaction, and provide the instructor an opportunity to take part in the celebration of learning (i.e., the 'aha!' moment).

The participants in this study expressed concern over fostering interaction, providing feedback, facilitating learning and course organization. These same broad categories were identified as important strategies by Lewis and Abdul-Hamid (2006). Lewis and Abdul-Hamid (2006) interviewed 30 graduate and undergraduate instructors at the University of Maryland University College (UMUC), to understand effective online strategies. Of particular interest, Lewis and Abdu-Hamid identified these strategies as similar to a traditional classroom. This aligns with the concept that instructors adapt to online courses based on their experience in traditional instruction. Lewis and Abdul- 
Hamid identified that much greater emphasis is placed on building a community of learners in online education. Interaction with others-in this study participants mentioned colleagues and students-impacts course decisions, similar to the results found by Christensen and Osguthorpe (2004). Roblyer and Wiencke (2004) suggested that the amount of interaction within an online course is an indicator of a successful learning experience and quality online course.

Providing feedback to students was specifically indicated as important to encourage interaction and develop connections by the participants. This is supported by research, Pate et al. (2009) suggested that instructors should model behavior, like thoughtful responses with a personal tone to help build classroom connections and build a community. One of the participants in this study mentioned the need to set an example for students by responding promptly to questions. Some of the participants in this study used video conferencing tools to provide feedback and interact with students. Ice, Curtis, Phillips, and Wells (2007) compared the use of asynchronous audio feedback in an online course to text-based feedback. Students $(\mathrm{N}=34)$ surveyed reported preferring audio feedback because the audio helped students understand the nuances of the feedback and feel more connected to their instructor. Students in another study, however, preferred a combination of text and audio feedback (Oomen-Early, Bold, Wiginton, Gallien, \& Anderson, 2008), which was used more often by participants in this study. The default in the studies, however, points to Clark's (1994) study that the instructional design of a course has a greater impact on students than the medium. 
Participants discussed needing to adhere to their institution's policies on QM, using a template, and described institutional support available to students, elements of learner-environment interaction (Burnham \& Walden, 1997). The participants identified the need of both the instructor and student to contend with technology (e.g., the LMS, computer, and software) to navigate and communicate with others in online courses, components of learner/interface interaction (Wilson \& Weiser, 2001). In online courses, the institution, as part of the environment, intercedes itself to impact course design. In general, however, the participants of this study, like the learners in Rhode's (2009) study, place the most value on interaction between students and content, and students and the instructor. This finding has also been supported in other research (Gallien \& Early, 2008; Nwankwo, 2015; Perry \& Edwards, 2005; Stein et al., 2005).

\section{$\underline{\text { Social Order }}$}

The results of this study confirm that online education requires different ways of communicating, new teaching strategies, and thus different design strategies (Hu, 2009). The change in social order, in which learning is no longer transmitted through instructors' lectures has been frequently argued in research. Fabry (2009) suggested the need to change the delivery of instruction to one in which students play an active role in the learning process. Moore and Kearsley (2011) indicated teaching online should accommodate new ways of learning that incorporate greater involvement of the students (i.e., emphasizing knowledge construction). Encouraging students to build a community between themselves has been cited as an effective way to aid students who enjoy the convenience of learning anytime, anyplace, without the direct presence of an instructor 
(Duffy \& Kirkley, 2003). The participants in this study acknowledged that in online courses students play an active role by using technology to learn for maximum effectiveness.

The participants also indicated the manner and tone used by online students appears to them often more fraught with emotions than in the traditional classroom. In frustration, students may send a distraught message to an online instructor, addressing the instructor in a manner that would be unacceptable in face-to-face communication. Olson et al. (2013) found students need to adapt to communicating with instructors online. The current findings add to existing research by pointing out that online students are less likely to view the instructor in a formal sense as the person in charge. This may be the result of not "seeing" the professor leading the course. The online environment can become an emotionally charged atmosphere when students are concerned about how to access content and complete assignments. As a result, the participants indicated the importance of responding to student communication with carefully considered responses. This finding supports the need for clear and organized online courses to prevent confusion and promote confidence among learners (Arbaugh, 2004). Eliminating confusion helps boost students' satisfaction and reduce communication about non-content related items. As one participant stated, "students should be focused on learning." This also supports the suggestion by participants that online education is "more deliberate than face-to-face" courses.

The participants' description of online course design strategies is reminiscent of the masked man in black dueling on the Cliffs of Insanity (Goldman, 1973). Similar to 
the masked man in black, holding his sword in either his left or right hand to duel his ambidextrous foe, the participants are driven to adjust and develop strategies in response to the need to adapt to the new environment and win over stakeholders. Online instructors are adapting to the environment using the skills they know in an effort to adapt and gain acceptance.

\section{Desire for Acceptance}

In Chapter Four the desire for acceptance was identified as the core category. The participants want validation (i.e., desire acceptance) for the online courses they design and teach. The participants want acknowledgement from their students, colleagues, and administrators that online courses have similar value as face-to-face courses. The participants understand the reluctance toward online courses. The participants are aware that faculty instructors may struggle with the value and legitimacy of online education (Allen \& Seaman, 2016). Yet the participants often described benefits of the online environment. They are eager to share the online strategies that they have found effective. Rich content was mentioned by the participants, as they described different strategies for presenting information. This item was also the most important item in Chapman and Henderson's (2010) study of business instructors and online learning coordinators, as well. This research supports the concept that the online environment is only a carrier (as per Clark, 1994) for the content the participants work to deliver to students.

\section{$\underline{\text { Benefits of Online Courses }}$}

As a result of designing online courses and implementing strategies with which they were familiar with from face-to-face instruction, the participants gained personal 
acceptance for instruction in the online environment. The participants in this study were overwhelmingly proud of their ability to create interactive and meaningful courses that help students learn. Research has documented the ability of instructors to create interactive, meaningful online courses that encourage learning (Bolliger \& Wasilik, 2009; Carr-Chellman \& Duchastel, 2000). The participants in this study expressed satisfaction with their efforts designing and instructing online courses. They expressed concern, however, that their peers who do not instruct online do not understand the advantages of the online environment.

Instructors who have taught online view online courses more favorably than instructors without online experience. In a survey of instructors associated with the American Association of University Professors (AAUP), Ciabocchi et al. (2016) found that respondents felt instructors are often insufficiently trained to teach online, there is a lack of accountability in online courses, and a lack of clarity in how to determine quality online. Yet, the half of the instructors in Ciabocchi et al.'s study had not taught an online course before. Allen and Seaman (2012) reported two-thirds of faculty surveyed indicate face-to-face courses produce superior learning outcomes when compared to online courses. In both studies, instructors with direct online teaching experience were more likely to be positive about the quality of online student learning. In Ciabocchi et al.'s study, $49 \%$ of faculty who had never taught online recommended an online course, compared to $87 \%$ of instructors who had taught online. Several of the participants in the current study noted a divide between instructors who had taught online and appreciated the advantages of the format, and those who had yet to teach online and were circumspect 
of online courses. The participants in this study reported feeling greater satisfaction with online courses than their peers who were not involved with online education.

Online is "Different"

The instructors are aware that online courses are "different." Some of them report initially being wary about online courses, before becoming online instructors. This is supported by other research. Bunk, Li, Smidt, Bidetti, and Malize (2015) surveyed 152 part-and full-time faculty from a midsize public university who suggested that instructors who do not teach online were more likely to experience fear towards the online environment. The Babson Research Group tracked faculty acceptance of online teaching for twelve years and found "no more than one-third of chief academic officers reported that their faculty accepted the value and legitimacy of online education" (Allen \& Seaman, 2016, p. 6). However, faculty at institutions with a large amount of online students report the most acceptance of online education (Allen \& Seaman, 2016). The participants in this study acknowledge that online is "different" from the standpoint of student evaluations. The participants in this study indicated their evaluations from students are lower in online courses, a disconcerting difference of teaching online (especially since student evaluations are frequently linked to promotion). The participants in this study worried that some student's evaluations were influenced by students' technological abilities, more than the instruction of the course. This issue is supported by research. Olson et al.'s (2013) study found students need to adapt to online courses, and course evaluations tend to be lower online. Green et al.'s (2009) participants expressed interest in student evaluation instruments that fairly assess how well instructors 
facilitate a course, not on the vagaries of the LMS. In a comparison of student ratings of instruction, Young and Duncan (2014) compared 11 courses that were taught by the same instructor using both online and face-to-face delivery methods. Students in face-to-face instruction rated their instructors significantly higher than the same instructors in online courses. Young and Duncan suggested, “online instructors be given additional consideration in tenure, promotion, and reappointment decisions" (p. 76) due to the likelihood of receiving less positive course evaluations.

The participants in this study have a desire for acceptance of online courses from colleagues and administrators. They acknowledged that online is "different" yet they proudly touted the benefits of online course. The participants in this study use online course design strategies as a way to provide a quality experience for students and try to gain acceptance for online education.

\section{The Theory of Adaptation and Acceptance in Online Course Design}

Instructors who design online courses at public four-year colleges and universities adapt to the online environment by adjusting what they do in a traditional (e.g., face-toface) classroom for this new environment. The instructors create online courses using online course design strategies that seek to adapt or improve upon face-to-face instruction in their quest for acceptance from stakeholders (Figure 6). 


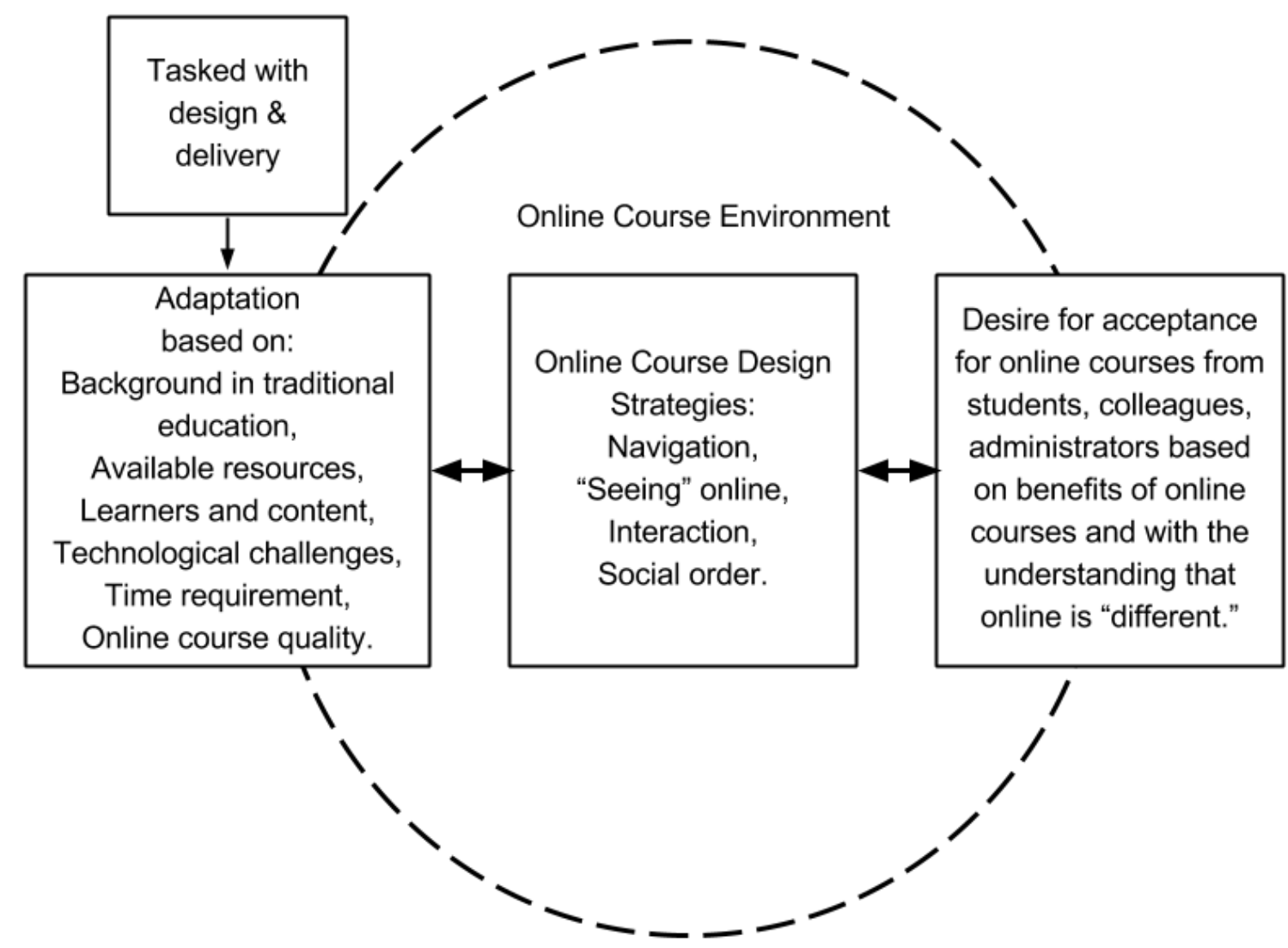

Figure 6. Visual representation of the theory of adaptation and acceptance in online course design.

In keeping with grounded theory, the diagram above shows the interrelationships of the core category and themes, and it takes into account the conditions, context, contingencies, consequences, and covariances discussed in the beginning of Chapter Four. These serve as the basis for the consequence of instructor adaptation and adaptive strategies. The circle in the diagram above represents the online course environment, which can be closely allied with the technological developments that were earlier identified as providing the general context in the theoretical coding model described in Chapter Four. The core category in this study, acceptance, is shown on one side of this circle, and the second overarching theme of adaptation is shown on the other. The circle 
intersects these two boxes/themes as a confirmation of the outcome category, that "online is different, as discussed in Chapter Four. This difference means that strategies must be adapted from outside the online realm, from face-to-face instruction, and that the desire for acceptance also connects the online instructors interviewed to the institutional, faceto-face world of student assessment results and other factors involved in gaining the positive approval of peers and superiors. The process of adaptation is based on the instructors' background in traditional education in the offline world, the available resources, instructors' understanding of the learners and content, technological challenges, the time requirement of online course design and instruction, and online course quality expectations. The instructors adapt to the online environment by using online course design strategies to facilitate navigation, encourage students and instructors to "see" each other online, and to compensate for the differences in social order. The online course design strategies serve as a conduit for instructors to adapt to the online environment in their desire for acceptance from students, colleagues, and administrators based on the benefits of online courses and as a result of online being "different." Two lines with arrows on each endpoint are displayed linking adaptation, online course design strategies, and acceptance. These lines are used to depict the interplay between the instructors' adaptation to the online course environment, the use of online course strategies, and the instructors' desire for acceptance. The two lines help to show that the components of this figure work together: the use of online course strategies help the instructors adapt to the online environment and serve as ways for the instructors to gain the acceptance of online courses. The desire for acceptance is evident in the instructors' 
use of online course design strategies that often mimic, reconfigure, or translate face-toface education as the instructors adapt to the online environment. For example, instructors mimic traditional face-to-face discussions by using online discussion forums. Instructors add group work to online courses to increase student interaction, reconfiguring the activity to allow students to interact virtually. Instructors try to "see" the students (as they are accustomed to in face-to-face courses) by using video conferencing tools, in an attempt to translate face-to-face education online. The theory of adaptation and acceptance in online course design is discussed further below.

\section{$\underline{\text { Adaptation }}$}

Even though instructors know that online courses are different, they continue to compare online instruction to face-to-face instruction. Instructors adapt to the online environment by incorporating what they are familiar with from face-to-face instruction, based on their background in traditional education. They use available resources from existing face-to-face courses and information from the Internet. They adapt to technological challenges and technological developments, and to different time requirements. The instructors note the need for the administration to acknowledge the additional time involved in designing online courses when compared to face-to-face courses. Furthermore, there are still differences perceived by faculty in the value and legitimacy of online education compared to face-to-face courses, according to surveys of chief academic officers (Allen \& Seaman, 2013, 2016).

Typically, the instructors are not subject to a set evaluation instrument in their face-to-face courses, beyond student evaluations. However, some institutions use 
evaluation instruments to certify the quality of online courses (e.g., QOLT, QM). For the most part, the current evaluation instruments fail to support the validation that the instructors are seeking. The instructors would appreciate course reviews from trusted peers without the constraints of a set instrument; a situation that is more akin to what they are used to in a traditional classroom. Participants in this study want to provide a quality online experience as a result of their desire for acceptance.

In an attempt to adapt the content, and transition the students, and even themselves to online courses, the instructors use online course design strategies to bridge or overcome the differences between traditional (i.e., face-to-face) instruction and online instruction. Instructors use technology to recreate what they know, and what others in education expect. As phenomenological and other qualitative research has shown, very specific experiences of online courses can be fruitfully compared to parallel experiential moments in face-to-face classes (e.g., Dreyfus, 2009; Friesen, 2011) For the students, the experience of either an online or face-to-face course typically starts when they with the first class or day of classes. In a typical face-to-face class, students walk through a door, enter a classroom full of seats with a central focal point (Figure 7). The need for orientation and acclimation is typically minimal. Online, many instructors use templates to help acclimate students quickly to an online classroom (by helping them navigate through the course). A template can be seen as the equivalent to a classroom set up with seats and a central point: it helps students understand what to do. In a typical face-to-face classroom after the students enter, they likely wait for the instructor. Online, students are often welcomed by a video from the instructor (and this can be compared to the arrival of 
the instructor). Also online, students are often instructed to introduce themselves to the class to help re-create the classroom experience. Instructors try to design online courses that are easy for the students to navigate intuitively through the use of templates. This reduces student confusion, which lessens an instructor's time commitment in answering non-content related questions. For instructors who design their own online courses, course design and teaching are closely linked. The online instructors prescribe what they will teach and how it will be taught through the design of their online course. The instructors consider online course design strategies to communicate content, while reducing confusion and increasing interaction. In comparison, in a typical face-to-face course, the instructor makes flexible plans that allow greater spontaneity.

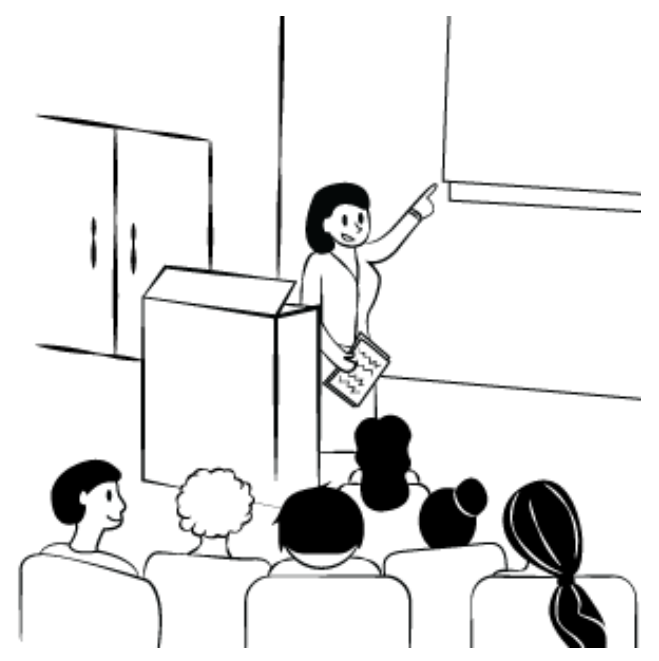

Figure 7. Typical traditional classroom format.

"Seeing" online is an element that was frequently mentioned when the instructors compared online courses with face-to-face learning. The participants are accustomed to seeing their students' reaction to instruction with traditional courses. This is an important part of the teaching process, in which "seeing" the students is helpful in establishing 
presence in the classroom and confirming understanding. In a search for "the whites of students' eyes," instructors use advanced technologies (e.g., FaceTime, Skype) to "meet" with students and bridge the distance. Technology both separates and unites the instructor and students in online courses. Through course design strategies, instructors incorporate elements (e.g., video conferences) to recapture the experience of a face-to-face classroom.

Interaction between the students, the students and the instructor, and the students and content is crucial to education and a regular occurrence in a traditional classroom where students physically see one another and hand in assignments to the instructor. When designing courses online, instructors create interaction by introducing discussion boards, using group work, and multimedia recording software tools like VoiceThread. Together, these tools work to encourage interaction. Online, instructors report spending a great deal of time providing feedback to students, much more than in a traditional classroom. Engaging in this task helps to acknowledge the instructors' presence for students and also helps instructors guide students in a personal way. The instructors are mindful of the difference in social order, and endeavor to use course design strategies to present instruction in an environment in which students play an active role in the process (rather than passively listening to a lecture).

Desire for Acceptance

Instructors designing online courses desire acceptance from students, colleagues, and other stakeholders. Acceptance is linked to respect and status (Triandis, Vassiliou, \& Thomanek, 1966). Instructors who design online courses are trying to obtain the respect 
and status that they are accustomed to from face-to-face courses. Instructors endeavor to design courses that engage students in the content and with each other. They want to make sure the students understand that online courses are not easier, but different. Often, according to the instructors interviewed, online courses are harder and more time consuming for students and instructors. While the instructors who design and teach online courses have adapted their teaching activities to reflect the new medium, they suggest that others need to realize and accept the benefits (e.g., authentic activity) and side effects (e.g., greater time, technology support) that result from online courses.

The instructors desire acceptance for the strategies they are using in online courses that they see as drawing the students into the content. Because online is different, one can conclude that the instructors enjoy the creativity that technology affords them to deepen the learning experience, beyond a typical lecture course format, to offer an opportunity for students to engage in meaningful activities enriched by technology.

\section{Transferability and Limitations of the Theory of Adaptation and Acceptance in}

\section{Online Course Design}

One of the tenets of grounded theory is that the theory, which is built upon a basic social process, is transferable to other areas (Glaser, 1992). The transferability of the theory of adaptation and acceptance developed here can be illustrated by comparing the world of online education to that of online dating. Instructors who design online courses are similar to early entrants in the online dating business. Initially, people were wary of meeting potential mates online (Slater, 2013). Online dating was considered impersonal, different, and lacking in genuine interaction (much like online education). Naysayers 
assured participants online dating would never work. In a short time, however, online dating has become socially acceptable and a societal change in how people meet (Slater, 2013). Online dating companies have been able to create an atmosphere of social presence and online interaction for daters. Increased technology use has helped consumers adjust to online dating; adapting to the online dating culture. This process includes sharing personal details and photos online, as compared to meeting face-to-face (also similar to online education). Online dating companies have been able to show distinguishable advantages to online dating (e.g., the ability to find a "better" match through algorithms) (Slater, 2013). Online dating has lost its stigma, and now nearly half the U.S. population knows someone who met a spouse or partner online via online dating or who uses online dating (Smith \& Anderson, 2016). This acceptance was achieved through market demand and by helping consumers (i.e., daters) take advantage of the benefits of technology, and displaying the results of successful matches (through advertising and word of mouth). Just as in online courses, there were many stakeholders to win over (e.g., potential daters, parents, friends) but the tide has now turned to show the benefits of this model of dating, and as a result, online dating has become an acceptable method of meeting a mate (Ansari \& Klinenberg, 2015).

This study shows that instructors involved in online course design and teaching are interested in a similar acceptance. They see the benefits of having the ability to have every student participate in a discussion. They acknowledge that students can take the knowledge they are gaining and use it in the "real world" through authentic activities. Accepting online education is a matter of acknowledging the differences and capitalizing 
on the benefits of the different environment. It is not the same as traditional education, but those who are accustomed to traditional education can adjust to the new media, as witnessed by the participants in this study. The theory of adaptation and acceptance in online course design suggests that instructors designing online courses adapt to the online format, in search of acceptance of their teaching strategies in the new environment from themselves, their colleagues, administrators, and students.

As with all research, there are limitations to this study. In Chapter Three it was discussed that a grounded theory's workability, relevance, fit and modifiability should be enough to ensure the plausibility of the theory (Glaser, 1978, 1998; Glaser \& Strauss, 1967). Workability means that the theory should work or function to explain participants' main concern of the participants in the area of interest. The main area of interest for the participants of the study was their adaptation to online environment as they seek acceptance for online courses. I attempted to increase the workability of the theory presented by fitting (almost) all of the evidence or concepts provided in the data into the theoretical account to show the participant's area of interest. However, a limitation might be my ability as a researcher to achieve this goal.

Relevance indicates that the theory should be important to someone. The theory presented explains the reasons and rationale for the design and delivery of online courses by tenured and tenure-track instructors at public four-year colleges and universities. This theory is likely to be of interest to instructors involved in course design and administrators who oversee these instructors. However, the instructors involved in course design and administrators who oversee these instructors will need to judge the relevance 
of the study. The explanation of the findings may limit the relevance. Readers interested in this topic are encouraged to contact me directly.

Fit and modifiability means that the theory can be changed to fit the data, and modified based on changing data (Glaser, 1992). The theory fits the current set of participants based on the data collected. This study may be limited in its fit and modifiability should new or different data be collected. However, I attempted to limit these issues by performing constant comparison of data throughout the data collection and analysis process, and reaching theoretical saturation with my data collection.

Credibility, transferability, dependability and confirmability are additional ways to increase trustworthiness of grounded theory studies (Sikolia et al., 2013). This study's credibility (i.e., "how much the data collected accurately reflects the multiple realities of the phenomenon" (Sikolia et al., 2013, p. 2)) may be limited as a result of using snowball sampling to recruit participants. In the early part of the data collection, participants were often linked by institution or area of interest. In response, I posted a recruitment flyer on social media to expand the participant pool. The transferability may be questioned since the instructors who volunteered to participate may represent a sample that views online education, course design, and instruction in particular ways. They also represent a group that designs courses without the assistance of instructional designers. While I endeavored to include participants with a wide range of experience in online course design, from a variety of disciplines and institutions (as discussed in Chapter Three), readers should be aware of this potential limitation. The views of the interviewed instructors may or may not represent the views of a larger group. 
Dependability refers to confirmation that the data "represents the changing conditions of the phenomenon under study" (Sikolia et al., 2013, p. 3). This could be verified through an independent auditor. An additional limitation of this study is the lack of an independent auditor to review research procedures. Confirmability refers to the ability for another researcher to confirm the results, when presented with the same data (Sikolia et al., 2013). The lack of another researcher reviewing my notes represents a limitation. However, all of the notes, memos, sorted categories, and drafts have been retained, should another researcher wish to evaluate and confirm this study. A conscientious attempt was made to follow procedures to ensure trustworthiness but more experience or better guidance would have improved results.

The use of grounded theory as a research method relies upon the creativity of the researcher, and her ability to be sensitive to drawing concepts from the data. In working through the collection and coding process, I tried to focus on the tenets of grounded theory, based on my understanding. Grounded theory is subjective, and my personal bias formed a part of the study. I have been an online student, instructor, and course designer. This knowledge and understanding helped generate categories (i.e., develop theoretical sensitivity) but the process of constant comparison encouraged me to look at the emerging phenomenon from many directions. These aspects must be considered for future researchers wishing to verify the research. The findings of this study could be verified using studies of a different design (e.g., an experiment or survey) (Glaser, 1992). 


\section{Value of Research}

This study offers insight into the reasons and rationale for the design process of online courses by tenured and tenure-track instructors at public four-year colleges and universities. It illustrates how instructors adapt to the online environment, based on their experiences as traditional face-to-face instructors. In addition, it indicates that instructors are motivated to use online course design strategies to compensate for differences between online courses and face-to-face instruction (e.g., navigation, "seeing" online).

This study provides information on online course design strategies tenured and tenure-track instructors at public four-year colleges and universities use to design online courses, an area of interest to many stakeholders. This study may help inform faculty development practices and the future design of quality evaluation instruments used in online course design.

By understanding how instructors design online courses, institutions may be able to develop professional development activities tailored to the needs of new instructors, and instructors new to online instruction. Professional development for online instructors should highlight the importance of creating easy to navigate online courses.

Adding opportunities for instructors to "see the whites of students' eyes" is also important. Professional development for online instructors should also address the need for authentic communication and assignments. Institutions may consider highlighting changes that students may experience (e.g., difficulty with technology or navigation), as well as address ways to deal with these issues. Professional development for online instructors may also consider recommending time management strategies for online 
instructors. In addition, institutions may consider showcasing exemplary online courses to help share best practices and highlight quality online courses.

New instructors may gain greater understanding of successful strategies used in the online environment, as a result of the adaptation strategies used by participants in this study. Instructional design strategies are generally understood in the context of systemsbased instructional design processes and models. However, this study shows that the terms and categories used in these models — such as prototyping, design phases, or needs assessments - are rather alien to the strategies and concerns of instructors tasked with the design and delivery of online courses. Professional development can be focused on helping instructors overcome the differences between the online and traditional environment, emphasizing the critical areas revealed from this study (e.g., navigation, "seeing" online, interaction, and social order).

In addition, institutions and instructional development personnel may consider using the findings from this study to help instructors bridge traditional and online instructional practices to develop better courses. There is an opportunity to take advantage of the strategies instructors utilize in a traditional classroom, online, and vice versa. This study draws attention to how instructors transfer traditional instructional practices to online courses, which may be used to help new instructors be more comfortable designing and instructing online courses. This study may draw further attention of people not currently involved in online education to the unique advantages of online education. The participants described their ability to use multimodal strategies and rich media to creatively offer authentic assignments to students. They also described the 
ability to offer online courses that they felt were more socially and culturally responsive than would be possible in a traditional course on campus (by providing authentic, active assignments appropriate for each student). Online course design, as described by the participants in this study, provides instructors freedom to innovate traditional strategies, in a new environment, rich with possibilities.

Since some participants in this study indicated concern over current quality evaluation instruments, and further research could investigate the effectiveness of other methods of monitoring quality in online courses. This study also may provide a further impetus for continued study of the time involved in online course design and the impact of online course design and instruction to student evaluation and instructor promotion. Compensation for online course design should also be reviewed.

The drive for acceptance of online courses as a viable option for quality learning encourages instructors who design online courses to utilize strategies that resemble elements of traditional courses. They respond in this manner as they acclimate to the online environment, and also in response to what others (e.g., students, colleagues) expect in a course. This research provides information to help administrators, LMS executives, and instructors understand the reason for the design strategies used by instructors, and potentially adjust their programs to help facilitate instructor development and delivery of quality online courses. 


\section{REFERENCES}

Acceptance. (2017). In The Oxford University Press dictionary. Retrieved April 24, 2017, from https://en.oxforddictionaries.com/definition/acceptance

Adaptation. (2017). In The Merriam-Webster dictionary. Retrieved April 24, 2017, from https://www.merriam-webster.com/dictionary/adaptation

Adaptation. (2017). In The Oxford University Press dictionary. Retrieved April 24, 2017, from https://en.oxforddictionaries.com/definition/adaptation

Addelson, K. P. (1990). Why philosophers should become sociologists (and vice versa). In C. Nelson, P. A. Treichler, \& L. Grossberg (Eds.), Symbolic interaction and cultural studies (pp. 119-147). Chicago, IL: The University of Chicago Press.

Agosto, D. E., Copeland, A. J., \& Zach, L. (2013). Testing the benefits of blended education: Using social technology to foster collaboration and knowledge sharing in face-to-face LIS courses. Journal of Education for Library and Information Science, 54(2), 94-107.

Allen, I. E., \& Seaman, J. (2012). Conflicted: Faculty and online education. Babson Park, MA: Babson Survey Research Group.

Allen, I. E., \& Seaman, J. (2013). Changing course: Ten years of tracking online education in the United States. Newburyport, MA: Sloan Consortium.

Allen, I. E., \& Seaman, J. (2016). Online report card. Tracking online education in the United States. Babson Park, MA: Babson Survey Research Group. 
Alvarez, I., Guasch, T., \& Espasa, A. (2009). University teacher roles and competencies in online learning environments: A theoretical analysis of teaching and learning practices. European Journal of Teacher Education, 32(3), 321-336.

Aman, R. R. (2009). Improving student satisfaction and retention with online instruction through systematic faculty peer review of courses. [Doctoral dissertation]. Retrieved from ProQuest Dissertations \& Theses Global. (304974844).

Anand, B. (2016). The content trap: A strategist's guide to digital change. New York, NY: Random House Group.

Anderson, T. (2004). Teaching in an online learning context. Theory and Practice of Online Learning, 273-294.

Anderson, T., \& Garrison, D. R. (1998). Learning in a networked world: New roles and responsibilities. In CC Gibson (Ed.) Distance Learners in higher education: Institutional responses for quality outcomes (pp. 97-112). Madison, WI: Atwood.

Anderson, T., Rourke, L., Garrison, D. R., \& Archer, W. (2001). Assessing teaching presence in a computer conferencing context. Journal of Asynchronous Learning Network, 5(2), 1-17. doi:10.1.1.95.9117

Andrews, D. H., \& Goodson, L. A. (1980). A comparative analysis of models of instructional design. Journal of Instructional Development, 3(4), 2-16. Ansari, A., \& Klinenberg, E. (2015). Modern romance. New York, NY: Penguin. 
Arbaugh, J. B. (2004). Learning to learn online: A study of perceptual changes between multiple online course experiences. The Internet and Higher Education, 7(3),169182.

Association to Advance Collegiate Schools of Business (AACSB). (2007). Quality issues in distance learning. The Association to Advance Collegiate Schools of Business. Retrieved from http://www.aacsb.edu/ /media/AACSB/Publications/whitepapers/wp-quality-issues-in-distance-edu.ashx

Baldwin, S. J., Ching, Y. -C., \& Friesen, N. (2017). Online course development among university and college instructors: A grounded theory model. Unpublished manuscript. Department of Educational Technology, Boise State University, Boise, Idaho.

Baran, E., Correia, A. -P., \& Thompson, A. (2011). Transforming online teaching practice: critical analysis of the literature on the roles and competencies of online teachers. Distance Education, 32(3), 421-439.

doi:10.1080/01587919.2011.610293

Barberà, E., Layne, L., \& Gunawardena, C. N. (2014). Designing online interaction to address disciplinary competencies: A cross-country comparison of faculty perspectives. The International Review of Research in Open and Distributed Learning, 15(2). Retrieved from http://www.irrodl.org/index.php/irrodl/article/view/1418/2840 
Barczyk, C., Buckenmeyer, J., \& Feldman, L. (2010). Mentoring professors: A model for developing quality online instructors and courses in higher education. International Journal on E-Learning, 9(1), 7-26.

Bawane, J., \& Spector, J. M. (2009). Prioritization of online instructor roles: Implications for competency-based teacher education programs. Distance Education, 30(3), 383-397. doi:10.1080/01587910903236536

Beck, V. S. (2010). Comparing online and face-to-face teaching and learning. Journal on Excellence in College Teaching, 21(3), 95-108.

Bernard, R. M., Abrami, P. C., Borokhovski, E., Wade, C. A., Tamim, R. M., Surkes, M. A., \& Bethel, E. C. (2009). A meta-analysis of three types of interaction treatments in distance education. Review of Educational Research, 79(3), 12431289. doi:10.3102/0034654309333844

Betts, K. (2014). Factors influencing faculty participation \& retention in online \& blended education. Online Journal of Distance Learning Administration, 17(1), 120.

Black, R.S., Sileo, T. W., \& Prater, M. A. (2000). Learning journals, self-reflection and university students' changing perceptions. Action in Teacher Education, 21(4), 71-89.

Bloom, B. S. (1965). Taxonomy of educational objectives: The classification of educational goals. New York: David McKay Company, Inc. 
Blumer, H. (1969). Science without concepts. In H. Blumer, Symbolic interactionism: Perspective and method (pp. 153-170). Englewood Cliffs, NY: Prentice Hall.

Bolliger, D. U., \& Wasilik, O. (2009). Factors influencing faculty satisfaction with online teaching and learning in higher education. Distance Education, 30(1), 103-116.

Bonk, C. J., \& Cunningham, D. J. (1998). Searching for learner-centered, constructivist, and sociocultural components of collaborative educational learning tools. In C. J. Bonk, \& K. S. King (Eds.), Electronic collaborators: Learner-centered technologies for literacy, apprenticeship, and discourse (pp. 25-50). Mahwah, NJ: Erlbaum.

Bower, B. L. (2001). Distance education: Facing the faculty challenge. Online Journal of Distance Learning Administration, 4(2), 1-6.

Bozarth, J., Chapman, D. D., \& LaMonica, L. (2004). Preparing for distance learning: Designing an online student orientation course. Educational Technology \& Society, 7(1), 87-106.

Bradford, G. R. (2011). A relationship study of student satisfaction with learning online and cognitive load: Initial results. The Internet and Higher Education, 14(4), $217-$ 226.

Branch, R. M., \& Merrill, M. D. (2012). Characteristics of instructional design models. In R. A. Reiser \& J. V. Dempsey (Eds.) Trends and Issues in Instructional Design and Technology (3 ${ }^{\text {rd }}$ ed.) (pp. 8-16). Saddle River, NJ: Pearson Education. 
Brigance, S. K. (2011). Leadership in online learning in higher education: Why instructional designers for online learning should lead the way. Performance Improvement, 50(10), 43-48.

Brown, S. C., Stevenson, R. A., Troiano, P. F., \& Schneider, M. K. (2002). Exploring complex phenomena: Grounded theory in student affairs research. Journal of College Student Development, 43(2), 173-183.

Bruce, M. A., Young, S., \& Kennedy, A. (2012, October). Discovering student and instructor perceptions of trust-building in online courses. Paper presented at the 30th Annual Conference of the Northern Rocky Mountain Educational Research Association, Park City, UT.

Bunk, J., Li, R., Smidt, E., Bidetti, C., \& Malize, B. (2015). Understanding faculty attitudes about distance education: The importance of excitement and fear. Online Learning, 19(4), 1-11. Retrieved from http://files.eric.ed.gov/fulltext/EJ1079611.pdf

Burnham, B. R., \& Walden, B. (1997, May). Interactions in distance education: A report from the other side. In Annual Adult Education Research Conference Proceedings (pp. 49-54).

Cain, D. L., \& Pitre, P. E. (2008). The effect of computer mediated conferencing and computer assisted instruction on student learning outcomes. Journal of Asynchronous Learning Networks, 12, 31-52. 
Canney, C. (2015). Elements that affect student engagement in online graduate courses. [Doctoral dissertation]. Available from ProQuest Dissertations \& Theses Global. (1682465830).

Carr-Chellman, A., \& Duchastel, P. (2000). The ideal online course. British Journal of Educational Technology, 31(3), 229-241.

Cavanaugh, J. (2005). Teaching online-a time comparison. Online Journal of Distance Learning Administration, 8(1). Retrieved from: https://www.westga.edu/ distance/ojdla/spring81/cavanaugh81.htm

Chao, I. T., Saj, T., \& Hamilton, D. (2010). Using collaborative course development to achieve online course quality standards. International Review of Research in Open and Distance Learning, 11(3), 106-126. Retrieved from http://www.irrodl.org/index.php/irrodl

Chao, T., Saj, T., \& Tessier, F. (2006). Establishing a quality review for online courses. Educause Quarterly, 29(3), 32-39.

Chapman, B. F., \& Henderson, R. G. (2010). E-learning quality assurance: A perspective of business teacher educators and distance learning coordinators. The Journal of Research in Business Education, 52(1), 16-31.

Chen, L. L. (2015). Pedagogically effective online instructional design model. In S. Carliner, C. Fulford \& N. Ostashewski (Eds.), Proceedings of EdMedia: World Conference on Educational Media and Technology 2015 (pp. 1551-1554). Association for the Advancement of Computing in Education (AACE). 
Choi, S. Y., \& Ahn, S. H. (2010). Quality assurance for online programs. International Journal of Advancements in Computing Technology, 2(4), 88-94.

Christensen, T. K., \& Osguthorpe, R. T. (2004). How do instructional-design practitioners make instructional-strategy decisions? Performance Improvement Quarterly, 17(3), 45-65.

Ciabocchi, E., Ginsberg, A. P., \& Picciano, A. G. (2016). A study of faculty governance leaders' perceptions of online and blended learning. Online Learning, 20(3), 5273.

Clark, H. H., \& Brennan, S. E. (1991). Grounding in communication. Perspectives on Socially Shared Cognition, 13(1991), 127-149. Retrieved from http://www.psychology.sunysb.edu/sbrennan-/papers/clarkbrennan.pdf

Clark, L. M. (2015). Online discussion forums and their connection to student learning outcomes. [Doctoral dissertation]. Retrieved from ProQuest Dissertations \& Theses Global. (1733635452).

Clark, R. E. (1994). Media will never influence learning. Educational Technology Research and Development, 42(2), 21-29.

Clase, K., Hein, P., \& Pelaez, N. (2008). Demand for interdisciplinary laboratories for physiology research by undergraduate students in biosciences and biomedical engineering. Advances in Physiology Education, 32, 256-260. doi:10.1152/advan.00105.2007 
Cochran, C. E. P. (2015). Faculty transitions to online instruction: A qualitative case study. [Doctoral dissertation]. Retrieved from ProQuest Dissertations \& Theses Global. (1707689068).

Cole, J. E., \& Kritzer, J. B. (2009). Strategies for success: Teaching an online course. Rural Special Education Quarterly, 28(4), 36-40.

Conrad, D. L. (2002). Engagement, excitement, anxiety, and fear: Learners' experiences of starting an online course. The American Journal of Distance Education, 16(4), 205-226.

Contreras, A. L. (2009). The legal basis for degree-granting authority in the United States. Boulder, CO: State Higher Education Executive Officers.

Cooney, A. (2010). Rigor and grounded theory. Nurse Researcher, 14(4), 17 - 22.

Corbin, J., \& Strauss, A. (1990). Grounded theory research: Procedures, canons and evaluative criteria. Zeitschrift für Soziologie, 19(6), 418-427.

Creswell, J. W. (2007). Educational research: Planning, conducting, and evaluating quantitative and qualitative research ( $4^{\text {th }}$ ed.). Upper Saddle River, NJ: Pearson.

Creswell, J. W. (2013). Qualitative inquiry and research design: Choosing among five approaches $\left(3^{\text {rd }}\right.$ ed.). Thousand Oaks, CA: Sage Publications.

Danesh, A., Bailey, A., \& Whisenand, T. (2015). Technology and instructor-interface interaction in distance education. International Journal of Business and Social Science, 6(2) 39-47. 
Dempsey, J. V., Albion, P., Litchfield, B. C., Havard, B., \& McDonald, J. (2007). What do instructional designers do in higher education? A written symposium. 2007: 221-233.

Dewey, J. (1938), Logic: The theory of inquiry. New York, NY: Henry Holt and Company.

Dick, W. (1996). The Dick and Carey model: Will it survive the decade? Educational Technology Research and Development, 44(3), 55-63.

Dick, W., \& Carey, L. M. (1996). The systematic design of instruction (4 ${ }^{\text {th }} \mathrm{ed}$.). New York, NY: HarperCollins.

Dick, W., Carey, L., \& Carey, J. O. (2004). The systematic design of instruction (6 ${ }^{\text {th }}$ ed.). Boston, MA: Allyn \& Bacon.

Dreyfus, H. L. (2009). On the internet (2 ${ }^{\text {nd }}$ ed.). New York, NY: Routledge

Duffy, T. M., \& Kirkley, J. R. (Eds.). (2003). Learner-centered theory and practice in distance education: Cases from higher education. Mahwah, NY: Lawrence Erlbaum Associates.

Duhigg, C. (2013). The Power of Habit: Why we do what we do and how to change. New York, NY: Random House.

Eagan, K., Stolzenberg, E. B., Lozano, J. B., Aragon, M. C., Suchard, M. R., \& Hurtado, S. (2014). Undergraduate teaching faculty: The 2013-2014 HERI faculty survey. Higher Education Research Institute. Graduate School of Education \& Information Studies. University of California, Los Angeles. 
Elliott, N., \& Higgins, A. (2012). Surviving grounded theory research method in an academic world: Proposal writing and theoretical frameworks. The Grounded Theory Review, 11(2), 1-12.

Emerson, H. (1912). The twelve principles of efficiency. The Engineering Magazine. Ertmer, P. A., Stepich, D. A., York, C. S., Stickman, A., Wu, X. L., Zurek, S., \& Goktas, Y. (2008). How instructional design experts use knowledge and experience to solve ill-structured problems. Performance Improvement Quarterly, 21(1), 17-42.

Ertmer, P. A., York, C. S., \& Gedik, N. (2009). Learning from the pros: How experienced designers translate instructional design models into practice. Educational Technology, 49(1), 19-26.

Esani, M. (2010). Moving from face-to-face to online teaching. Clinical Laboratory Science, 23(3), 187-190.

Fabry, D. L. (2009). Designing online and on-ground courses to ensure comparability and consistency in meeting learning outcomes. Quarterly Review of Distance Education, 10(3), 253-261.

Fink, L. D. (2003). A self-directed guide to designing courses for significant learning. University of Oklahoma, 27: 1-33. Retrieved from http://www.deefinkandassociates.com/GuidetoCourseDesignAug05.pdf

Friesen, N. (2011). The place of the classroom and the space of the screen: Relational pedagogy and internet technology. New York, NY: Peter Lang.

Gagné, R. M. (1965). The conditions of learning. New York, NY: Holt, Rinehart and Winston, Inc. 
Gallien, T., \& Early, J. O. (2008). Personalized versus collective instructor feedback in the online course room: Does type of feedback affect student satisfaction, academic performance and perceived connectedness with the instructor? International Journal on E-Learning, 7(3), 463-476.

Garbett, C. (2011). Activity-based costing models for alternative modes of delivering online courses. European Journal of Open, Distance and E-learning, 14(2), 181195.

Gardner, J., (2011). How award-winning professors in higher education use Merrill's first principles of instruction. International Journal of Instructional Technology and Distance Learning, 8(5), 3-16.

Garrison, D. R., Anderson, T., \& Archer, W. (2004). Critical thinking, cognitive presence, and computer conferencing in distance education. The American Journal of Distance Education, 13(1), 57-75.

Gibson, P. A., \& Dunning, P. T. (2012). Creating quality online course design through a peer-reviewed assessment. Journal of Public Affairs Education,18(1), 209-228.

Gillespie, F. (1998). Instructional design for the new technologies. New Directions for Teaching and Learning, 1998(76), 39-52.

Glaser, B. G. (1978). Theoretical sensitivity: Advances in the methodology of grounded theory. Mill Valley, CA: Sociology Press.

Glaser, B. (1992). Basics of grounded theory analysis. Mill Valley, CA: Sociology Press.

Glaser, B. G. (1998). Doing grounded theory: Issues and discussions. Mill Valley, CA: Sociology Press. 
Glaser, B. (1999). The future of grounded theory. Qualitative Health Research, 9(6), 836845.

Glaser, B. (2002). Conceptualization: On theory and theorizing using grounded theory. International Journal of Qualitative Methods, 1(2), 5-8.

Glaser, B. (2009). Jargonizing: Using the grounded theory vocabulary. Mill Valley, CA: Sociology Press.

Glaser, B. G. (2012). Stop, write: Writing grounded theory. Mill Valley, CA: Sociology Press.

Glaser, B. G. (2014). Memoing: A vital grounded theory procedure. Mill Valley, CA: Sociology Press.

Glaser, B. G., \& Holton, J. (2004, May). Remodeling grounded theory. In Forum Qualitative Sozialforschung/Forum: Qualitative Social Research, 5, (2). Retrieved from http://www.qualitativeresearch.net/index.php/fqs/article/view/607/1315

Glaser, B., \& Strauss, A. (1967). The discovery of grounded theory: Strategies for qualitative research. Hawthorne, NY: Walter de Gruyter, Inc.

Goldman, W. (1973). The princess bride: S. Morgenstern's classic tale of true love and high adventure. New York, NY: Houghton Mifflin Harcourt.

Goodyear, P., Salmon, G., Spector, J., Steeples, C., \& Tickner, S. (2001). Competences for online teaching: A special report. Educational Technology Research and Development, 49(1), 65-72. doi: 10.1007/BF02504508 
Gormley, C. (2014). Teaching the principles of effective online course design: What works? Irish Journal of Academic Practice, 3(1), 3.

Green, T., Alejandro, J., \& Brown, A. H. (2009). The retention of experienced faculty in online distance education programs: Understanding factors that impact their involvement. The International Review of Research in Open and Distributed Learning, 10(3). Retrieved from http://www.irrodl.org/index.php/irrodl/article/view/683/1279

Gunawardena, C. N., \& Zittle, F. J. (1997). Social presence as a predictor of satisfaction within a computer-mediated conferencing environment. American Journal of Distance Education, 11(3), 8-26.

Gustafson, K. L., \& Branch, R. M. (1997). Survey of instructional development models. Syracuse, NY: Information Resources Publications, Syracuse University.

Gustafson, K. L., \& Branch, R. M. (2002). What is instructional design? Trends and Issues in Instructional Design and Technology, 16-25.

Hara, N. (2000). Student distress in a web-based distance education course. Information, Communication \& Society, 3(4), 557-579.

Haynie, D. (2015, February 5). Study shows sluggish online learning growth for second year. U.S. News and World Report. Retrieved from http://www.usnews.com/education/online-education/articles/2015/02/05/studyshows-sluggish-online-learning-growth-for-second-year

Heath, H., \& Cowley, S. (2004). Developing a grounded theory approach: A comparison of Glaser and Strauss. International Journal of Nursing Studies, 41, 141-150. 
Herrington, J., \& Oliver, R. (2002). Designing for reflection in online courses. HERDSA 2002 Conference Proceedings, 313-319.Retrieved from http://citeseerx.ist.psu.edu/viewdoc/download?doi=10.1.1.120.1530\&rep=rep1\&t ype $=$ pdf

Hillman, D. C., Willis, D. J., \& Gunawardena, C. N. (1994). Learner-interface interaction in distance education: An extension of contemporary models and strategies for practitioners. American Journal of Distance Education, 8(2), 30-42.

Hirumi, A. (2006). Analyzing and designing e-learning interactions. In C. Juwah (Ed.) Interactions in online education: Implications for theory and practice, pp. 46-71. New York, NY: Routledge.

Hollerbach, K. (2004). It's a brave new online world. Phi Kappa Phi Forum, 84(4), 4041.

Holton, J. A. (2007). The coding process and its challenges. In A. Bryant \& K. Charmaz (Eds.), The Sage handbook of grounded theory (pp. 265-289). Thousand Oaks, CA: Sage Publications.

Holton, J. A. (2008). Grounded theory as a general research methodology. The Grounded Theory Review, 7(2), 67-93.

Holton, J. A. (2009). Qualitative tussles in undertaking a grounded theory study. The Grounded Theory Review, 8(3), 37-49.

Horspool, A., \& Lange, C. (2012). Applying the scholarship of teaching and learning: student perceptions, behaviours and success online and face-to-face. Assessment \& Evaluation in Higher Education, 37(1), 73-88. 
$\mathrm{Hu}, \mathrm{W}$. (2009). A qualitative study of education faculty's experiences in online instruction. [Doctoral dissertation]. Retrieved from ProQuest Dissertations \& Theses Global. (304894928).

Huguet, M. C. (2008). Rethinking instructional design: Considering the instructor---A case study. [Doctoral dissertation]. Retrieved from ProQuest Dissertations \& Theses Global. (304352638).

Ice, P., Curtis, R., Phillips, P., \& Wells, J. (2007). Using asynchronous audio feedback to enhance teaching presence and students' sense of community. Journal of Asynchronous Learning Networks, 11(2), 3-25.

Institute for Dynamic Educational Advancement (IDEA). (2016). What is an online course? Retrieved from http://www.idea.org/blog/2012/01/11/what-is-an-onlinecourse/

Jeffries, P. R. (2005). Development and testing of a hyperlearning model for design of an online critical care course. Journal of Nursing Education, 44(8), 366-372

Johnson, S. D., \& Aragon, S. R. (2003). An instructional strategy framework for online learning environments. New Directions for Adult and Continuing Education, 2003(100), 31-43. doi:10.1002/ace.117

Jonassen, D. H. (1997). Instructional design models for well-structured and ill-structured problem-solving learning outcomes. Educational Technology Research and Development, 45(1), 65-94. 
Kang, S. (2000). An investigation of instructional design processes for web-based courses. [Doctoral dissertation]. Retrieved from ProQuest Dissertations \& Theses Global. (304613134).

Ke, F., \& Kwak, D. (2013). Constructs of student-centered online learning on learning satisfaction of a diverse online student body: A structural equation modeling approach.

Journal of Educational Computing Research, 48(1), 97-122.

Ke, J. \& Wenglensky, S. (2010). Grounded theory. Keep It Simple. Retrieved from http://avantgarde-jing.blogspot.com/2010/03/grounded-theory.html

Kelle, U. (2005). "Emergence" vs." forcing" of empirical data? A crucial problem of "grounded theory" reconsidered. Emergence, 6(2), 1-17.

Kenny, R., Zhang, Z., Schwier, R., \& Campbell, K. (2005). A review of what instructional designers do: Questions answered and questions not asked. Canadian Journal of Learning and Technology/La revue Canadienne de l'apprentissage et de la technologie, 31(1). Retrieved from http://cjlt.csj.ualberta.ca/index.php/cjlt/article/view/147/140

Kidder, L. C. (2015). The multifaceted endeavor of online teaching: The need for a new lens. In B. Hokanson, G. Clinton, M. Tracy (Eds.) The design of learning experience (pp. 77-91). New York City, NY: Springer International Publishing.

Kihato, M., \& Bednar, C. (2004). Importance of online course components: A survey of instructors and students. Journal of the American Dietetic Association, 104(40), 9-26. 
Kirschner, P., Carr, C., van Merriënboer, J., \& Sloep, P. (2002). How expert designers design. Performance Improvement Quarterly, 15(4), 86-104.

Koehler, M. J., \& Mishra, P. (2005). What happens when teachers design educational technology? The development of technological pedagogical content knowledge. Journal of Educational Computing Research, 32(2), 131-152.

Koehler, M. J., \& Mishra, P. (2009). What is technological pedagogical content knowledge? Contemporary Issues in Technology and Teacher Education, 9(1), $60-70$.

Koszalka, T. A., \& Ganesan, R. (2004). Designing online courses: A taxonomy to guide strategic use of features available in course management systems (CMS) in distance education. Distance Education, 25(2), 243-256.

Kruger, J., Epley, N., Parker, J., \& Ng, Z. W. (2005). Egocentrism over e-mail: can we communicate as well as we think? Journal of Personality and Social Psychology, $89(6), 925-936$.

Lackey, K. (2011). Faculty development: An analysis of current and effective training strategies for preparing faculty to teach online. Online Journal of Distance Learning Administration, 14(4), 1-27. doi:10.1632/ade.56.13

Larson, M., \& Lockee, B. B. (2014). Streamlined ID: A practical guide to instructional design. New York, NY: Routledge.

Lee, S. J., Srinivasan, S., Trail, T., Lewis, D., \& Lopez, S. (2011). Examining the relationship among student perception of support, course satisfaction, and 
learning outcomes in online learning. The Internet and Higher Education, 14(3), 158-163.

Legon, R. (2015). Measuring the impact of the Quality Matters Rubric ${ }^{\mathrm{TM}}$ : A discussion of possibilities. American Journal of Distance Education, 29(3), 166-173.

Lewis, C. C., \& Abdul-Hamid, H. (2006). Implementing effective online teaching practices: Voices of exemplary faculty. Innovative Higher Education, 31(2), 8398. doi:10.1007/s10755-006-9010-z

Little, B. B. (2009). Quality assurance for online nursing courses. Journal of Nursing Education, 48(7), 381-387.

Liu, I. F., Chen, M. C., Sun, Y. S., Wible, D., \& Kuo, C. H. (2010). Extending the TAM model to explore the factors that affect intention to use an online learning community. Computers \& Education, 54(2), 600-610.

Mandernach, B. J., Hudson, S., \& Wise, S. (2013). Where has the time gone? Faculty activities and time commitments in the online classroom. Journal of Educators Online, 10(2), 1-15.

Mariasingam, M. (2005). Quality criteria and benchmarks for online degree programs. [Doctoral dissertation]. Retrieved from ProQuest Dissertations \& Theses Global. (305378650).

McDonald, J. (2009). Designing and implementing online discussion forums: An Australian case study. International Journal of Networking and Virtual Organisations, 6(5), 518-531. 
McGahan, S. J., Jackson, C. M., \& Premer, K. (2015). Online course quality assurance: Development of a quality checklist. InSight: A Journal of Scholarly Teaching, 10, 126-134

Means, B., Toyama, Y., Murphy, R., Bakia, M., \& Jones, K. (2010). Evaluation of evidence-based practices in online learning: A meta-analysis and review of online learning studies. U.S. Dept. of Education, Office of Planning, Evaluation and Policy Development, Policy and Program Studies Service website. Retrieved from gov/rschstat/eval/tech/evidence-based-practices/finalreport. Pdf

Mentzer, G. A., Cryan, J., \& Teclehaimanot, B. (2007). Two peas in a pod? A comparison of face-to-face and web-based classrooms. Journal of Technology and Teacher Education, 15(2), 233-246.

Merrill, M. D., Drake, L., Lacy, M. J., Pratt, J. (1966). Reclaiming instructional design. Educational Technology, 36(5), 5-7. Retrieved from http://mdavidmerrill.com/Papers/Reclaiming.PDF

Michailidou, E., Harper, S., \& Bechhofer, S. (2008, September). Visual complexity and aesthetic perception of web pages. In Proceedings of the 26th Annual ACM International Conference on Design of Communication (pp. 215-224).

Miller, J. L. (2007). The new education professionals: The emerging specialties of instructional designer and learning manager. International Journal of Public Administration, 30(5), 483-498. doi: 10.1080/01900690701205970 
Miner, R. C. (2003). A framework for learner-instructor interaction in the online, distance education environment. [Doctoral dissertation]. Retrieved from ProQuest Dissertations \& Theses Global. (305303313).

Mishra, P., \& Koehler, M. J. (2006). Technological pedagogical content knowledge: A framework for teacher knowledge. Teachers College Record, 108, 1017-1054. doi: 10.1111/j.1467-9620.2006.00684.x

Moore, M. G. (1989). Three types of interaction. American Journal of Distance Education, 3(2), 1-6.

Moore, M. G. (1993). Theory of transactional distance. Theoretical Principles of Distance Education, 22-38.

Moore, M. G., \& Kearsley, G. (2011). Distance education: A systems view of online learning. San Francisco, CA: Cengage Learning. Retrieved from https://books.google.com/books?id=dU8KAAAAQBAJ\&lpg=PR4\&ots=D10iZ4F shx\&dq=kearsley $\% 2 \mathrm{C} \% 2 \mathrm{C} \% 20$ guide $\% 20$ to $\% 20$ online $\% 20 \mathrm{ed} \& \operatorname{lr} \& \mathrm{pg}=\mathrm{PA} 122 \# \mathrm{v}=$ onepage $\& \mathrm{q}=$ poor $\% 20 \mathrm{design} \& \mathrm{f}=$ false

Morse, J. M. (2008). Confusing categories and themes. Qualitative Health Research, 18(6), 727-728.

Moskal, T. M. (2012). Instructional designers in higher education. [Doctoral dissertation]. Retrieved from ProQuest Dissertations \& Theses Global. (3546879). National Center for Education Statistics. (2016). Characteristics of Degree-Granting Postsecondary Institutions. Institute of Education Science. Retrieved from https://nces.ed.gov/programs/coe/indicator_csa.asp 
National Science Foundation. (2006). National Science Foundation strategic plan FY 2006-2011. Retrieved from http://www.nsf.gov/pubs/2006/nsf0648/nsf0648.jsp

Nwankwo, A. A. (2015). Students' learning experiences and perceptions of online course content and interactions. [Doctoral dissertation]. Retrieved from ProQuest Dissertations \& Theses Global. (3672558).

Olson, B., Mata, M., \& Koszalka, T. (2013). Implementing an online curriculum for medical education: Examining the critical factors for success. International Journal on E-Learning, 12(2), 197-208.

O'Neil, C. A., Fisher, C. A., \& Newbold, S. K. (2004). Developing an online course: Best practices for nurse educators. New York, NY: Springer Publishing Company.

Oomen-Early, J., Bold, M., Wiginton, K. L., Gallien, T. L., \& Anderson, N. (2008). Using asynchronous audio communication (AAC) in the online classroom: A comparative study. Journal of Online Learning and Teaching, 4(3), 267-276.

Paechter, M., Maier, B., \& Macher, D. (2010). Students' expectations of, and experiences in e-learning: Their relation to learning achievements and course satisfaction. Computers \& Education, 54(1), 222-229.

Parsad, B., \& Lewis, L. (2008). Distance education at degree-granting postsecondary institutions: 2006-07 (Report No. NCES 2009-044). Washington, DC: U.S. Department of Education, National Center for Education Statistics.

Pate, A., Smaldino, S., Mayall, H. J., \& Luetkehans, L. (2009). Questioning the necessity of nonacademic social discussion forums within online courses. The Quarterly Review of Distance Education, 10(1), 1-8. 
Patton, M. Q. (2001). Qualitative research and evaluation methods ( $2^{\text {nd }}$ ed.). Thousand Oaks, CA: Sage Publications.

Perry, B., \& Edwards, M. (2005). Exemplary online educators: Creating a community of inquiry. Turkish Online Journal of Distance Education, 6(2), 1-10. Retrieved from http://files.eric.ed.gov/fulltext/ED490370.pdf

Phipps, R., \& Merisotis, J. (2000). Quality on the line: Benchmarks for success in internet-based distance education. Washington, DC: Institute for Higher Education Policy. Retrieved from http://files.eric.ed.gov/fulltext/ED444407.pdf

Phipps, R. A., Wellman, J. V., \& Meisotis, J. P. (2002). Assuring quality in distance learning. Washington, DC: Council for Higher Education Accreditation.

Piaget, J. (1952). The origins of intelligence in children. New York, NY: International University Press.

Pieters, J. (1995). The empirical basis of designing instruction. Performance Improvement Quarterly, 8(3),118-129.

Reeves, P. M., \& Reeves, T. C. (2008). Design considerations for online learning in health and social work education. Learning in Health \& Social Care, 7(1), 46-58. doi:10.1111/j.1473-6861.2008.00170.x

Reigeluth, C. M. (Ed.). (2013). Instructional design theories and models: An overview of their current status. Hillsdale, NJ: Lawrence Erlbaum Associates, Publishers. Retrieved from https://books.google.com/books?id=0BpDf6AkqPAC\&lpg=PR1\&ots=42N1MthO 0B\&lr\&pg=PA9\#v=onepage \&q\&f=false 
Reiser, R. A. (2001a). A history of instructional design and technology: Part I: A history of instructional media. Educational Technology Research and Development, 49(1), 53-64.

Reiser, R. A. (2001b). A history of instructional design and technology: Part II: A history of instructional design. Educational Technology Research and Development, 49(2), 57-67.

Reiser, R. A., \& Dempsey, J. V. (2012). Trends and issues in instructional design and technology ( ${ }^{\text {rd }}$ ed.). Upper Saddle River, NJ: Merrill Prentice Hall.

Renner, P. (1993). The art of teaching adults: How to become an exceptional instructor \& facilitator. Westborough, MA: Training Associates.

Rhode, J. (2009). Interaction equivalency in self-paced online learning environments: An exploration of learner preferences. The International Review of Research in Open and Distributed Learning, 10(1). Retrieved from http://www.irrodl.org/index.php/irrodl/article/view/603/1178

Robinson, C. C., \& Hullinger, H. (2008). New benchmarks in higher education: Student engagement in online learning. Journal of Education for Business, 2, 101-108.

Roblyer, M. D., \& Wiencke, W. R. (2004). Exploring the interaction equation: Validating a rubric to assess and encourage interaction in distance courses. Journal of Asynchronous Learning Networks, 8(4), 24-37.

Sasse, C. M., Schwering, R., \& Dochterman, S. (2008). Rethinking faculty role in a knowledge age. Allied Academies International Conference. Academy of Educational Leadership. Proceedings, 12(2), 35-48. 
Schrum, L., Burbank, M. D., Engle, J., Chambers, J. A., \& Glassett, K. F. (2005). Postsecondary educators' professional development: Investigation of an online approach to enhancing teaching and learning. Internet and Higher Education, $8,279-289$.

Seale, J. K., \& Cann, A. J. (2000). Reflection on-line or off-line: The role of learning technologies in encouraging students to reflect. Computers and Education, 34(3), 309-320.

Seaman, J. (2009). Online learning as a strategic asset. Volume II: The paradox of faculty voices--views and experiences with online learning. Results of a national faculty survey, part of the online education benchmarking study. Conducted by the APLU-Sloan National Commission on Online Learning. Association of Public and Land-grant Universities.

Sebastianelli, R., Swift, C., \& Tamimi, N. (2015). Factors affecting perceived learning, satisfaction, and quality in the online MBA: A structural equation modeling approach. Journal of Education for Business, 90(6), 296-305.

Selejan, O., Muresanu, D. F., Popa, L., Muresanu-Oloeriu, L., Iudean, D., Buzoianu, A., \& Suciu, S. (2016). Credibility judgments in web page design-a brief review. Journal of Medicine \& Life, 9(2) 115-119.

Selvaraj, N., \& Fields, B. (2009, September). A grounded theory approach towards conceptualizing CIS for heterogeneous work communities. In Proceedings of the 23rd British HCI Group Annual Conference on People and Computers: Celebrating People and Technology (pp. 471-479). British Computer Society. 
Shambaugh, R. N., \& Magliaro, S. G. (1997). Mastering the possibilities: A process approach to instructional design. Boston, MA: Allyn and Bacon.

Shattuck, K. (2010). Quality Matters: A faculty-centered program to assure quality in online course design. Collected Essays on Learning and Teaching, 3, 49-53.

Shea, P. (2007). Bridges and barriers to teaching online college courses: A study of experienced online faculty in thirty-six colleges. Journal of Asynchronous Learning Networks, 11(2), 73-128.

Shea, P. J., Fredericksen, E. E., Pickett, A. M., \& Pelz, W. E. (2004). Faculty development, student satisfaction, and reported learning in the SUNY learning network. In T. M. Duffy \& J. R. Kirkley (Eds.), Learner-centered theory and practice in distance education: Cases from higher education (pp. 343-377).

Mahwah, NJ: Lawrence Erlbaum Associates, Inc.

Shenton, A. K. (2004). Strategies for ensuring trustworthiness in qualitative research projects. Education for Information, 22(2), 63-75. Retrieved from http://www.crec.co.uk/docs/Trustworthypaper.pdf

Silber, K. H. (2007). A principle-based model of instructional design: A new way of thinking about and teaching ID. Educational Technology, 47(5), 5-19.

Sikolia, D., Biros, D., Mason, M. \& Weiser, M. (2013). Trustworthiness of rounded theory methodology research in information systems. MWAIS 2013 Proceedings (16). Retrieved from http://aisel.aisnet.org/cgi/viewcontent.cgi?article=1006\&context=mwais2013 
Shulman, L. S. (1986). Those who understand: Knowledge growth in teaching. Educational Researcher, 15(2), 4-14. doi:10.3102/0013189X015002004

Slater, D. (2013). Love in the time of algorithms: What technology does to meeting and mating. New York, NY: Penguin.

Smith, A., \& Anderson, M. (2016, February 29). 5 facts about online dating. Pew Research Center. Retrieved from http://www.pewresearch.org/facttank/2016/02/29/5-facts-about-online-dating/

Smith, G. G., Ferguson, D., \& Caris, M. (2001). Teaching over the WEB versus face to face. In ED-Media 2001 World Conference on Educational Multimedia, Hypermedia \& Telecommunications. 13th Proceedings, Tampere, Finland, June 25-30, 2001, 1761-1766.

Smith, P. L., \& Ragan, T. J. (2005). Instructional design ( $3^{\text {rd }}$ ed.). Hoboken, NJ: John Wiley \& Sons, Inc.

Smith, M., \& Winking-Diaz, A. (2004). Increasing students' interactivity in an online course. The Journal of Interactive Online Learning, 2(3), 1-25.

Snyder, M. M. (2009). Instructional-design theory to guide the creation of online learning communities for adults. TechTrends, 53(1), 48-56. doi:10.1007/s11528-009-02372

Straumsheim, C., Jaschik, S., \& Lederman, D. (Eds.). (2015). 2015 Inside Higher Ed survey of faculty attitudes on technology. Inside Higher Ed, 1-49. Retrieved from https://www.insidehighered.com/system/files/media/Faculty\%20Attitudes\%20on \%20Technology\%202015.pdf 
Strauss, A., \& Corbin, J. (1994). Grounded theory methodology. Handbook of Qualitative Research, 273-285.

Strauss, A., \& Corbin, J. (1998). Basics of qualitative research ( $2^{\text {nd }}$ ed.). Thousand Oaks, CA: Sage.

Stein, D. S., Wanstreet, C. E., Calvin, J., Overtoom, C., \& Wheaton, J. E. (2005). Bridging the transactional distance gap in online learning environments. The American Journal of Distance Education, 19(2), 105-118.

Swan, K. (2001). Virtual interaction: Design factors affecting student satisfaction and perceived learning in asynchronous online courses. Distance Education, 22(2), 306-31.

Sweller, J., van Merriënboer, J. J. G., \& Paas, F. (1998). Cognitive architecture and instructional design. Educational Psychology Review, 10(3), 251-296.

Taft, S. H., Perkowski, T., \& Martin, L. S. (2011). A framework for evaluating class size in online education Quarterly Review of Distance Education, 12(3), 181-197.

Tessmer, M., \& Wedman J. F. (1990). A layers-of-necessity instructional development model. Educational Technology Research Development, 38(2), 77-85.

Tomei, L. A. (2006). The impact of online teaching on faculty load: Computing the ideal class size for online courses. Journal of Technology and Teacher Education, $14(3), 531-538$.

Topper, A. (2007) Are they the same? Comparing the instructional quality of online and face-to-face graduate education courses, Assessment \& Evaluation in Higher Education, 32(6), 681-691. doi: 10.1080/02602930601117233 
Triandis, H. C., Vassiliou, V., \& Thomanek, E. K. (1966). Social status as a determinant of respect and friendship acceptance. Sociometry, 396-405.

Twigg, C. A. (2001). Quality assurance for whom? Providers and consumers in today's distributed learning environment. The Pew Symposia in Technology and Learning $\left(3^{\text {rd }}\right)$, Lake George, New York, July 13-14, 2000.

van Merriënboer, J. J. G. (1997). Training complex cognitive skills: A four-component instructional design model for technical training. Englewood Cliffs, NJ:

Educational Technology Publications.

Visser, J. A. (2000). Faculty work in developing and teaching Web-based distance courses: A case study of time and effort. The American Journal of Distance Education, 14(3), 21-32. doi:10.1080/08923640009527062

Wedman, J., \& Tessmer, M. (1993). Instructional designers' decisions and priorities: A survey of design practice. Performance Improvement Quarterly, 6(2), 43-57.

West, J. A., \& West, M. L. (2009). Using wikis for online collaboration: The power of the read-write web. Hoboken, NJ: John Wiley \& Sons.

Whetten, D. A. (2007). Principles of effective course design: What I wish I had known about learning-centered teaching 30 years ago. Journal of Management Education, 31(3), 339-357.

Whitaker, J. P. (2015). Traditional faculty in transition: Theory, change, and preparation for the online paradigm. [Doctoral dissertation]. Retrieved from ProQuest Dissertations \& Theses Global. (1728059461). 
Wiggins, G. P., \& McTighe, J. (2005). Understanding by design. Alexandria, VA: Association for Supervision and Curriculum Development.

Williams, P. (2003). Roles and competencies for distance education programs in higher education institutions. American Journal of Distance Education, 17(1), 45-57. doi: 10.1207/S15389286AJDE1701_4

Willis, J. (1995). A recursive, reflective instructional design model based on constructivist-interpretivist theory. Educational Technology, 35(6), 5-23.

Wilson, B. G. (1997). Thoughts on theory in educational technology. Educational Technology (37), 22-26.

Wilson, R. L., \& Weiser, M. (2001). Adoption of asynchronous learning tools by traditional full-time students: A pilot study. Information Technology and Management, 2(4), 363-375.

Windes, D. L., \& Lesht, F. L. (2014). The effects of online teaching experience and institution type on faculty perceptions of teaching online. Online Journal of Distance Learning Administration, 17(1).

Worthen, H. (2013). What do we know about teaching online? Academe, 99(5), 28-33.

Yang, Y., \& Cornelious, L. F. (2005). Preparing instructors for quality online instruction. Online Journal of Distance Learning Administration, VIII(c), 1-15. doi:10.1002/ace.118

Yang, Y., \& Durrington, V. (2010). Investigation of students' perceptions of online course quality. International Journal on E-Learning, 9(3), 341-361. 
York, C. S., \& Ertmer, P. A. (2011). Towards an understanding of instructional design heuristics: An exploratory Delphi study. Educational Technology Research and Development, 59(6), 841-863.

York, C. S., \& Richardson, J. C. (2012). Interpersonal interaction in online learning: Experienced online instructors' perceptions of influencing factors. Journal of Asynchronous Learning Networks, 16(4), 83-98.

Young, S., \& Bruce, M. A. (2011). Classroom community and student engagement in online courses. Journal of Online Learning and Teaching, 7(2), 219.

Young, S., \& Duncan, H. E. (2014). Online and face-to-face teaching: How do student ratings differ? Journal of Online Learning and Teaching, 10(1), 70-79.

Zierer, K., \& Seel, N. M. (2012). General didactics and instructional design: Eyes like twins A transatlantic dialogue about similarities and differences, about the past and the future of two sciences of learning and teaching. SpringerPlus, 1(1), 1-22. 
APPENDIX A

Snowball Letter 


\section{$\boldsymbol{B}$}

BOISE STATE UNIVERSITY

Dear [Mr. / Ms. / Dr. LAST NAME],

Thank you for your interest in the Online Course Design Study. I am writing to ask whether you would be willing to pass along the enclosed information to other faculty members who may also be interested in learning about this research study? You are under no obligation to share this information and whether or not you share this information will not affect your relationship with the staff at Boise State University.

Thank you for your time and consideration.

Sincerely,

Sally Baldwin

Principal Investigator

Attachment: Recruitment flyer 
APPENDIX B

Online Course Design Study Recruitment Script 
On the Phone:

"Hello, my name is Sally Baldwin. I am a doctoral candidate at Boise State University. I am conducting a research study about online course design for my dissertation. I am calling to ask if you would be willing to let me interview you. It should take about 30 minutes to complete the interview.

If you would be interested in participating in this interview, we can set up a time now or you can let me know when a good time would be to schedule it."

If interested, the investigator will set up date and time and will provide subject with the investigator's contact information. "I have you scheduled for an interview on . If you have questions, I can be reached at 707.688.6022 or sallybaldwin@u.boisestate.edu. Thank you for your help."

If not interested, investigator will end the call: "Thank you for your time." 
APPENDIX C

Recruitment Flyer 


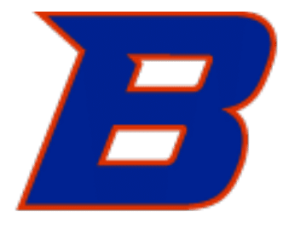

\title{
BOISE STATE UNIVERSITY
}

\author{
VOLUNTEERS WANTED \\ FOR A RESEARCH STUDY \\ Online Course Design
}

Are you a tenured or tenure-track instructor who has designed online courses? We are conducting a research study about online course design and looking for your input! The study aims to understand how instructors design online courses. The researchers' hope is to provide information that helps instructors in designing online courses. To participate in the study you will be asked to describe your experience with creating online courses in a thirty minute interview. Tenured or tenured-track faculty members at four-year public colleges or universities who have designed online courses may participate.

If you are interested in participating, please contact Sally Baldwin at sallybaldwin@u.boisestate.edu. Sally is a doctoral candidate who is conducting this research under the direction of Dr. Yu-Hui Ching, Educational Technology Department.

(IRB number: \# 104-SB16-162.) 
APPENDIX D

Interview Script and Questions 
"Thank you for agreeing to speak with me today."

"The purpose of this interview is to learn more about the perceptions of instructors designing online courses. The information gathered will be used to encourage quality online course development by redirecting the conversation of instructional design to one that is grounded in practice."

"Your identity will be kept strictly confidential and your personal information will not be shared with anyone. In addition, your name will not be used at any point in this research project. Finally, none of your answers will ever be linked back to you in any way or form."

"The interview will last about thirty minutes. You may choose to ask me to stop the interview at any time."

"Do you have any questions for me before we begin?"

"What is your current position?"

"How many online courses have you designed?"

"How many online courses have you taught?"

"What type of learning management system do you use?"

"How many years have you taught overall?"

"How many years have you been creating online courses?"

"What subject(s) do you teach?"

"How long have you taught online?"

"Do you teach in person?"

"For how long?"

"Please rate your technology skills:

Novice Intermediate Advanced" 
"What is your age range?

22-29

30-39

40-49

50 and above"

"Based on your experience, what do you think about the design of online courses"

Additional questions that may be asked:

- Why did you start designing online courses?

- What training have you had to designing online courses?

- What course features do you consider to be important?

- What supports are provided by your institution for online course design?

- Do you take advantage of these supports? Why or why not?

- How do you perceive the effectiveness of these supports?

- Do you use a course evaluation rubric? If so, which one? Why that specific rubric?

- What is the worst part about designing an online course?

- What is the best part about designing an online course?

"Do you have anything else you would like to add?"

"Thank you for your time." 
APPENDIX E

Memo Example 


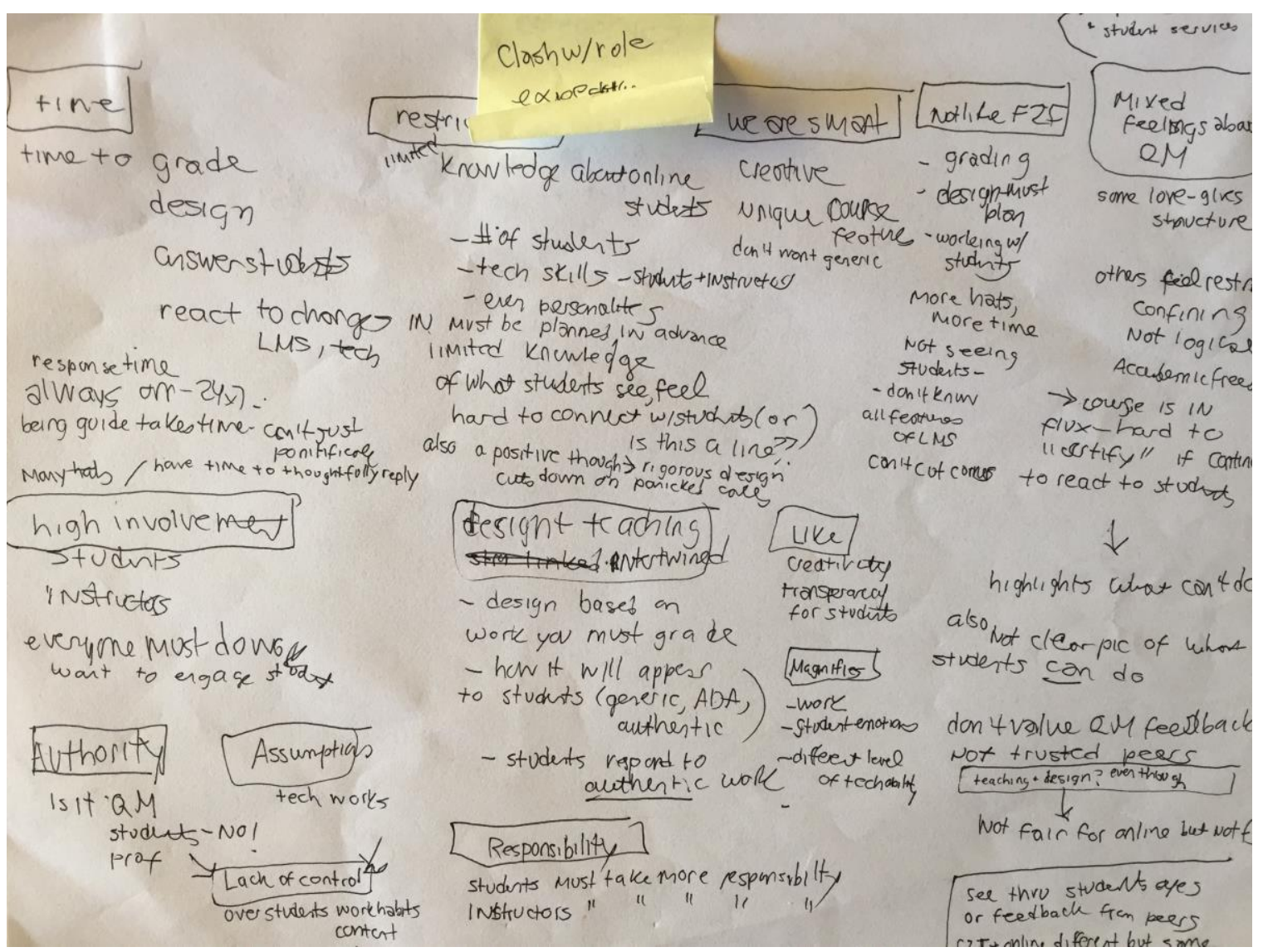


APPENDIX F 
This research was conducted with approval of the Institutional Review Board at Boise State University, protocol \#104-SB16-162 